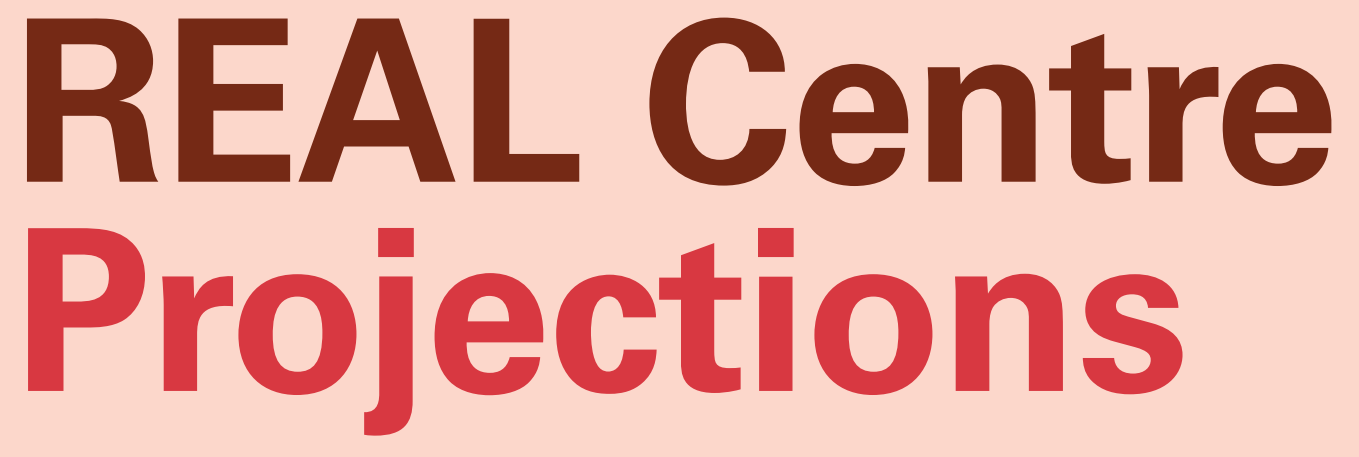

\title{
Health and social care funding projections 2021
}

Report $\bullet$ October 2021

Stephen Rocks, Giulia Boccarini,

Anita Charlesworth, Omar Idriss,

Ruth McConkey, Laurie Rachet-Jacquet

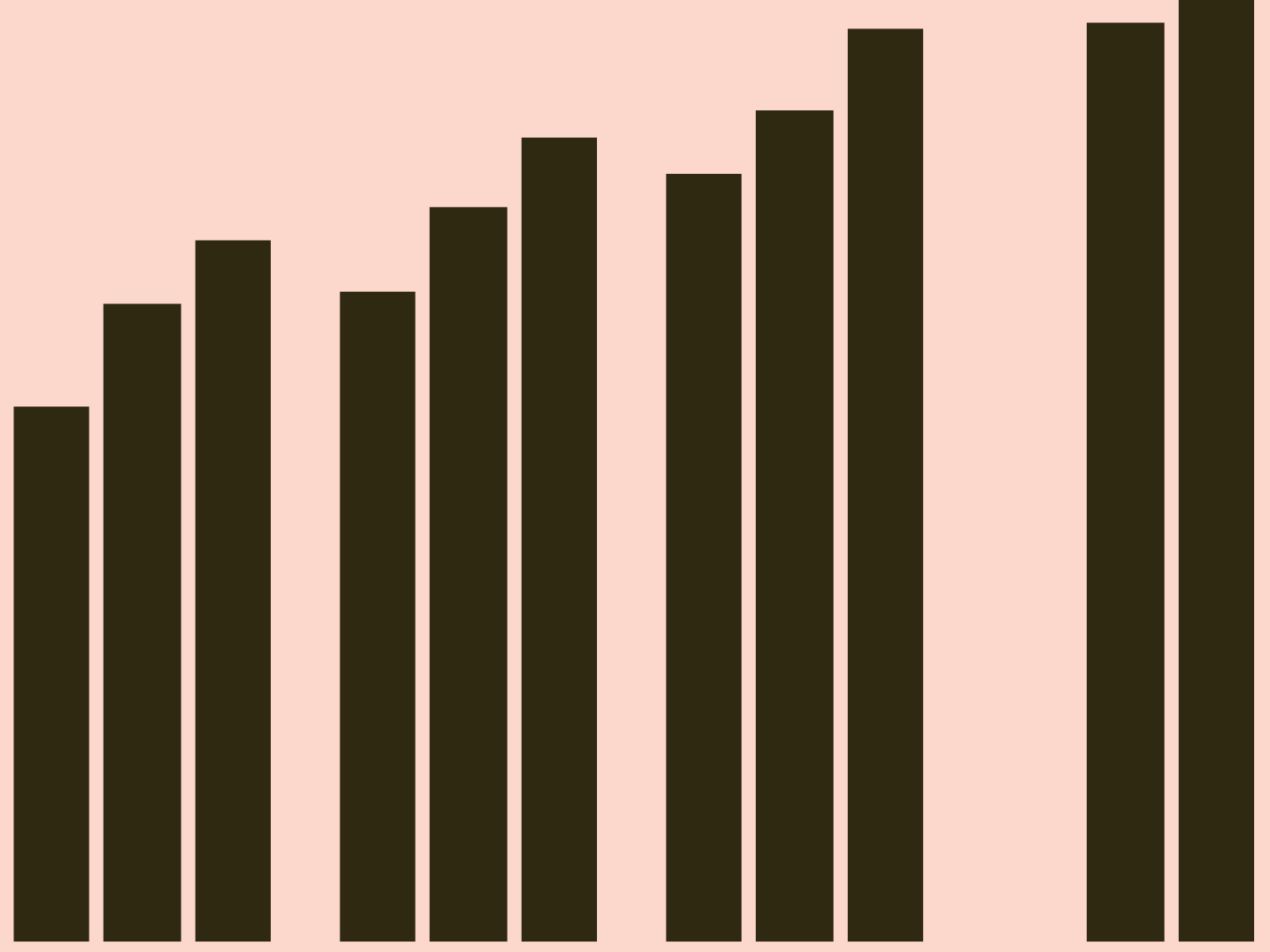

The

Health

Foundation 


\section{About the REAL Centre}

The Health Foundation's REAL Centre (research and economic analysis for the long term) provides independent analysis and research to support better long-term decision making in health and social care.

Its aim is to help health and social care leaders and policymakers look beyond the short term to understand the implications of their funding and resourcing decisions over the next 10-15 years. The Centre will work in partnership with leading experts and academics to research and model the future demand for care, and the workforce and other resources needed to respond.

The Centre supports the Health Foundation's aim to create a more sustainable health and care system that better meets people's needs now and in the future. 


\section{Contents}

$\begin{array}{ll}\text { Acknowledgements } & 2\end{array}$

Executive summary $\quad 3$

1. Introduction 11

2. Health and social care funding trends 14

3. Approach to modelling funding pressures 29

$\begin{array}{ll}\text { 4. Funding pressures } & 37\end{array}$

5. Funding projections and scenarios 60

$\begin{array}{ll}\text { 6. Implications } & 72\end{array}$

Glossary $\quad 84$

$\begin{array}{ll}\text { References } & 86\end{array}$ 


\section{Acknowledgements}

The authors are grateful for input and comment given by Siva Anandaciva and Luca Lorenzoni; attendees at an expert workshop on early findings; Rowena Jacobs and María José Aragón from the Centre for Health Economics at the University of York; the NHS Business Services Authority; and colleagues from across Number 10, HMTreasury, the Department of Health and Social Care and NHS England. Their input has informed development of assumptions, construction of scenarios, interpretation of results and the key implications identified.

We would like to thank the Strategy Unit for their work modelling additional demand for mental health services arising as a result of COVID-19. In addition, the authors would like to thank REAL Centre and wider Health Foundation colleagues for their input, support and guidance, with particular thanks to: Hugh Alderwick, Nuha Bazeer, Jennifer Dixon, David Finch, Tim Horton, Abigail Lampkin, Ann Raymond, Nihar Shembavnekar, Charles Tallack, Ruth Thorlby and Toby Watt.

We would also like to thank members of the Health Foundation communications team, particularly: Kate Addison, Sean Agass, Creina Lilburne and Peter Stilwell.

Errors and omissions remain the responsibility of the authors alone.

The analysis presented in this report was prepared ahead of the government announcements for health and social care funding on 6 and 7 September 2021. The analysis presents a benchmark to compare those funding announcements against. Therefore, data presented here, including the budget allocations to the Department of Health and Social Care, do not reflect the latest funding commitments for the period up to $2024 / 25$. The report highlights a number of key places where the budget allocations do not reflect the September 2021 announcements.

When referencing this publication please use the following URL:

https://doi.org/10.37829/HF-2021-RC18 


\section{Executive summary}

This report presents the REAL Centre's projections of future health and social care funding requirements, both for the next 3 years and longer term funding to 2030/31. The projections are based on underlying funding pressures - such as population size and age structure - and additional funding pressures, such as potential policy choices. The report seeks to answer the question of how much funding the health and social care system may need over the next decade. This includes overall Department of Health and Social Care (DHSC) budgets, day-to-day NHS funding and the funding made available to local authorities for adult social care.

Although the report does not seek to recommend a course of action, it does set out the funding implications of choices about the speed of service recovery and staff pay. As such, scenarios and sensitivity analysis are presented to reflect considerable uncertainty, including in the external environment, particularly regarding COVID-19, and in the trade-offs and decisions government will need to make about its level of ambition for the pandemic recovery.

The report presents two scenarios that reflect varying levels of ambition for the post-pandemic world - stabilisation and recovery. In the longer term to 2030/31, the scenarios require real-terms average annual increases in NHS funding of $3.1 \%$ and $3.5 \%$ respectively. In the short term, the stabilisation scenario would require additional NHS funding over and above that set out in the NHS Long Term Plan. This equates to an additional $£ 4.7 b n$ in $2021 / 22$, $£ 4.0$ bn in $2022 / 23$ and $£ 2.9 b n$ in $2023 / 24$. The scenarios include funding to enable a modest expansion in the availability of adult social care services, support provider sustainability and pay social care workers more. To achieve these aims funding for adult social care would need to rise more quickly than for the NHS.

\section{Scenarios}

Our scenarios hold constant assumptions on many of the underlying drivers that are largely out of the control of health and social care policy. Assumptions around other drivers more directly in the control of policy makers, such as pay and decisions about access to care, are varied.*

Our stabilisation scenario would see pay and productivity growth in line with long-term forecasts, the backlog of NHS care being cleared in 2028/29, waiting times back to where they were going into the pandemic and a relatively less generous settlement for public health and adult social care, compared to our recovery scenario. Stabilisation also assumes that health service pay broadly 
rises in line with whole economy earnings growth and productivity growth in line with the long-term average (0.8\% per annum). However, COVID-19 has had a significant effect on the economy and GDP is not expected to return to prepandemic levels until late in 2021. As a result of the economic shock, the OBR forecasts that earnings growth across the economy will be lower than expected before COVID-19.

Our more ambitious recovery scenario assumes higher pay and a decade of NHS productivity growth at $1.2 \%$ per annum. This would imply substantial service transformation and is ambitious, requiring the service to match the highest sustained increase in productivity from over the past two decades. It would likely require take up of productivity-enhancing technologies, better use of skill mix, adoption of new care models and the reduction of unwarranted variation in clinical practice. In addition, the scenario involves addressing the backlog of NHS care resulting from the pandemic by 2024/25; the 4-hour A\&E waiting times target being met (having not been achieved since 2011/12); higher public health spending and a generous adult social care settlement to improve access, provider sustainability and pay.

\section{Short-term funding requirements}

\section{Health care}

For day-to-day NHS spending (NHS RDEL) our projections imply the following above the long term plan (2021/22 prices):

- Under stabilisation: an additional $£ 4.7 b n$ in $2021 / 22$, £4.0bn in $2022 / 23$ and f2.9bn in 2023/24.

- Under recovery: an additional f7.7bn in $2021 / 22, f 7.1 \mathrm{bn}$ in $2022 / 23$ and $f 6.7 \mathrm{bn}$ in 2023/24.

- In $2024 / 25$, NHS RDEL would need to be $£ 153 b n$ in stabilisation and $£ 158 b n$ in recovery. 
Figure 1: Potential additional funding needed for NHS England

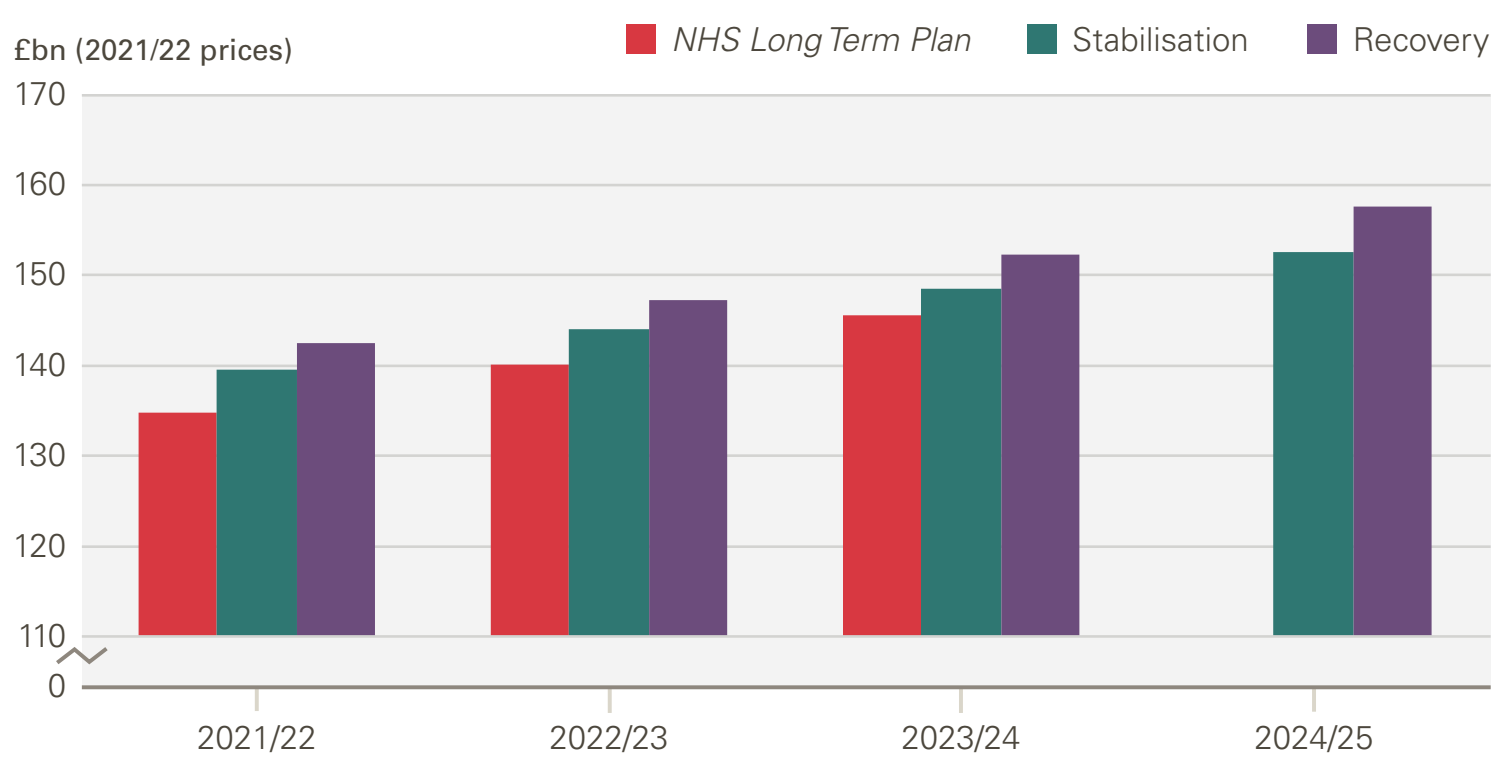

Source: REAL Centre calculations.

Notes: NHS RDEL excludes $£ 2.85 \mathrm{bn}$ for pensions; NHS Long Term Plan funding includes an additional $£ 1$ bn for the elective backlog and $£ 500 \mathrm{~m}$ for mental health as part of the COVID-19 response.

Our analysis shows that the NHS will not be able to deliver on all of the long term plan ambitions, alongside making even modest inroads into the elective backlog within the current funding settlement, requiring a significant further increase in the last year of current parliament (2024/25). In 2022/23 alone our projections suggest the NHS would need at least $£ 4$ bn in additional funding above the current funding settlement. It would also mean a further significant increase in $2024 / 25$, with funding needing to rise to at least $£ 153 \mathrm{bn}$. The potential level of additional funding required depends on both the speed at which the government seeks to reduce the elective care backlog and the ongoing impact of COVID-19 on the delivery of care. Our analysis suggests that funding for the NHS falls short of what would be needed to meet the current pressures on the system by at least $£ 4.7 \mathrm{bn}$.

The main reasons for higher costs in these early years are the funding needs for meeting the elective backlog and increasing hospital capacity. These long term plan funding figures include the $£ 1$ bn committed for the elective backlog and $£ 500 \mathrm{~m}$ for mental health in $2021 / 22$. However, these numbers exclude other ongoing COVID-19 costs for running the NHS. In our scenarios every $1 \%$ hit to productivity arising from infection prevention and control (IPC) measures and staff absences, for example, would require around an additional £1.5bn per year. A $10 \%$ hit would require $\mathrm{f14}-16 \mathrm{bn}$ per year over this period.

\section{Adult social care}

A substantial increase in adult social care funding would be required to expand access to care, pay more for care to sustain the provider sector and pay higher wages. These increases are comparable to, or exceed, the funding needs of the NHS and to some extent reflect the comparative lack of funding for adult social care over 
the past decade. The level of funding needed is sensitive to how quickly access can be expanded under the stabilisation and recovery scenarios. The analysis shows this expansion of access happening in 2021/22, but in practice achieving this objective would likely be smoothed over a few years.

Table 1: Short-term funding requirements for social care

\begin{tabular}{|c|c|c|c|c|c|}
\hline & & $2021 / 22$ & $2022 / 23$ & $2023 / 24$ & $2024 / 25$ \\
\hline \multirow{2}{*}{$\begin{array}{l}\text { Current spending power (excluding } \\
\text { one-off COVID-19 funding) }\end{array}$} & fbn & 20.1 & 20.3 & 20.5 & 20.7 \\
\hline & $\begin{array}{l}\text { Annual real-terms } \\
\text { growth rate }\end{array}$ & $0.6 \%$ & $0.9 \%$ & $1.1 \%$ & $1.0 \%$ \\
\hline \multirow{3}{*}{$\begin{array}{l}\text { Stabilisation } \\
\text { Meet future demand and improve } \\
\text { access to care }\end{array}$} & fbn & 23.1 & 24.0 & 24.7 & 25.5 \\
\hline & $\begin{array}{l}\text { Additional funding } \\
\text { (compared to current } \\
\text { spending power, fbn) }\end{array}$ & 3.0 & 3.7 & 4.2 & 4.8 \\
\hline & $\begin{array}{l}\text { Annual real-terms } \\
\text { growth rate }\end{array}$ & $8.6 \%$ & $3.6 \%$ & $3.2 \%$ & $3.2 \%$ \\
\hline \multirow{3}{*}{$\begin{array}{l}\text { Recovery } \\
\text { Meet future demand, improve } \\
\text { access to care and pay more for care } \\
\text { (leading to higher staff pay) }\end{array}$} & fbn & 27.2 & 28.2 & 29.1 & 30.0 \\
\hline & $\begin{array}{l}\text { Additional funding } \\
\text { (compared to current } \\
\text { spending power, fbn) }\end{array}$ & 7.1 & 7.9 & 8.6 & 9.3 \\
\hline & $\begin{array}{l}\text { Annual real-terms } \\
\text { growth rate }\end{array}$ & $17.4 \%$ * & $3.6 \%$ & $3.2 \%$ & $3.2 \%$ \\
\hline
\end{tabular}

Source: REAL Centre calculations.

Note: figures are for England. Annual real-terms growth rates are relative to the previous year.

* Fast increase is driven by the projected increase in social care package and staff pay.

Funding would need to be approximately $25 \%$ ( $£ 4.8 \mathrm{bn}$ ) to $50 \%$ (£9.3bn) higher in real terms by $2024 / 25$ under the stabilisation and recovery scenarios respectively. In addition, this analysis assumes no productivity improvements in the sector, nor any additional costs associated with COVID-19 (eg personal protective equipment - PPE). 


\section{Long-term funding requirements}

\section{Health care}

For health care (DHSC RDEL), stabilisation would require average real-terms annual increases of $3.2 \%$, with $3.5 \%$ for recovery. This equates to between $f 63 \mathrm{bn}$ and $\mathrm{f} 72 \mathrm{bn}$ in additional annual funding in 2030/31 over 2018/19. ${ }^{*}$ This is lower than the longterm average increase in health funding (3.7\%) for at least three reasons: first, the elective backlog is met by $2030 / 31$ in both scenarios; second, it factors no further policy driven improvements in quality or access to care after 2024/25 (eg for mental health and primary care); and third, high wage growth in recovery is coupled with high productivity growth.

Table 2: Average annual increase in funding for health care, projected and historical

\begin{tabular}{|c|c|c|c|}
\hline Government & Years & \multicolumn{2}{|c|}{$\begin{array}{l}\text { Average annual increase for } \\
\text { health care }\end{array}$} \\
\hline Whole period & $1949 / 50$ to $2019 / 20$ & \multicolumn{2}{|l|}{$3.7 \%$} \\
\hline Coalition government & $2009 / 10$ to $2014 / 15$ & \multicolumn{2}{|l|}{$1.1 \%$} \\
\hline Cameron and May Conservative governments & $2014 / 15$ to $2018 / 19$ & \multicolumn{2}{|l|}{$1.5 \%$} \\
\hline Johnson Conservative government (long term plan) & $2018 / 19$ to $2023 / 24$ & \multicolumn{2}{|l|}{$3.4 \%$} \\
\hline \multirow[t]{3}{*}{ Scenarios } & $2018 / 19$ to $2030 / 31$ & \multicolumn{2}{|c|}{ Projected growth rates } \\
\hline & & Stabilisation & Recovery \\
\hline & & $3.2 \%$ & $3.5 \%$ \\
\hline
\end{tabular}

Source: REAL Centre calculations.

\section{Social care}

For social care both the recovery and stabilisation scenarios would mean much higher growth than in recent years. The figures in Table 3 are for core spending on adult social care under the existing means-tested system. Addressing the issue of catastrophic care costs through the introduction of a cap, as recommended in the Dilnot Commission and enacted in the 2014 Care Act, would add to these costs. These growth rates imply an additional f8.9bn and f14.4bn in 2030/31 over 2019/20 for the stabilisation and recovery scenarios respectively. 
Table 3: Average annual increase in funding for social care, projected and historical

\begin{tabular}{|c|c|c|c|}
\hline Government & Years & \multicolumn{2}{|c|}{$\begin{array}{l}\text { Average annual increase for } \\
\text { social care }\end{array}$} \\
\hline Coalition government & 2009/10-2014/15 & \multicolumn{2}{|l|}{$-2.0 \%$} \\
\hline Cameron and May governments & 2014/15-2018/19 & \multicolumn{2}{|l|}{$1.8 \%$} \\
\hline Johnson Conservative government & 2018/19-2020/21 & \multicolumn{2}{|l|}{$1.7 \%$} \\
\hline \multirow[t]{3}{*}{ Scenarios } & $2019 / 20-2030 / 31 *$ & \multicolumn{2}{|c|}{ Projected growth rates } \\
\hline & & Stabilisation & Recovery \\
\hline & & $4.3 \%$ & $5.8 \%$ \\
\hline
\end{tabular}

Source: REAL Centre calculations.

* For social care modelling, the baseline year is 2019/20.

COVID-19's economic legacy has an impact on the share of national wealth that would be spent on health and social care in response to rising funding pressures. Under both scenarios, the share of national income required to meet the funding needs for the UK would be in the range of $10 \%$ by $2030 / 31$. This is an increase of more than 2 percentage points against the 2018/19 baseline. This is similar to the levels projected by the OECD for France, Germany, Sweden and Norway, and above the OECD projection for the UK (8.8\%).

\section{Implications of our analysis}

\section{Underlying pressures}

Our analysis suggests that to deliver 2018/19 standards of NHS care to a growing and ageing population, with a rising number of chronic conditions, all NHS activity would need to increase by an average of $1.7 \%$ a year over the decade to $2030 / 31$ in line with the $1.8 \%$ annual growth over the past decade. For social care, activity would need to rise by $1.9 \%$ a year up to $2030 / 31$ to keep pace with demographic changes. This is also against a backdrop of the amount of care provided falling by $0.6 \%$ a year over the past decade.

In addition, the outlook for pay and productivity are critical for determining the funding implications associated with these demand pressures. Staff pay represents around two-thirds of acute health care costs and around three-quarters of nonacute care costs. Assumptions about future pay growth, in particular, are a key driver of future funding needs. 


\section{Backlog}

Our analysis suggests that delivering the constitutional standard of $92 \%$ of patients being treated within 18 weeks, by the end of $2024 / 25$, would require $£ 4.2 \mathrm{bn}$ a year in additional funding between $2021 / 22$ and 2024/25 (f16.8bn in total). This assumes that $75 \%$ of patients not referred for treatment during the pandemic return to seek treatment. The one-off (non-recurrent) cost of clearing the backlog corresponds to around $£ 3.9 \mathrm{bn}$ a year $(£ 15.7 \mathrm{bn}$ in total by $2024 / 25$ ) and there is an additional $£ 300 \mathrm{~m}$ a year (recurrent) to keep waiting lists at this level. However, there is a real question mark over the ability of the health service to treat sufficient patients over the next 4 years, even if funding were forthcoming.

If the backlog is cleared over a longer period (by 2028/29) and the policy goal is not to return to the constitutional standard but rather to 2018/19 levels of performance ( $87 \%$ within 18 weeks), then the additional funding for the remainder of this parliament would be $£ 1.8$ bn a year between $2021 / 22$ and 2024/25. The NHS was given $\mathrm{f} 1 \mathrm{bn}$ for 2021/22 to address the waiting times backlog in Budget 2021, below our estimate of what would be needed if waiting times were to get back to 2018/19 levels in 8 years' time. The cumulative (non-recurrent) cost of clearing the backlog is estimated to be $f 12.3 \mathrm{bn}$, however, these lower costs need to be weighed against the negative health impacts of patients waiting for longer.

\section{Ongoing impact of COVID-19}

It is anticipated that COVID-19 will move from a pandemic to an endemic disease. During the pandemic, IPC measures and higher rates of staff absence meant more beds and staff (inputs) were needed to deliver the same or less activity. A crucial question facing the NHS is for how long and to what extent this will continue. Every $1 \%$ hit to productivity (eg arising from IPC measures) would require around $£ 1.5 \mathrm{bn}$ per year (2021/22-2024/25). A 10\% hit would require $f 14-16 \mathrm{bn}$ over this period.

\section{Capacity}

Before the pandemic hospital bed occupancy rates were running at almost $90 \%$ and the NHS was struggling to meet both the waiting times targets for planned care and A\&E. With so little capacity in the system, spikes in demand placed huge pressures on staff during 'normal' winter pressures, with consequences for access to care and quality.

As the NHS emerges from the pandemic, government faces key decisions about how close to capacity the NHS should run. Reducing bed occupancy to $85 \%$, in line with guidance, would add $£ 1.6 \mathrm{bn}$ to the cost of delivering care in $2024 / 25$. 


\section{Adult social care}

The scenarios in our projections work suggest that this decade will see significant pressures from demography (1.9\% a year). The government faces significant decisions over the amount of funding it is prepared to commit to expand access to care, support provider stability and reform the staffing model for both care homes and home care. Alongside this the number of people who receive publicly funded adult social care has been falling, raising significant concerns about unmet need. These estimates do not include the cost of policy changes to the balance of funding between individuals and the state, such as imposing a cap on catastrophic care costs. Introducing a Dilnot-style cap - with lifetime costs capped at $£ 46,000$ before the state pays - would cost around $£ 3.1$ bn a year by $2023 / 24$.

\section{What our projections mean for the workforce}

Our projections imply that the NHS workforce would need to grow by over a fifth by $2024 / 25$, on top of growth to reduce current staffing shortages. The growth would be higher if the NHS sought to reduce bed occupancy to provide more resilience to health shocks. In addition, the social care workforce would need to grow by almost $30 \%$ over this period to keep pace with demographic pressures and reduce unmet need. By $2030 / 21$, the NHS workforce would need to grow by $40 \%$ and the adult social care workforce by $55 \%$, meaning over 1 million additional full-time equivalent staff.

\section{Conclusion}

Our analysis suggests that over the coming decade the underlying demand and cost pressures facing both the NHS and social care will rise at a faster rate than the economy. While ageing plays a part in driving funding requirements, it is clear that the pattern of chronic disease and the system response to it is an even bigger factor. COVID-19 has led to huge short-term costs for the health and social care systems, but its legacy will add significantly to funding pressures over the rest of this parliament. 


\section{1. \\ Introduction}

Health and social care are vital public services that form a large part of the UK economy and public spending. Together, they account for more than a tenth of UK employment, ${ }^{*}$ and more than a fifth of all UK government public spending equivalent to $9 \%$ of GDP. ${ }^{\dagger}$ Public spending on health has risen over time - from around $£ 500$ per person in $1971 / 72$ to near $£ 2,600$ in $2019 / 20$. ${ }^{\ddagger}$ This means that future decisions are critical for the public finances. Even more so after the COVID-19 pandemic, which the OBR has identified as a potentially catastrophic fiscal risk due to the legacy costs, including health care. ${ }^{1}$

Decisions about funding can seem remote from the care that individuals receive, but the potential impact of these decisions is broad and directly affects people's wellbeing. There were an estimated 564 million patient contacts with the NHS in $2018 / 19 ;{ }^{5}$ at some point in our lives we are all likely to come into contact with the NHS. ${ }^{2}$ Additionally, the NHS is generally seen as an asset and over the past 30 years has been consistently identified by the public as the number one priority for additional government spending. ${ }^{3}$

At any point in time, fewer people are in contact with the social care system than the NHS. For example, around 630,000 people were receiving long-term support funded by their local authority at the end of 2019/20. However, social care need and the way it is met affects us in different ways. An estimated 4.5 million people are unpaid carers, supporting people with social care needs instead of, or in addition to paid care. ${ }^{5} \mathrm{~A}$ decade ago, the Dilnot Commission identified the risk of unpredictable and catastrophic care social care costs we all face as older people.

In both systems, funding is a key determinant of who receives care, which services are available, their quality and how long we might need to wait. The level of funding is therefore important, and decisions about funding levels were made more urgent by the COVID-19 pandemic. This leads us to ask: how much funding should health and social care services receive over the next decade?

Unfortunately, there is no 'correct' or purely objective answer to that question. How much funding is needed depends on how many people need care, which in turn depends on what health problems people are experiencing and what treatments are available to them. Analysis of trends in care needed can point to a certain level of funding. However, how much to spend is fundamentally a political decision

* Calculated using the ONS Labour Force Survey.

$\dagger \quad$ Calculated using UK functional health spending plus local government net spending on adult social care, divided by total managed expenditure or GDP respectively.

‡ $\quad$ Figures quoted are in 2021/22 prices.

$\S \quad$ This includes GP appointments, community health services, outpatient attendances, inpatient stays, A\&E attendances, calls to ambulances and NHS 111. 
affected by political priorities on tax and spending, the state of the public finances and the performance of the UK economy. Combined, these lead to an assessment of what is perceived as affordable. This assessment will also be informed by political views on the role for the state and the individual and trade-offs with spending on other priorities like education and the police.

Health and social care share a number of long-term issues: demand for care is growing, as are staff shortages, both compounded by the years needed to train new staff and embed new services. However, decisions on funding tend to be relatively short-term making it difficult to plan. ${ }^{6}$ Real-terms funding growth for health has varied across governments over the past few decades from a high of $6.0 \%$ (Blair and Brown Labour government) to a low of $1.1 \%$ (Coalition government). ${ }^{*}$ For a number of years local government has had to contend with short-term funding settlements for adult social care, built from a patchwork of national and local policies for raising funds.

While decisions about the level and timing of funding are ultimately taken by government, they can be better informed by objective, transparent analysis and projections. Such analysis allows for a clearer understanding of the pressures the NHS and social care are facing, the responses needed, and the trade-offs and risks of taking different decisions. It also facilitates an informed debate about priorities. However, beyond one-off exercises such as the Wanless review or high-level projections from the OBR, detailed official projections of the funding needed for health and social care are not published.

\section{About this report}

This analysis projects future costs using different sets of assumptions. The report summarises the funding pressures faced by health and social care over the next decade, combining these into two scenarios with varying levels of ambition for the post-pandemic world - stabilisation and recovery.

In doing this analysis, we seek to answer the following questions:

- How much funding is needed between now and 2030/31 to deliver prepandemic levels and patterns of care ${ }^{\dagger}$ based on existing trends in population size, age profile and morbidity (underlying funding pressures)?

- How does the level of funding that would be required change as a result of additional demand and supply pressures? For example, policy choices about levels of access, the range of services provided and levels of pay, including the existing long term plan commitments.

\footnotetext{
See Table 4.

$\dagger \quad$ This is based on the patterns of care in $2018 / 19$, the last full year of data unaffected by the pandemic.
} 
- How will the COVID-19 pandemic impact funding decisions? For example, what is the impact on future productivity rates, or of an ongoing vaccination programme?

- What are the implications of these funding pressures on workforce and capacity, assuming existing models of care and patterns of staffing?

The REAL Centre will update this analysis and report future findings. It is hoped this will inform future government decision making, the political debate and understanding of the challenges and trade-offs in relation to health and social care funding. 


\section{2.}

\section{Health and social care funding trends}

This chapter provides the context for our funding projections. First, we review the various definitions of health and social care spending used in this report. We then look at the evolution of departmental spending for health, including the NHS budget and social care spending since the early 2000s, considering historical trends, existing political commitments and the impact of the COVID-19 crisis. Finally, we look at how the UK health system compares with other developed economies across a range of areas, including public spending for health and social care, capital investment, and workforce and infrastructure available relative to population size. In chapter 6 we discuss the results of our funding projections using this analysis.

\subsection{Alternative measures of health and social care spending}

There are different ways to measure health care spending. Measures can look at who is spending (government spending, insurance, out-of-pocket payments), different types of spending (day-to-day running costs, capital investment in equipment, buildings and research and development), the geography (UK or individual countries within the union) and the range of services (the NHS or health more broadly including some long-term care).

In the UK, health and social care are devolved matters. The UK government makes decisions about state funding for health in England (75\% of UK health spending comes from public sources). These do not automatically lead to changes in health spending in the rest of the UK. Instead, the decisions lead to changes in the overall spending power of the devolved administrations in Scotland, Wales and Northern Ireland. It is then for each administration to set its health budget and policy.

In adult social care state funding is determined by local authorities. Again, this is influenced by the UK government's decisions about the level of grants provided to local authorities and the rules governing local authority finances. For example, in recent years the UK government has specified that local authorities can levy a tax locally of up to $2-3 \%$, which must be spent on adult social care. Long term care (LTC) spending refers to social care spending used in international comparisons and by the OECD, which includes a health and social care component. We discuss these international comparisons further in section 2.4. 
In this report we focus on spending under the direction and influence of the UK government. This includes the decisions it makes about the budget needed for paying staff salaries or buying medicines (DHSC Resource Departmental Expenditure Limits - RDEL); for purchasing new medical equipment or building new facilities (DHSC Capital Departmental Expenditure Limits - CDEL); and for other budgets, such as public health and Health Education England. These aggregates are all captured in the total budget for the DHSC (DHSCTotal Departmental Expenditure Limits -TDEL), which in turn sets the budget for the NHS in England (NHS England RDEL). We then look at what that would imply for spending in Scotland, Wales, and Northern Ireland.

For adult social care we examine spending pressures in England (spending by local authorities, including transfers of funding from the NHS but net of any fees raised from service users) and what these would mean for the combined spending power of local authorities from local revenue and central government grants, and the implications for Scotland, Wales and Northern Ireland.

We do not model or project other components of total health and care spending, such as private insurance and out-of-pocket payments. Instead, we hold spending for these components constant. This allows us to explore the implications of different levels of NHS spending for overall health spending as a share of GDP.

Figure 2 shows a summary of current health care and long term care spending, (both health and social components) within England and the UK.

The departmental budget for health is the amount that the UKTreasury allocates to DHSC for health care expenditure in England. The functional health spending is the amount that DHSC, devolved administrations and other departments spend for the health function, as defined by the UN's Classification of the Functions of Government (COFOG) framework. The System of Health Accounts (SHA) government financed spending is a measure of public expenditure for day-today health care services, also including part of long-term care services, used in international comparisons.

For more information about the different measures of health and social care spending, see Appendix A. 


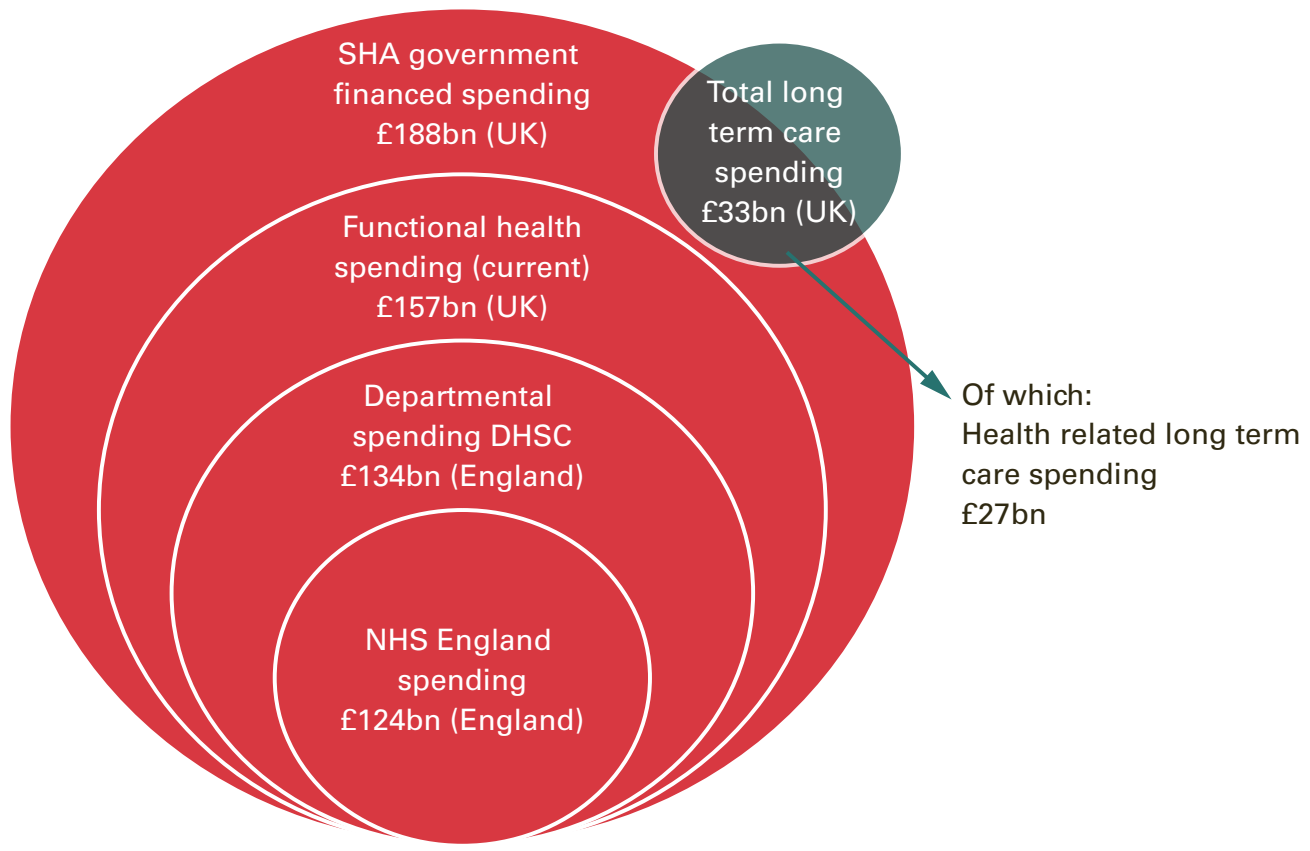

Source: OECD Health Database and Public Health Statistical Analyses 2021 (PESA).

\subsubsection{Departmental spending for health}

In $2019 / 20$ the UK government and devolved administrations spent $£ 157 \mathrm{bn}$ on day-to-day health care services, ${ }^{*} 7 \%$ of GDP and equivalent to $20 \%$ of total current government expenditure. Publicly funded spending on adult social care in the UK was around $£ 23 \mathrm{bn}$ in the same financial year, around $1 \%$ of GDP, equivalent to around $3 \%$ of overall government current spending ${ }^{\dagger}$ and $14 \%$ of total current spending by local authorities. ${ }^{\ddagger}$

Growth in government spending for health care has varied across decades and governments. In 2019/20, spending was about 12 times the level in 1949/50 when the NHS was founded. Average annual growth in funding peaked at $6.6 \%$ per year in the first decade of the 2000s, followed by substantially lower growth of $1.7 \%$ over the past decade (up to 2019/20). However, as a result of the funding commitments introduced in the NHS Long Term Plan, ${ }^{7}$ spending is expected to increase under the current Conservative government by an average of $3.4 \%$ per year up to 2023/24 (see Table 4). This expected growth does not include spending resulting directly from the COVID-19 crisis. The share of national income spent on health had decreased since the financial crisis but peaked again in 2019/20.

$\dagger \quad$ All figures and growth rates referenced in this chapter are in real terms in 2021/22 prices, unless otherwise stated. Figures are adjusted for inflation by using the latest OBR GDP deflator (March 2021).

‡ REAL Centre calculations based on PESA tables. 
Table 4: Average annual increase in health care expenditure over time real-terms 2021/22 prices

\begin{tabular}{lll}
\hline Government & Years & Average annual increase \\
\hline Whole period & $1949 / 50$ to $2019 / 20$ & $3.7 \%$ \\
\hline Pre-1979 (various governments) & $1949 / 50$ to $1978 / 79$ & $3.5 \%$ \\
\hline Thatcher and Major Conservative governments & $1978 / 79$ to $1996 / 97$ & $3.3 \%$ \\
\hline Blair and Brown Labour governments & $1996 / 97$ to 2009/10 & $6.0 \%$ \\
\hline Coalition government & $2009 / 10$ to 2014/15 & $1.1 \%$ \\
\hline Cameron and May Conservative governments & $2014 / 15$ to 2018/19 & $1.5 \%$ \\
\hline Johnson Conservative government (long term plan) & $2018 / 19$ to 2023/24 & $3.4 \%$ \\
\hline
\end{tabular}

Source: REAL Centre calculations.

Spending on adult social care rose between 2000/01 and 2009/10 both in real terms and as a percentage of GDP. Spending grew at an average annual real rate of $5.7 \%$, rising from $0.9 \%$ to $1.3 \%$ of GDP. ${ }^{8}$ Since then it has fallen gradually, with a slight recovery in recent years. This means spending is at a similar level in real terms in 2019/20 as it was in 2009/10. In recent years spending on adult social care has become increasingly reliant on transfers of funding from the NHS and locally raised taxes, as grants from central to local government have fallen.

\subsection{Latest trends in departmental spending for health in England and impact from COVID-19}

The TDEL for DHSC is normally announced at spending reviews and is often set for a multi-year period. ${ }^{*}$ DHSC's total spending has followed an upwards trend since the financial crisis of 2007/08, and the pandemic required exceptional funding to support the health system. As of 2020/21, TDEL spending for health accounted for $34 \%$ of TDEL across all departments, up from about $26 \%$ in $2009 / 10$. Although austerity measures meant lower levels of public spending growth in the 10 years following the recession, funding for health was shielded from this impact.

Figure 3 shows how funding is allocated across the different services in 2019/20, the most recent year for which this breakdown is available. Most of the budget (87\%) goes to NHS commissioning, which funds services commissioned nationally and locally through Clinical Commissioning Groups (CCGs). About 38\% of the total departmental budget is spent on acute care ( $f 46 \mathrm{bn})$, followed by specialised services $(14 \%)$ and community care $(11 \%)$.

* There have been notable exceptions in recent years, with the Spending Review in 2019 and 2020 only covering 1 year. 
Figure 3: DHSC budget funding allocations across health care services, 2019/20

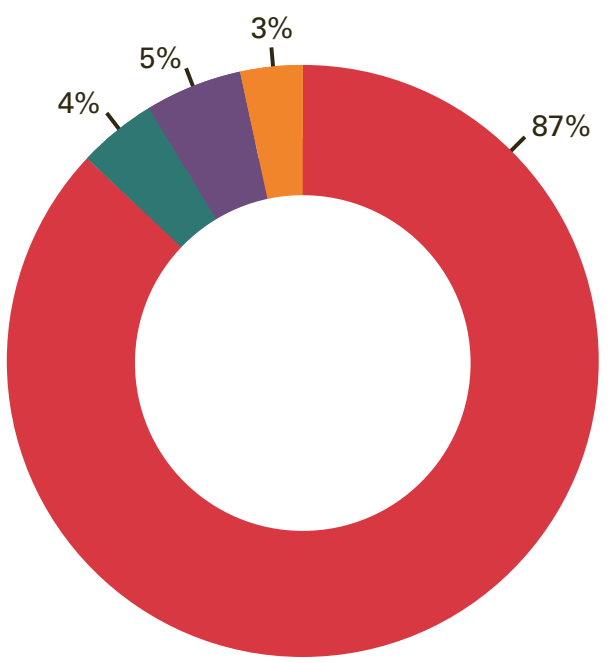

NHS commissioning

Public health

NHS support activity

DHSC programmes

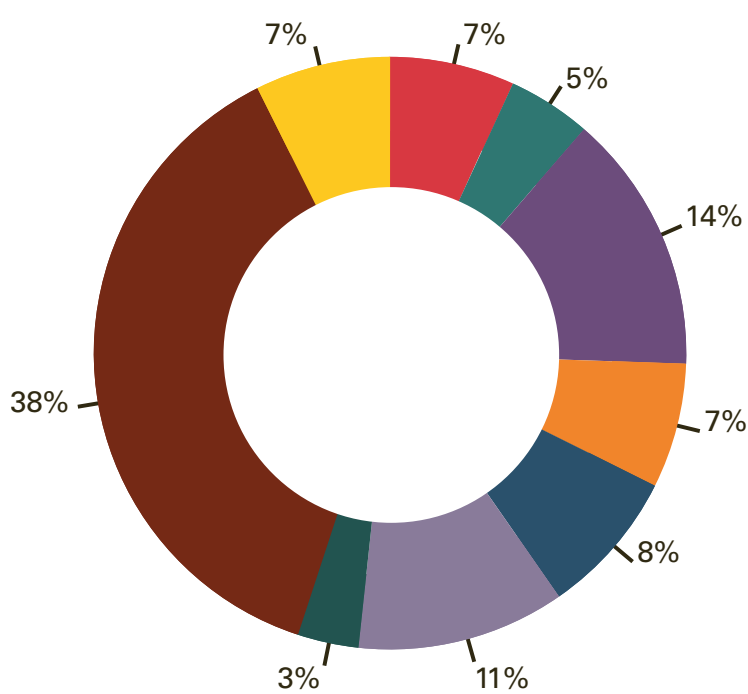

Directly commissioned (incl. public health)

Other primary care (incl. community pharmacy, dental services)

Specialised services

Primary care

Community prescriptions

Community health

Better care fund

place-based

Acute care

Mental health allocations

Source: HM Treasury, PESA 2021, and NHS England and NHS Improvement.

\section{NHS Long Term Plan funding}

In 2019, the long term plan committed to improvements in community, primary care, and mental health services. ${ }^{7}$ For primary care and community health services this includes a guaranteed funding increase of $£ 4.5 \mathrm{bn}$ in real terms by $2023 / 24$ over 2018/19. Meanwhile, the Mental Health Implementation Plan committed another £2.3bn a year in real terms for mental health services by $2023 / 24 .{ }^{9}$ The Mental Health Investment Standard mandates that funding should grow at least as fast as the rest of the budget. Figure 4 illustrates how the actual NHS RDEL spending has already been higher than the original plans based on these commitments. In 2020/21, actual spending was f14bn higher in real terms. This partly reflects the government's response to COVID-19, initially quantified as f18bn for the NHS in the 2021 budget. $^{*}$

The analysis presented in this report was prepared ahead of the government announcements for health and social care funding on 6 and 7 September 2021. The analysis presents a benchmark to compare those funding announcements against. Therefore, data presented here, for example the budget allocations to the DHSC and NHS England including the response to the pandemic, do not reflect the latest funding commitments for the period up to 2024/25. 
Figure 4: Trends in NHS RDEL spending

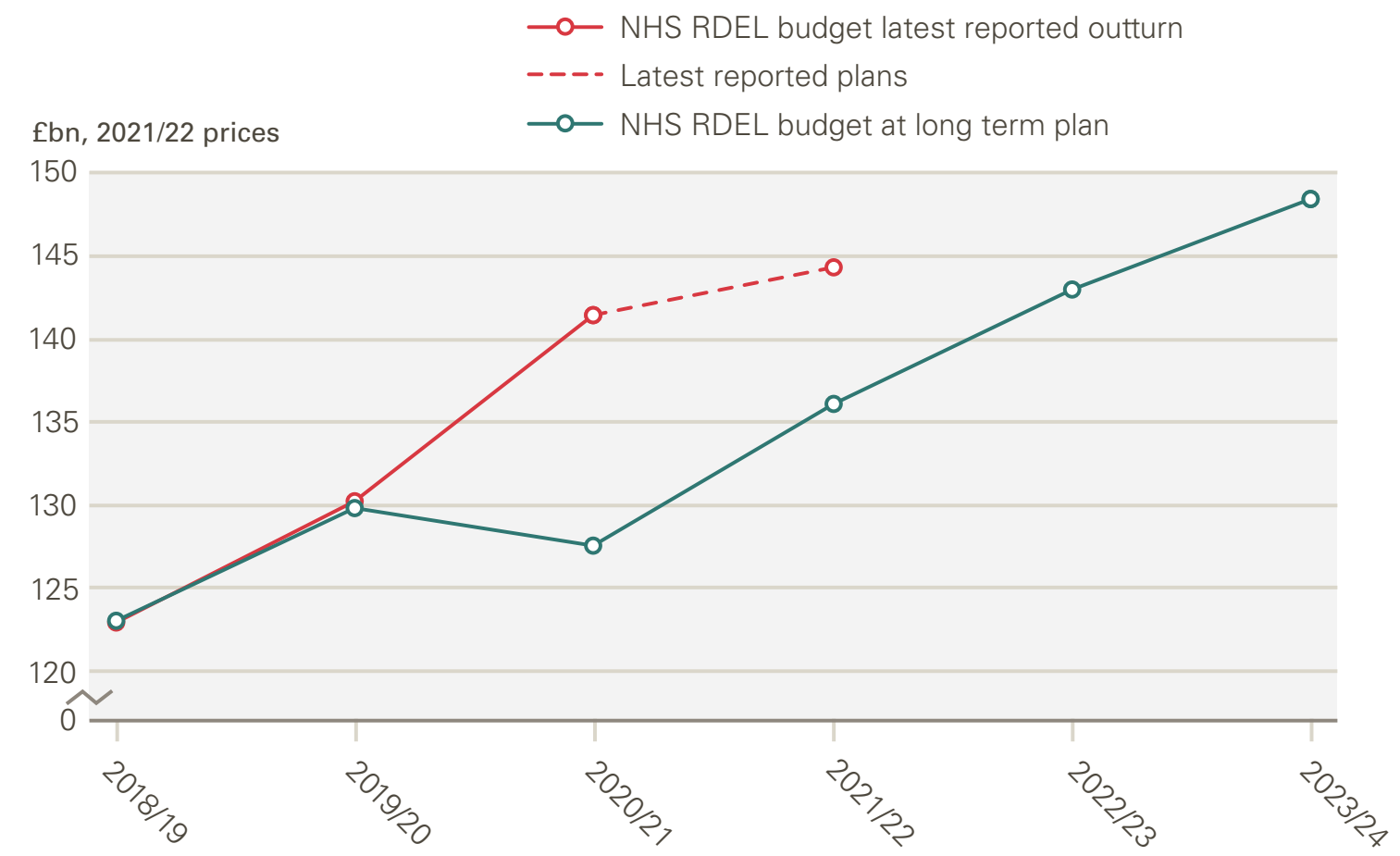

Source: DHSC, Annual Reports and Accounts 2019-20 and HM Treasury, PESA 2021.

\section{Funding allocation to devolved administrations and local authorities}

The devolved administrations in Scotland, Wales and Northern Ireland receive a spending allocation calculated using the Barnett formula, which includes funding for health. In 2019/20 they spent respectively around $£ 14 b n$, £8bn and £5bn for dayto-day health care services and capital investment.

\section{Funding for public health}

Local authorities are responsible for most aspects of public health and receive a grant from central government to fund these services. In 2019/20 local authorities spent $\mathrm{f3.4bn}$ on public health. This amount is expected to increase by less than $1 \%$ in 2020/21 and around 9\% in 2021/22, reaching 3.7bn in 2021/22 (about 3.5\% of the total net current spending from local authorities). Much of this increase in the budget is the result of the financial impact of COVID-19. ${ }^{10}$

\section{Funding allocation in response to the pandemic}

In the 2021 Budget the UK government committed total planned spending of $f 85 \mathrm{bn}$ to DHSC in response to the pandemic from 2020/21-2021/22, about $4 \%$ of national income. The NHS then received a further $f 7 \mathrm{bn}$ in support of the ongoing response 
to the pandemic. ${ }^{11}$ This brought the overall cost of the measures announced in response to COVID-19 to $£ 92 \mathrm{bn}$, of which less than half ( $£ 34 \mathrm{bn}$ ) had been reported as being spent by May 2021. ${ }^{12}$

As shown in Table 5, in the financial year 2020/21 DHSC received f59bn of RDEL and $£ 4$ bn of CDEL to cover various COVID-19-related costs, ${ }^{13,14}$ including NHSTest and Trace (£23bn), PPE (£15bn) and vaccine deployment (£3 bn). According to the IMF, between January 2020 and April 2021 the public financial support for health care in the UK was higher than in all other countries for which data are available..$^{1,15}$

In its 2021 to 2022 Mandate to NHS England and NHS Improvement, ${ }^{16}$ the government recognised that leading the NHS response to COVID-19 will be the key priority in 2021/22, but also renewed its commitment to improving access to primary and community care, and treating mental health with the same urgency as physical health. DHSC has received a provisional amount of $£ 29 \mathrm{bn}$ for the current year, including ongoing support for NHSTest and Trace ( $£ 15 \mathrm{bn}$ ) and recovery (almost f10bn).* and social care funding on 6 and 7 September 2021. The analysis presents a benchmark to compare those funding announcements against. Therefore, data presented here, for example the budget allocations to the DHSC and NHS England including the response to the pandemic, do not reflect the latest funding commitments for the period up to $2024 / 25$. 
Table 5: COVID-19-related spending in 2020/21 and 2021/22, fbn (cash values)

\begin{tabular}{lll}
\hline & $2020 / 21$ & $2021 / 22$ \\
\hline Resource spending, of which: & 59 & 29 \\
\hline NHS Test and Trace & 20 & 15 \\
\hline Support to NHS & 18 & 10 \\
\hline PPE procurement & 15 & 2 \\
\hline Vaccine deployment & 3 & 2 \\
\hline Other measures & 3 & 1 \\
\hline Capital spending, of which: & 4 & - \\
\hline NHS Test and Trace & 3 & - \\
\hline Other measures & 1 & - \\
\hline Total spending & 63 & - \\
\hline
\end{tabular}

Source: HM Treasury Supplementary Estimates 2020-21, PESA 2021, and DHSC Estimate Memoranda.

Note: Numbers may not sum up due to rounding

\subsection{Local authority spending on adult social care}

\subsubsection{Key trends in adult social care spending in England}

Current net spending on adult social care services by local authorities in England totalled almost $£ 20$ bn in 2019/20. As Figure 5 shows, after a period of constrained funding, spending has increased on average by $2 \%$ since $2015 / 16$, so current spending is at a similar level to $2009 / 10$. Spending per adult did not recover to the same extent and is $7 \%$ lower than in $2009 / 10$. 
Figure 5: Net local authority spend on adult social care (2021/22 prices)

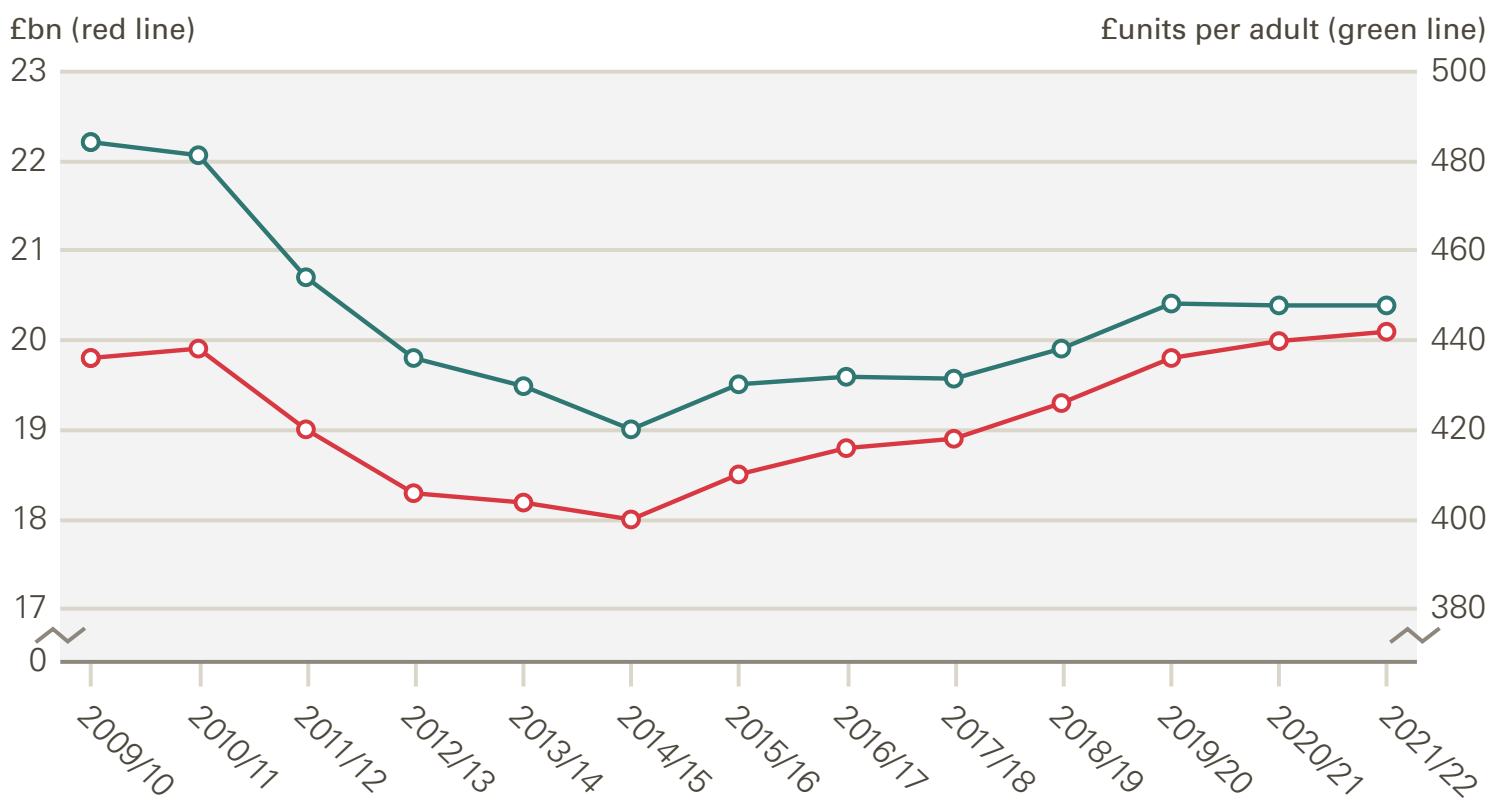

Source: NHS Digital. Adult Social Care Activity and Finance Report, England - 2019-20, REAL Centre ASC Funding Gap Projections 2021 and ONS Population estimates and 2018-based projections.

Adult social care spending has stagnated compared with health care spending, in particular between 2010/11 to 2014/15, as shown in Figure 6. This is despite social care and the NHS experiencing similar demographic pressures. As of 2019/20, current spending on health care and social care accounts for around $20 \%$ and $3 \%$ of overall public current spending respectively. Spending on adult social care is distributed across different age groups and care settings with almost $55 \%$ of net spending (excluding user fees) on working age adults. ${ }^{17}$ The adult social care sector received considerably less funding for COVID-19 than the health care sector, with total funding of over $£ 2 \mathrm{bn} .{ }^{18}$ This included funding for IPC measures and testing. 
Figure 6: Comparing spending on health and social care

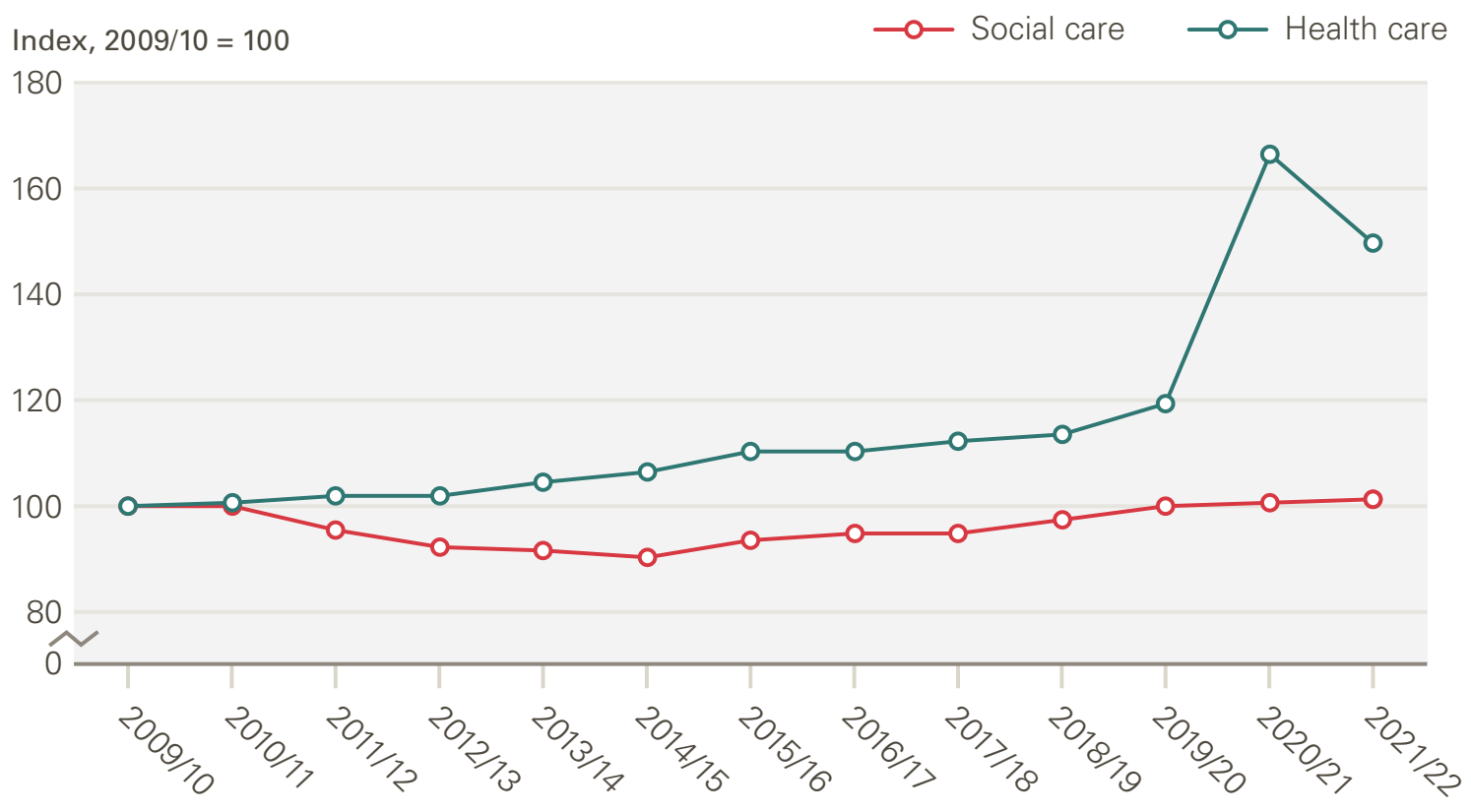

Source: NHS Digital Adult Social Care Activity and Finance Report, England - 2019-20, REAL Centre ASC Funding Gap Projections 2021, HM Treasury, PESA and Budget 2021.

\subsection{Public spending on health and social care: international comparison}

The funding pressures we discuss in the remainder of the report are not unique to the UK. In addition, the COVID-19 pandemic has brought into focus the differing capacity and readiness of health and public health systems across the world. It is therefore important to understand what is happening in other countries and how these challenges are being addressed, of which public spending is a key contributor. This section shows how the UK health system compares with other advanced economies across a range of dimensions:

- $\quad$ current public spending

- $\quad$ capital spending

- $\quad$ capacity and infrastructure, and

- $\quad$ public social care spending.

We discuss key definitions of health and care spending that are used to compare internationally, which differ from the definitions used in a UK-only context, and how the UK currently compares with different groups of countries. 


\subsubsection{Current health care spending}

Current health care spending is the headline statistic used in international comparisons. The OECD considers services that deliver through government and compulsory contributory schemes 'public' spending for health care (see Appendix A).

Figure 7 compares overall spending for health care across OECD countries and the split between public and private sources. As of 2019, total UK spending as a share of GDP had reached over 10\%. This is higher than both the OECD and the EU14 groups (both around 9\%), but below the G7 average (almost 12\%). Public spending for health care services alone follows a similar pattern, representing around $79 \%$ of overall current spending and around $8 \%$ of GDP in the UK. This is below the G7 average; however, this result is skewed by the US and its compulsory insurance health schemes being classified as 'public spending' (and accounting for $14 \%$ of GDP).

Figure 7: Health care spending as share of GDP, 2019: split by financing schemes

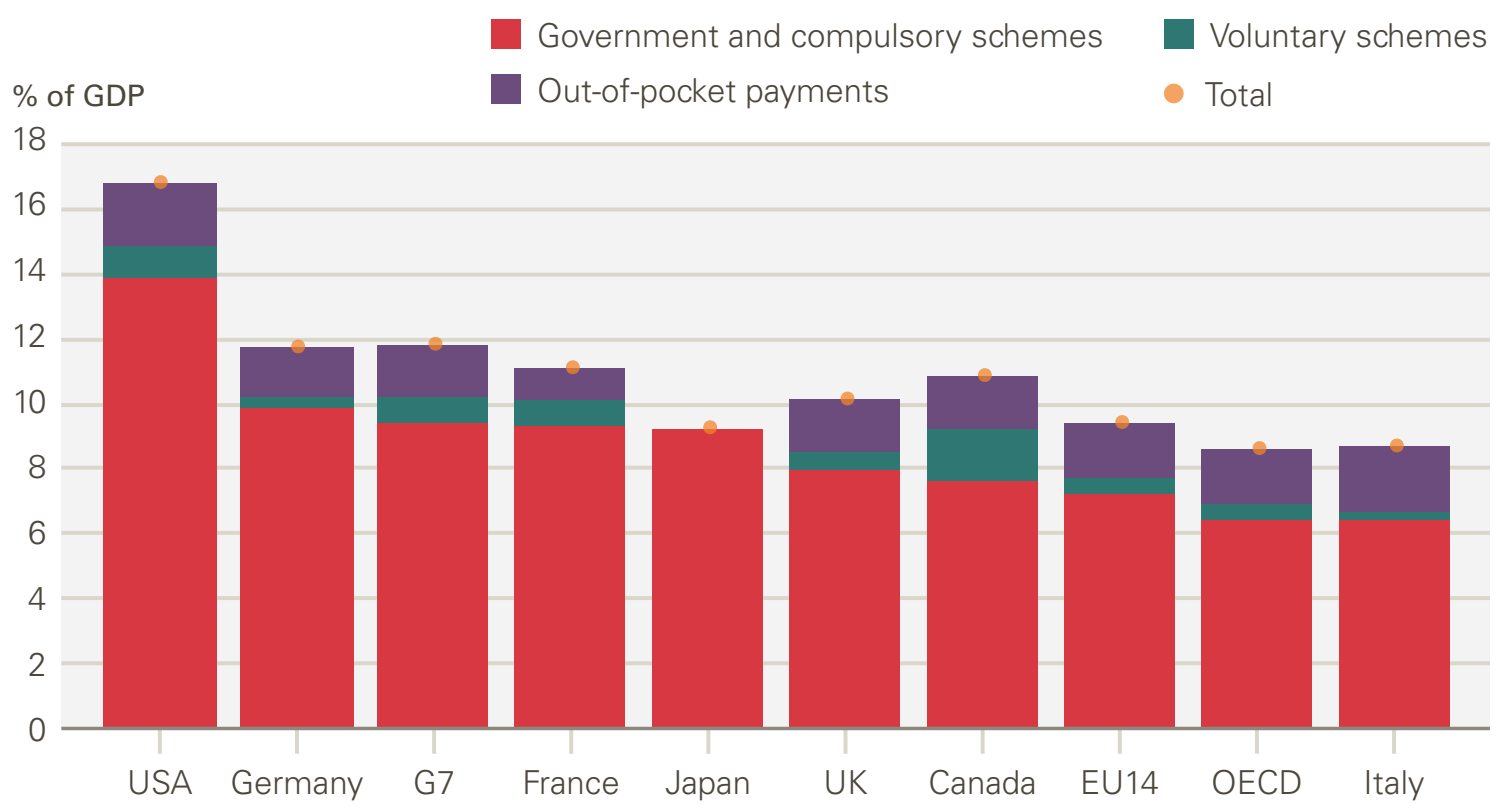

Figure 8 shows that in 2019 the UK government spent more in per capita terms than the OECD group in most of the health services, except for ancillary services, ${ }^{*}$ medical goods, governance and health system and financing administration. However, when compared with the G7 countries, the UK only spends more on outpatient and rehabilitative care. 
Figure 8: Public spending for health per capita: composition by function

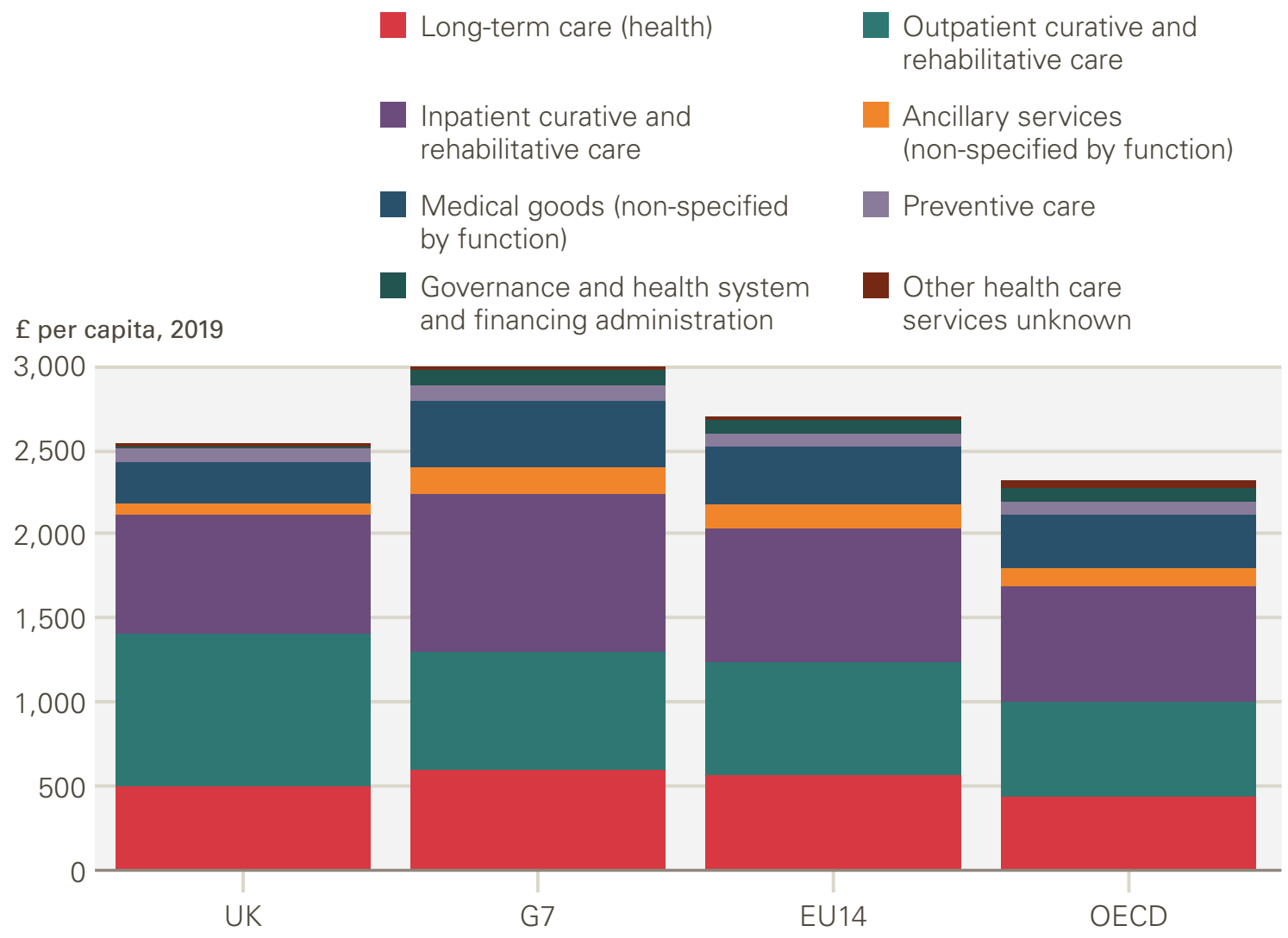

\subsubsection{Capital spending on health care}

The UK spend on capital in health care as a share of GDP is significantly lower than comparable countries. As shown in Figure 9, in 2019 the UK spent $0.3 \%$ of GDP on gross fixed capital formation* (GFCF) in health care compared with $0.5 \%$ in similar countries. Aside from the few years between 2007 and 2009, the UK has been consistently below the average since 2000. assets that health providers have acquired during the accounting period (less the value of the disposals of assets) and that are used repeatedly or continuously for more than one year in the production of health services. This aggregate then captures spending on capital assets, including hospital buildings and MRI machines. 
Figure 9: Gross fixed capital formation in the health care system as share of GDP

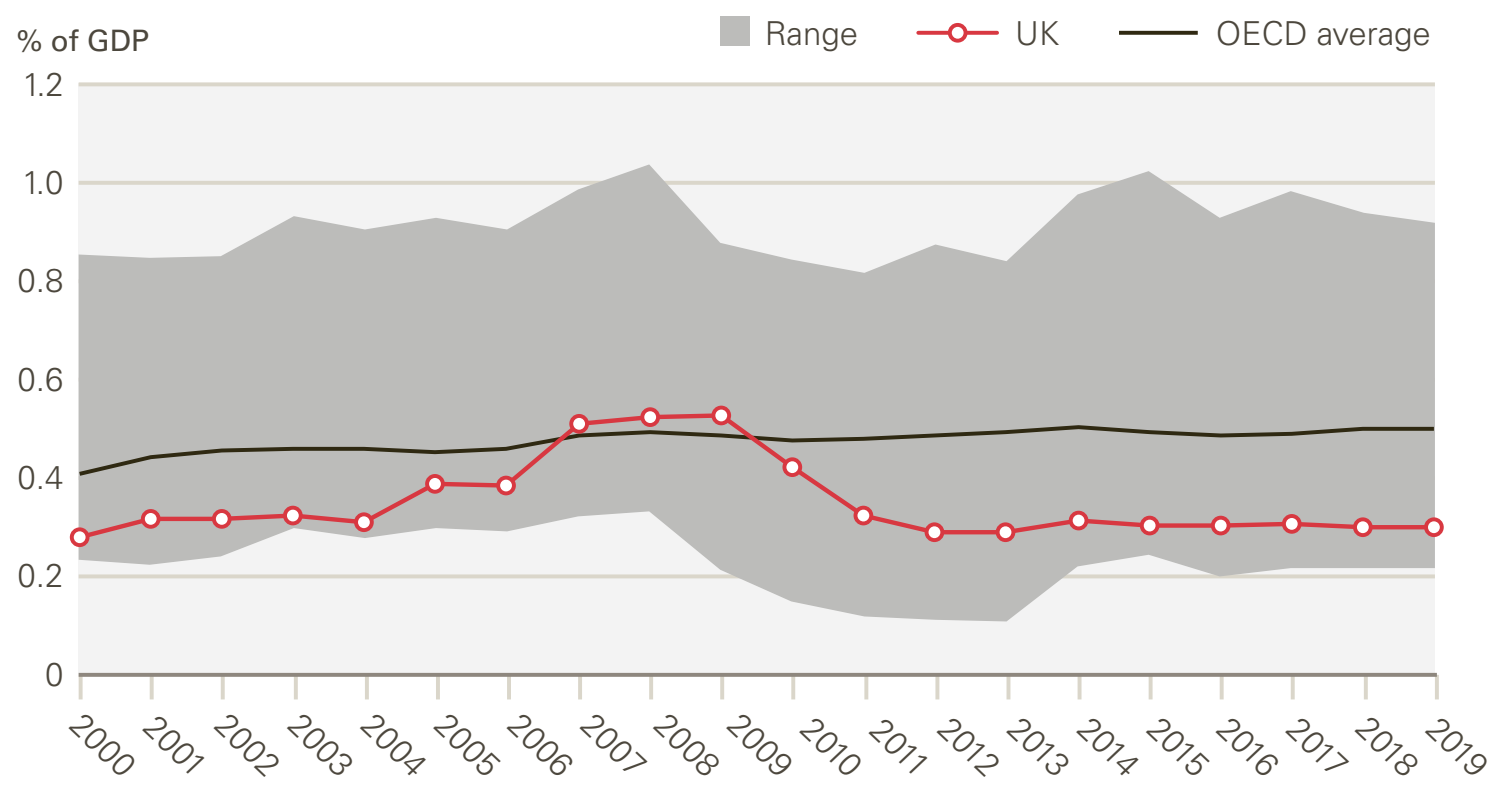

Source: OECD Health database.

Complete data on the composition of GFCF are not available for all countries. However, according to the most recent estimates, in 2019 the UK spent the same share of national income on the different components $(0.1 \%$ on capital infrastructure, machinery and equipment, and intellectual property products), falling short compared with similarly wealthy countries such as the US and Canada. In the same year, the US spent about $0.3 \%$ of GDP on capital infrastructure and $0.4 \%$ on machinery and equipment.

\subsubsection{Capacity and infrastructure in the health sector}

High health spending as a share of GDP does not always mean a higher level of inputs such as staff and equipment. As Figure 10 shows, a number of key input measures are lower in UK health spending per head of population, when compared with other advanced economies. For instance, as of 2019 the UK had eight practising nurses per 1,000 population compared with ten for the $\mathrm{G} 7$ as whole or the EU14. The UK health system also has a lower number of beds per 1,000 population - around two against an average of six for the G7 and four for the EU14. According to OECD estimates, ${ }^{19}$ the UK health system has fewer MRI scanners per head of population.

There are several potential reasons for the lower capacity in the UK. For instance, the unit price of inputs, eg wages, is comparatively high in the UK. Based on OECD evidence, ${ }^{20}$ health care prices in the UK are higher than in other economies, including France and Germany. 
Supply-side factors and policy choices also play a role in shaping the capacity of the health system. Recent REAL Centre analysis has shown how the number of acute beds fell sharply after 2000/01 as a result of technological change (which generally reduced the need for more beds), and also the policy push to treat more people in the community. ${ }^{21}$ This analysis showed ${ }^{*}$ that in the 10 years after the 2008 financial crisis, there was lower growth in NHS staff numbers than previously. This is particularly true for nurses and GPs. The bed shortage limits the health system's surge capacity, leaving services unable to deal with spikes in demand, as seen in winter months and, more dramatically, during the pandemic. Workforce shortages can have negative impacts on both access to and quality of care, as has been much reported. ${ }^{22}$

Figure 10: Capacity in the health care sector in 2019

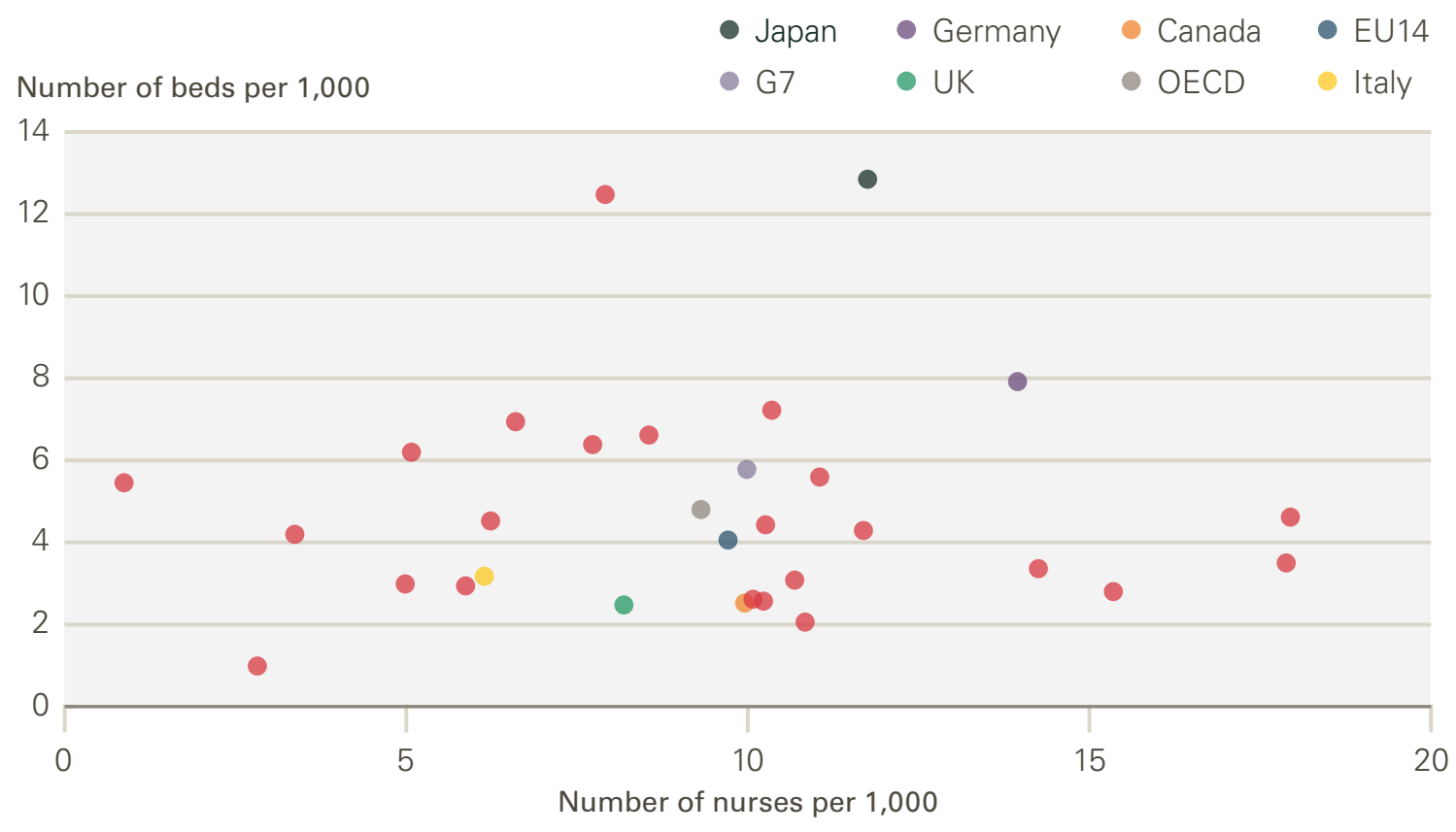

Source: OECD Health database.

Similarly, high spending for health care as a share of GDP does not always translate into high levels of access and efficiency: ${ }^{23}$ research suggests that relatively high public spending, combined with low levels of private spending, should allow for good access and efficiency in the provision of health care services. Studies have also concluded that good health outcomes and equity can be achieved if countries exhibit both high levels of expenditure and low levels of income inequality.

Evidence from the OECD ${ }^{22}$ shows that despite nearly all care in the UK being free at the point of use, waiting times have grown and there are still financial barriers to certain services (for instance, dental care).

See Figure 7 from Tallack C, Charlesworth A, Kelly E, McConkey R, Rocks S. The bigger picture: Learning from two decades of changing NHS care in England. The Health Foundation; 2020 (https://doi.org/10.37829/ HF-2020-RC10). 


\subsubsection{Social care spending}

Long term care (LTC) spending is used in international comparisons of social care spending and by the OECD. It is split into health-related and social components (see Appendix A). Figure 11 shows how health-related long term care spending in the UK compares with other countries. Figure 11 also shows the split across public and private sources. Overall, the UK spends $1.8 \%$ of national income on health-related long term care. This is above the average share for other groups of countries. $35 \%$ of health-related long term care is financed through private sources, while for the other groups of countries this share is lower (16\% for the EU14 and 25\% for the G7 on average).

Figure 11: LTC (health) spending as share of GDP in 2019: split by financing scheme

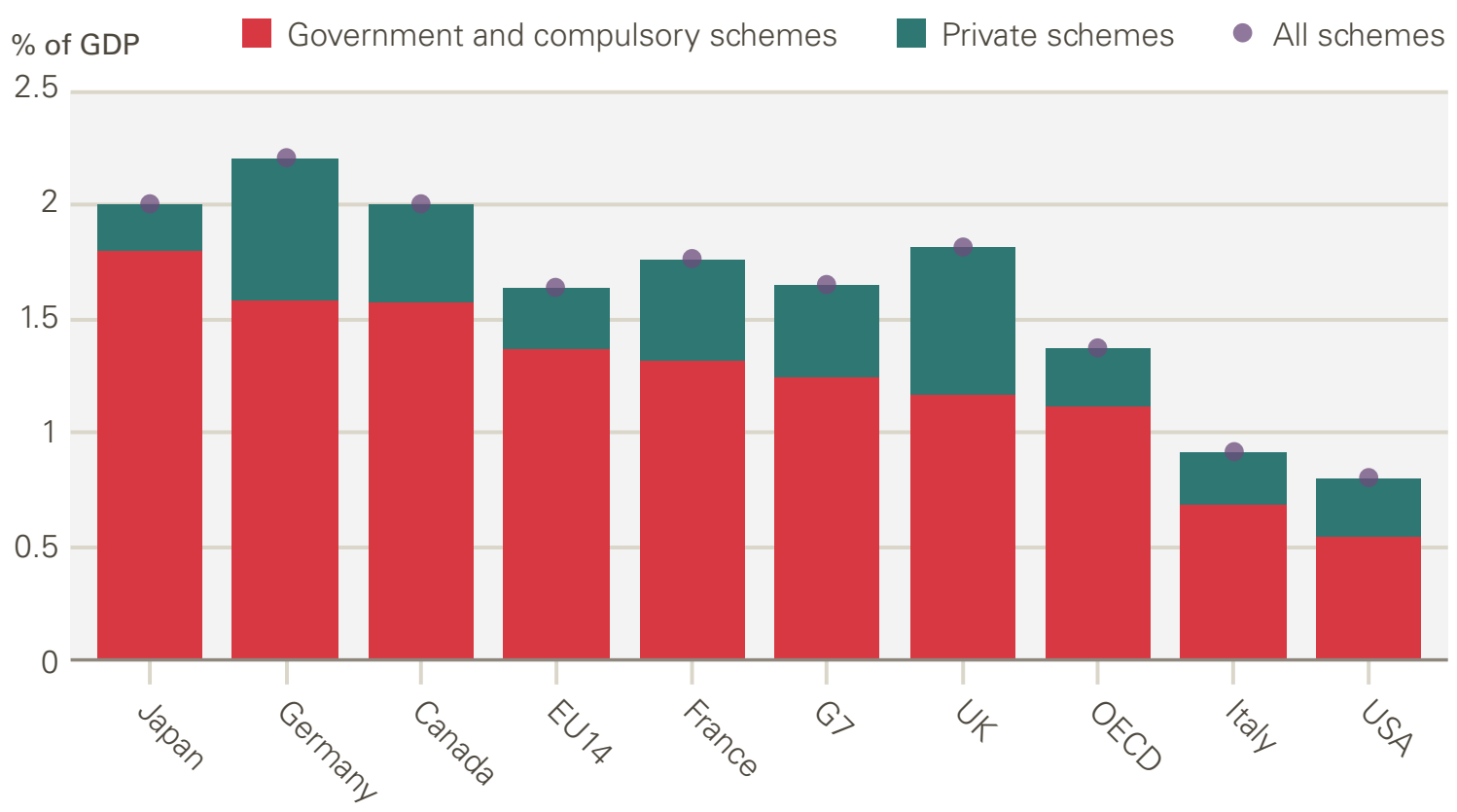

According to estimates, in 2019 the UK spent around $0.5 \%$ of national income on social long term care. $60 \%$ of this spending was financed publicly. The available data do not allow for a full OECD comparison however, they show that two countries (Denmark and Netherlands) spent more than twice the UK share of national income. 
3.

\section{Approach to modelling funding pressures}

In this chapter we summarise our approach to modelling funding pressures. We begin by introducing our modelling approach (summarised in Figures 12 and 13). We then discuss various demand and supply factors that act as drivers of health and social care expenditure in our model, before turning to the impact of additional funding pressures. Taken together these lead to our estimates of overall funding pressures to 2030/31. Finally, we discuss how we uplift our funding estimates for England to a UK-wide figure.

\subsection{Our modelling approach}

We take the 2018/19 patterns of service use in England as a baseline. Based on assumptions about demand-side drivers (see section 3.2), we project how much activity is needed to meet demand for health and social care services. ${ }^{21}$ Similarly, based on assumptions about supply-side drivers (see section 3.3), we project the cost of care over time. Combining projected activity with the projected cost gives an estimate of underlying funding needs, corresponding to the amount of funding required if existing trends in key drivers continue. To this, we add additional funding pressures arising from new pressures and policy choices (Figure 12). 
Figure 12: Key drivers of health and social care funding modelled in our approach

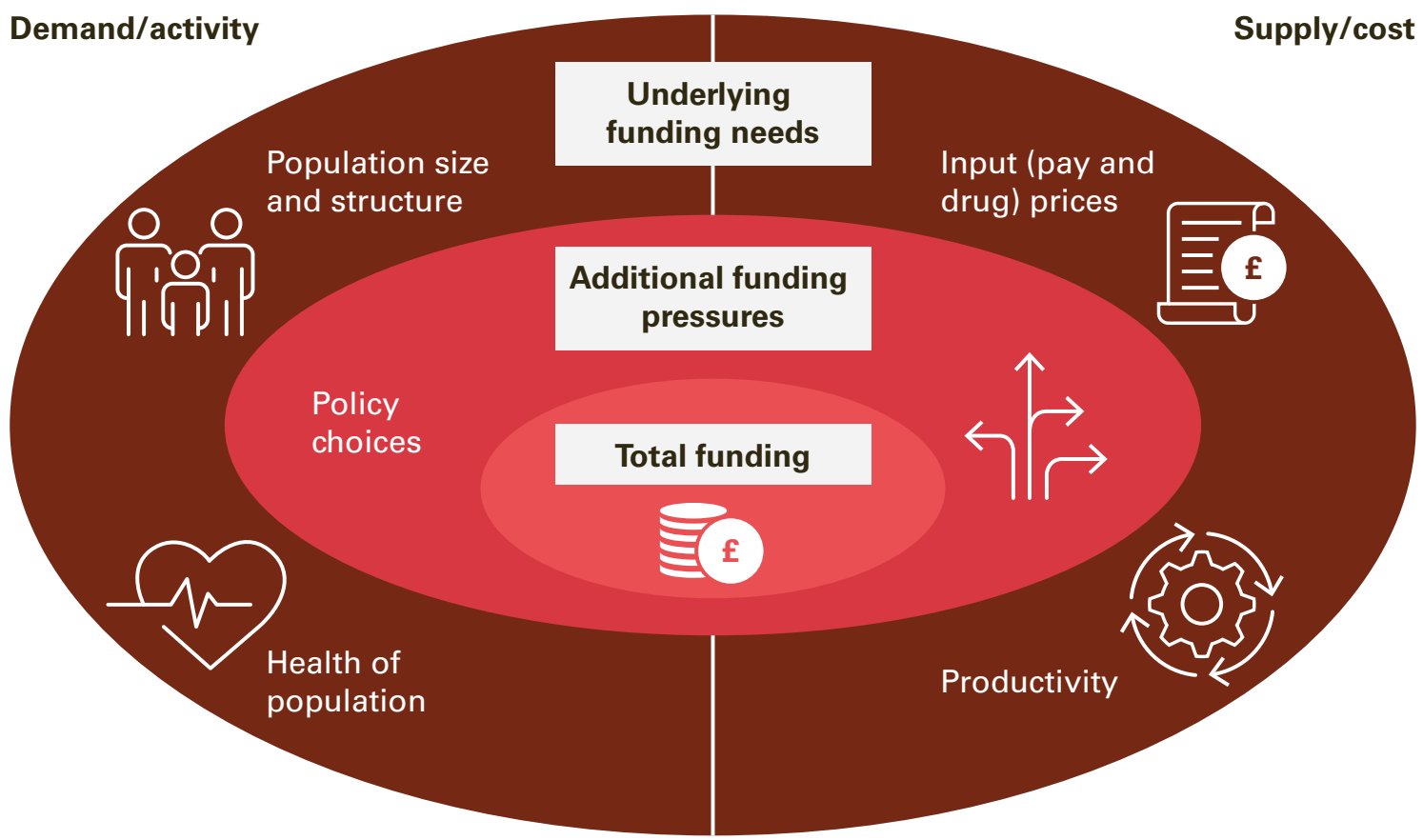

Source: The Health Foundation's REAL Centre analysis.

Figure 13 outlines the key steps in our modelling approach. As described, our modelling of demand relies on estimating the rates of care for a range of different health and social care services. This is known as a component-based model. Our model is reliant on a number of data sources, the quality of which varies across services. ${ }^{*}$ Further information on the different modelling approaches used in projecting health spending and sources of data used to estimate the activity and unit costs can be found in Appendix B.

For instance, we have detailed data for hospital services but rely on more experimental statistics for community care. 
Figure 13: Steps to our modelling approach

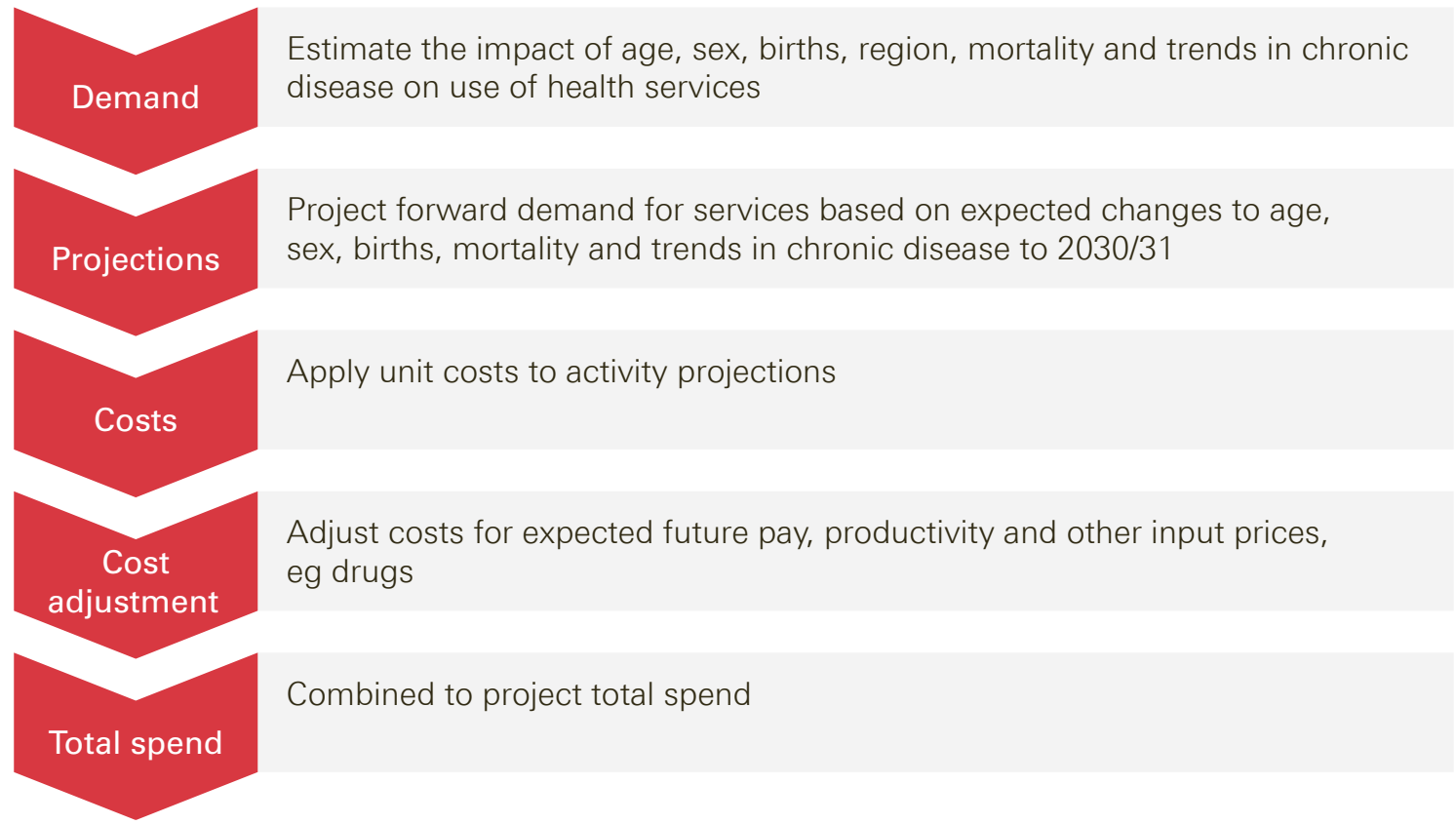

Source: Adapted from Securing the future: funding health and social care to the 2030s (2018).

Note: depending on the data source, patient gender or sex is reported. We use the terms as they are used in the data, even though the use of sex and gender terms in administrative data can be unclear and more is being done to develop datasets accordingly (eg in Hospital Episode Statistics (HES)).

For social care, the modelling approach is set out in detail in the REAL Centre analysis Social care funding gap. ${ }^{24}$ Estimates of social care demand are based on work by the Care Policy and Evaluation Centre (CPEC) at LSE. ${ }^{25}$ Demand projections cover publicly funded social care for all adults, for both community-based and residential care. In this report, we re-present the key assumptions so they can be compared with those used for health care modelling.

\subsection{Demand drivers of funding pressures}

Demand drivers influence the underlying health of the population and their potential need for health or social care services and as such, underpin our activity projections.

\subsubsection{Size and age structure of the population}

All else equal, a growing population means higher demand for health and social care. Moreover, average spending increases with age: Figures 14 and 15 show that for both males and females the average cost of health care increases quickly from the age of 45 . An increase in the proportion of the older population is therefore likely to increase the demand for both health and social care. 
Figure 14: Per capita age spending curves for health care (2018/19)

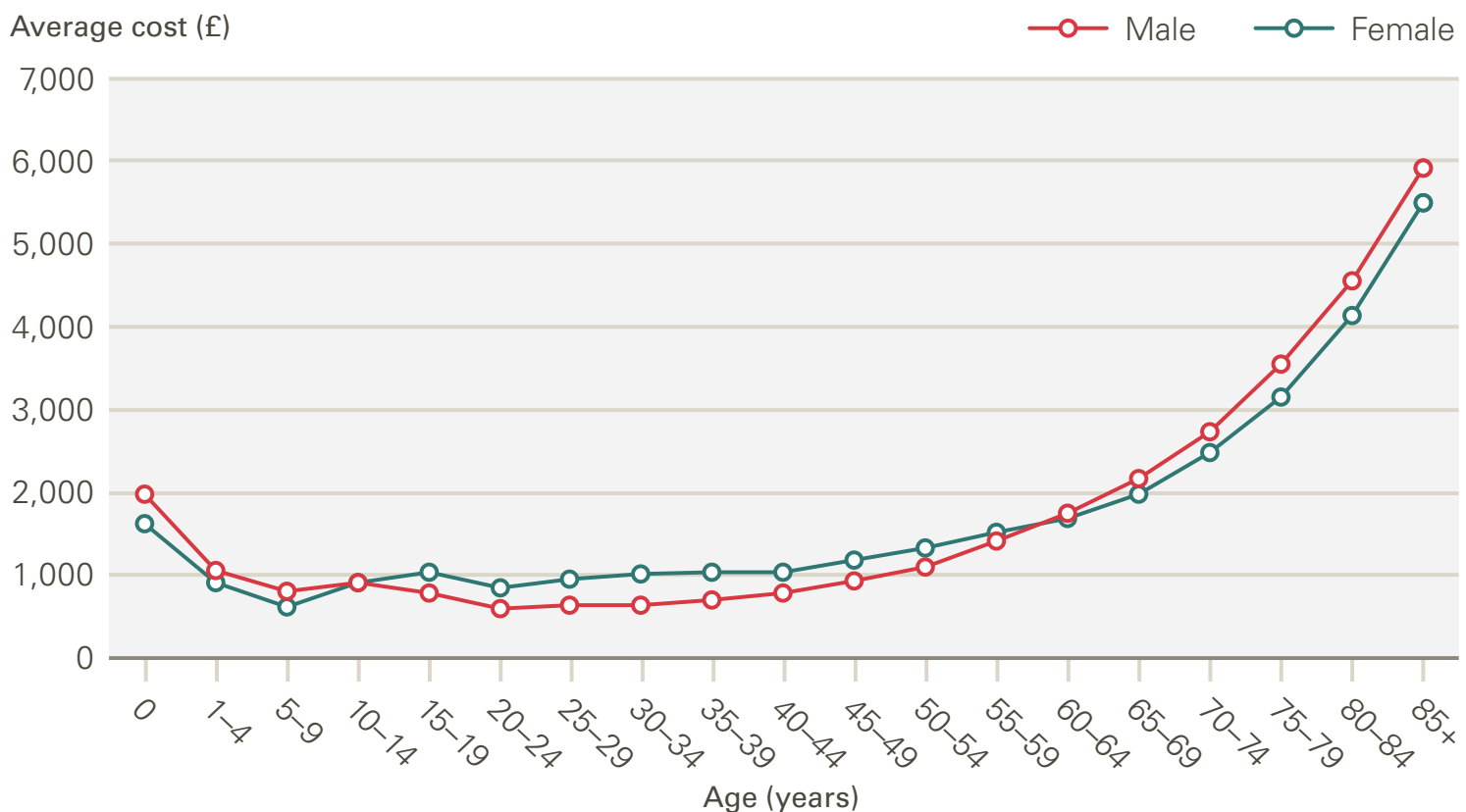

Source: REAL Centre analysis.

Note: Average costs of health care for males and females (acute and non-acute care) in the NHS in England.

Figure 15: Per capita age spending curves for social care (2018/19)

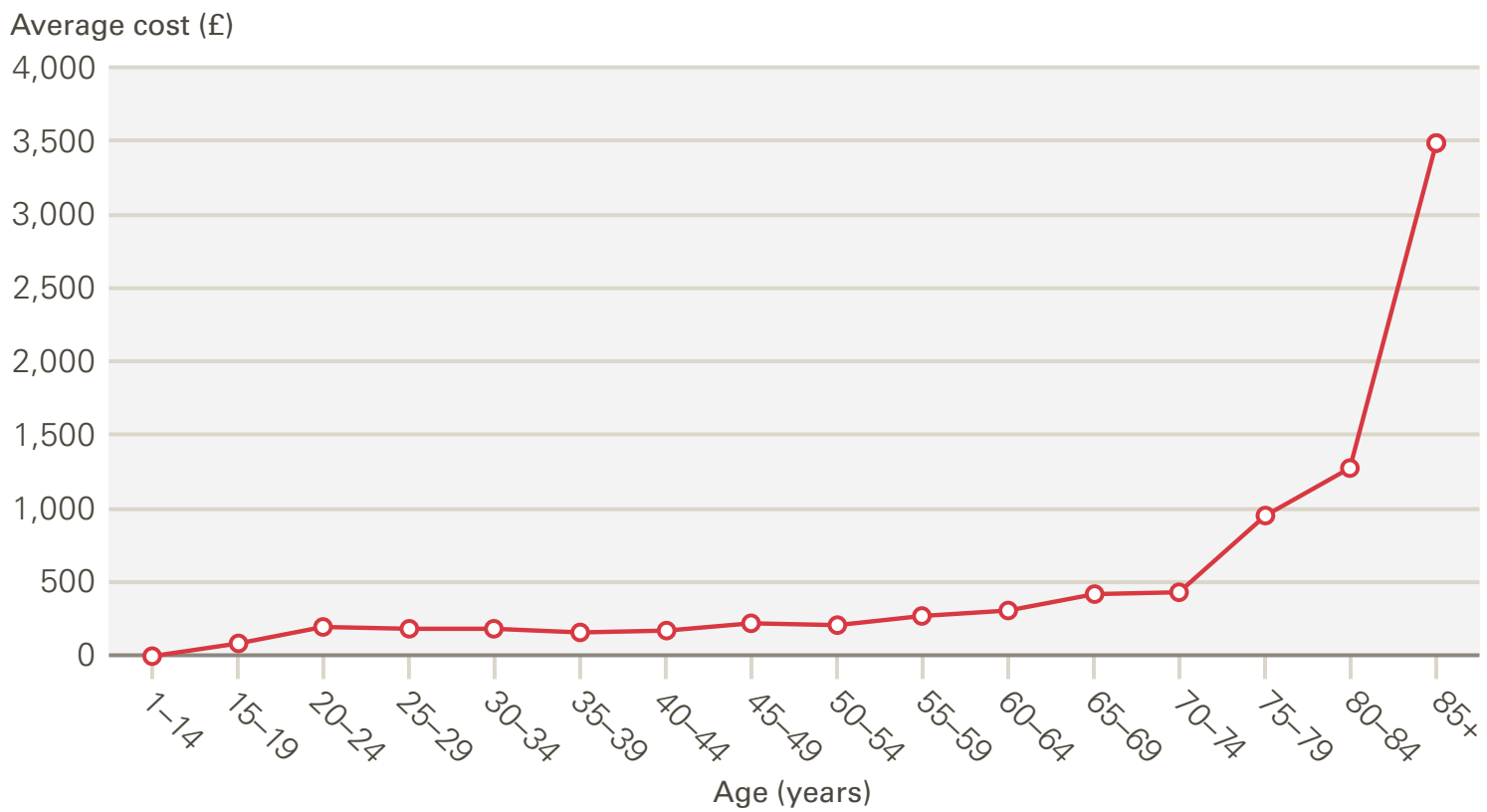

Source: REAL Centre analysis based on 2018/19 Adult Social Care Activity and Finance Report for England. Note: Average costs of social care for males and females.

However, there is a consensus that population change alone does not explain much of the recent rises in health expenditure. Studies suggest that age in itself is not the main driver of costs. Instead, increased morbidity and proximity to death, which are both associated with ageing, emerge as the most important factors. ${ }^{26}$ 


\subsubsection{Births and deaths}

Population structure is affected by changes in fertility and mortality rates, which will affect need for health and social care. Births are a driver of health care costs through maternity care. More broadly, health and social care costs rise sharply at the end of life as health deteriorates. ${ }^{27}$

\subsubsection{Changes in morbidity}

More people are living into older age, but the extent to which this increases pressure on the health and social care system depends on whether those additional years are spent in good health (compression of morbidity) or in ill health (expansion of morbidity).

Recent trends suggest more years are being spent in ill health. According to the ONS the average time spent in poor health has increased by just less than half a year for males and almost three-quarters of a year for females between 2009-2011 and $2016-2018 .{ }^{28}$ Meanwhile, a rising proportion of people are living with multiple co-morbidities. Recent evidence from the NHS in England indicates that this is an important driver of costs, especially for emergency care. ${ }^{29}$

\subsection{Supply drivers of funding pressures}

In addition to these demand factors, supply factors (eg staff pay, drug costs) also change over time and affect the cost of providing a given level and quality of health or social care.

\subsubsection{Pay}

Pay is an important supply factor and labour inputs accounted for around half of the total revenue expenditure of the NHS in 2019/20. A key driver of real pay is productivity growth. However, to recruit and retain workers, pay must be competitive with wages in the wider economy. Economic theory suggests that pay growth in services, such as health, must keep pace with other sectors despite often having lower productivity gains than more capital intensive sectors (known as the Baumol effect). ${ }^{30}$

\footnotetext{
* This comprises NHS provider permanent and bank staff working within hospital and community health spending, but excludes general practitioners, GP practice staff and general dental practitioners (https:// assets.publishing.service.gov.uk/government/uploads/system/uploads/attachment_data/file/966702/DHSCwritten-evidence-to-the-NHSPRB-2021-to-2022.pdf).
} 


\subsubsection{Drug costs}

The estimated costs of drugs ${ }^{*}$ was $£ 20.9 b n$ in $2019 / 20 .{ }^{31}$ The effect of medical innovation on drug prices is ambiguous (see Box 1). Drug prices decrease when drugs come off patent and generics enter the market; but new drugs that cover previously unmet needs or improve current treatments may drive costs upward. Historically, drug prices have grown faster than inflation. ${ }^{32}$

\subsubsection{Productivity}

Productivity is the relationship between the volume of outputs and the volume of inputs. A more productive health care system can achieve a certain level of output (eg treatments or admissions) with less input (eg staff). Likewise, with higher productivity, the same number of staff can deliver more care. As the Baumol effect highlights, ${ }^{+}$higher pay growth will increase the pressure on future health and social care spending, some of which may be offset by productivity gains. Productivity gains are therefore an important determinant of the future path of health and social care spending.

\section{Box 1: Technological change}

Technology is increasingly recognised as an important cost driver. The European Commission's The 2015 ageing report found that technological change explained between one-quarter and three-quarters of growth in health care expenditure. Similarly, in the UK, the Wanless review estimated that technology explained a fifth of spending increases over the previous two decades. The extent of the role attributed to technology, however, may depend in part on the analytic approach. Studies focusing on individual-level expenditure tend to find a greater role for morbidity in explaining increases in expenditure.

Indeed, the role of technological change is ambiguous in that it can impact the basket of available treatments (drugs, medical devices, or surgical procedures), their prices, or patterns of service use in different ways. Some developments may reduce the costs of delivering health care, such as when drugs come off patent or when the time needed for a given procedure falls (although a fall in cost can in turn fuel demand). Other technological developments may increase costs, such as when an expensive new treatment is developed for a previously unmet care need.

In our modelling, the impact of technological change on health expenditure is accounted for in two ways by:

- $\quad$ allowing for faster growth in certain categories of spending where new treatments are most likely to drive up costs (hospital drugs prices and specialised services).

- $\quad$ adjusting our funding estimates for productivity growth, where better treatment has the potential to reduce costs (eg by reducing the length of stay).

* Costs quoted are at list price, ie excluding VAT or dispensing costs and confidential discounts.

$\dagger \quad$ The Baumol effect occurs when wages rise in jobs that experience no or low productivity growth, in response to rising wages across the wider economy. This phenomenon can drive higher funding pressures in health and social care services when opportunities for productivity growth are limited. 


\subsection{Additional pressures, public expectations and policy choices}

We model underlying pressures by taking the rate of care delivered in 2018/19 as a starting point. However, there are several reasons, spanning both the demand and supply sides of care, that the rate of care delivered to a population might increase over time. One reason is that the population may demand more or better quality health and social care, particularly as the country gets wealthier. Another possibility is that clinicians - who are among the most informed about the range of available treatments - might push for more care needs to be met. In addition, the range of available treatments might increase, either for existing or new conditions. Or government may react to public expectations by increasing the supply of care. Examples of policies that respond to clinician and public expectations are access, waiting times and care quality targets.

For all these possible reasons, health spending tends to increase as a share of public spending as countries get wealthier. UK health spending has risen faster than GDP or inflation over time, and the OBR suggests that rising incomes have been an important driver. ${ }^{35}$ More macro-based models, such as those produced by the OECD, tend to focus on this relationship between health spending and national income.

\subsection{Uplifting to UK-wide funding projections}

The modelling described is for health and social care services in England. We use the results to estimate UK funding pressures for health care by taking the following steps:

- We calculate the spend per head in 2018/19 for each country using the Public Expenditure Statistical Analyses (PESA) and ONS population projections per constituent country.

- We apply the projected growth rate in funding to the spend per head for Scotland, Wales, and Northern Ireland.

2019 PESATable 5.1 (https://www.gov.uk/government/statistics/public-expenditure-statistical-

analyses-2019).

ONS: Principal projection -Wales summary

(https://www.ons.gov.uk/peoplepopulationandcommunity/populationandmigration/populationprojections/ datasets/tablea15principalprojectionwalessummary).

Principal projection - Scotland summary

(https://www.ons.gov.uk/peoplepopulationandcommunity/populationandmigration/populationprojections/ datasets/tablea16principalprojectionscotlandsummary).

Principal projection - Northern Ireland summary

(https://www.ons.gov.uk/peoplepopulationandcommunity/populationandmigration/populationprojections/

datasets/tablea17principalprojectionnorthernirelandsummary). 
- We obtain the total funding for each year by multiplying the projected health spend per head by the corresponding ONS population projections (see Table B3 in Appendix B). The estimated projected UK-wide health spend is the total of the spend in the constituent countries.

- $\quad$ To estimate health spending as a share of GDP, we rely on the OBR's GDP forecasts.* 


\section{4. \\ Funding pressures}

In this chapter we present results from our analysis of funding pressures for health and social care. First, we look at the impact of underlying funding pressures, based on assumptions around the demand and supply drivers of expenditure described in the previous chapter. The results are presented as activity and funding projections by services. We then present results from several additional funding pressures. These largely relate to policy choices, such as meeting NHS constitutional standards, meeting existing funding commitments (eg the long term plan) or increasing social care packages, and also include estimated ongoing costs from COVID-19. All funding figures are presented in real terms in 2021/22 prices unless otherwise stated.

\subsection{Underlying funding pressures}

\subsubsection{Demand factors}

We combine the following assumptions around key demand drivers to produce the activity projections by services presented in section 4.1.2.

\section{Size and age structure of the population}

The Office for National Statistics (ONS) estimates that the population of England will grow by 2.8 million by 2030 compared with 2019, an average annual population growth rate of $0.5 \%$. The proportion of people aged 65 and older is projected to rise to $21 \%$ by 2030 , from $16 \%$ and $18 \%$ in 2010 and 2019 respectively.

There is greater uncertainty than usual over population figures given the potential impact of COVID-19 on births, deaths and net migration, and that the census used for the population projections we used was completed 10 years ago. ${ }^{*}, 36$ Figure B1 in Appendix B shows a comparison of the ONS's principal, low and high population projections. Excess deaths that occurred in 2020/21 are not reflected in ONS population projections. Table B2 in Appendix B shows that accounting for these excess deaths does not significantly alter overall population projections. 


\section{Births and deaths}

Births are projected to fall slightly over the next decade due to lower fertility rates. By contrast the number of deaths is projected to increase. In 2030, births and deaths are projected to each account for around $1 \%$ of the population based on ONS 2018 population projections.

Figure 16: Projected births and deaths to 2030/31

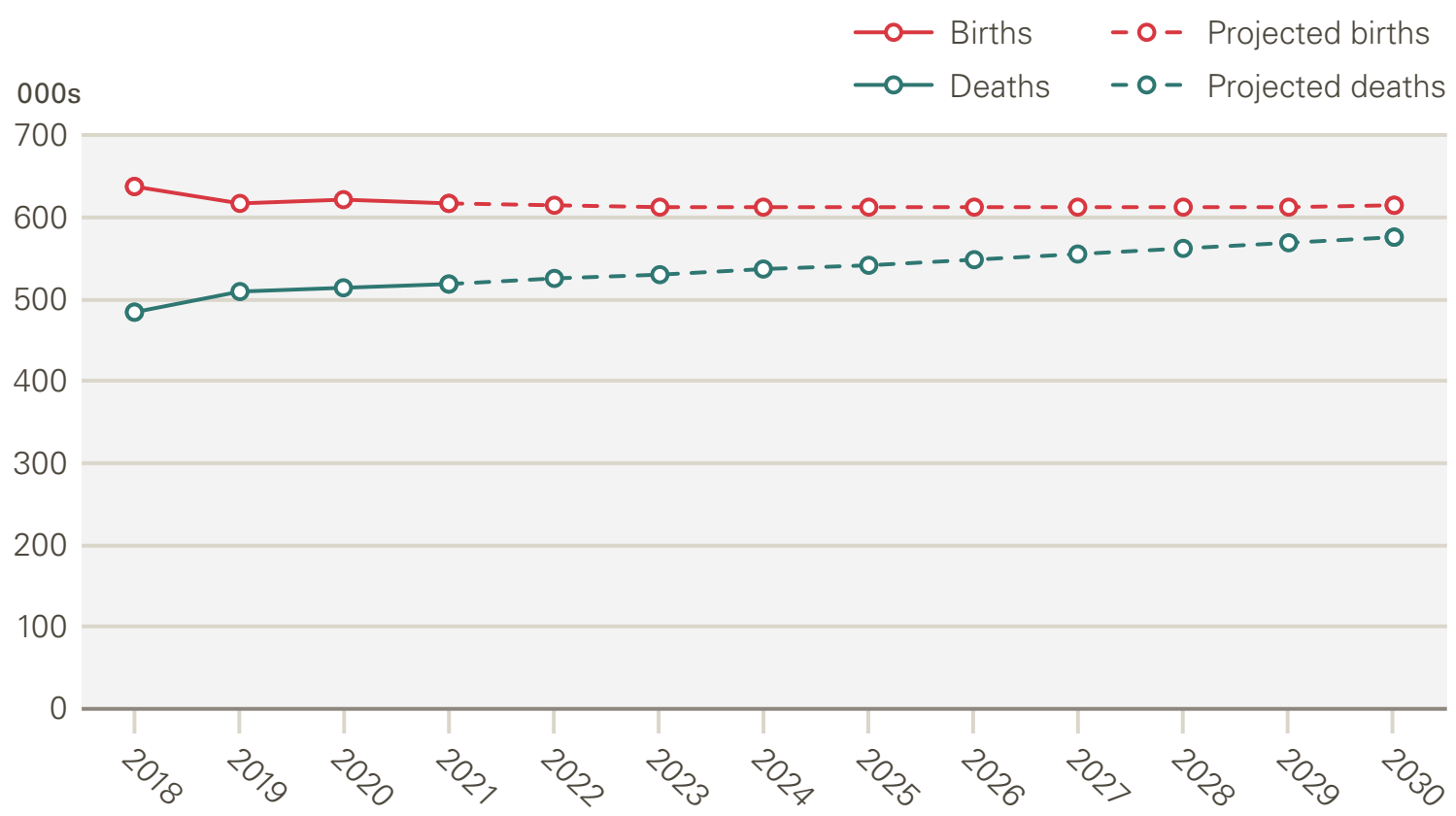

Source: ONS principal population projections.

\section{Morbidity}

For hospital (acute) care the rate of admissions for patients with one or more conditions recorded has risen over time. To account for growing morbidity in our funding projections, the historical trend in the age and gender-specific rate of admissions by condition is projected forward. Figure 17 shows how the proportion of females aged 85 and older admitted to hospital with multiple conditions will continue to rise.

This does not include all possible combinations of conditions, as some - eg diabetes, asthma and COPD are analysed separately in our model. 
Figure 17: Females aged 85 and older admitted to hospital with multiple conditions

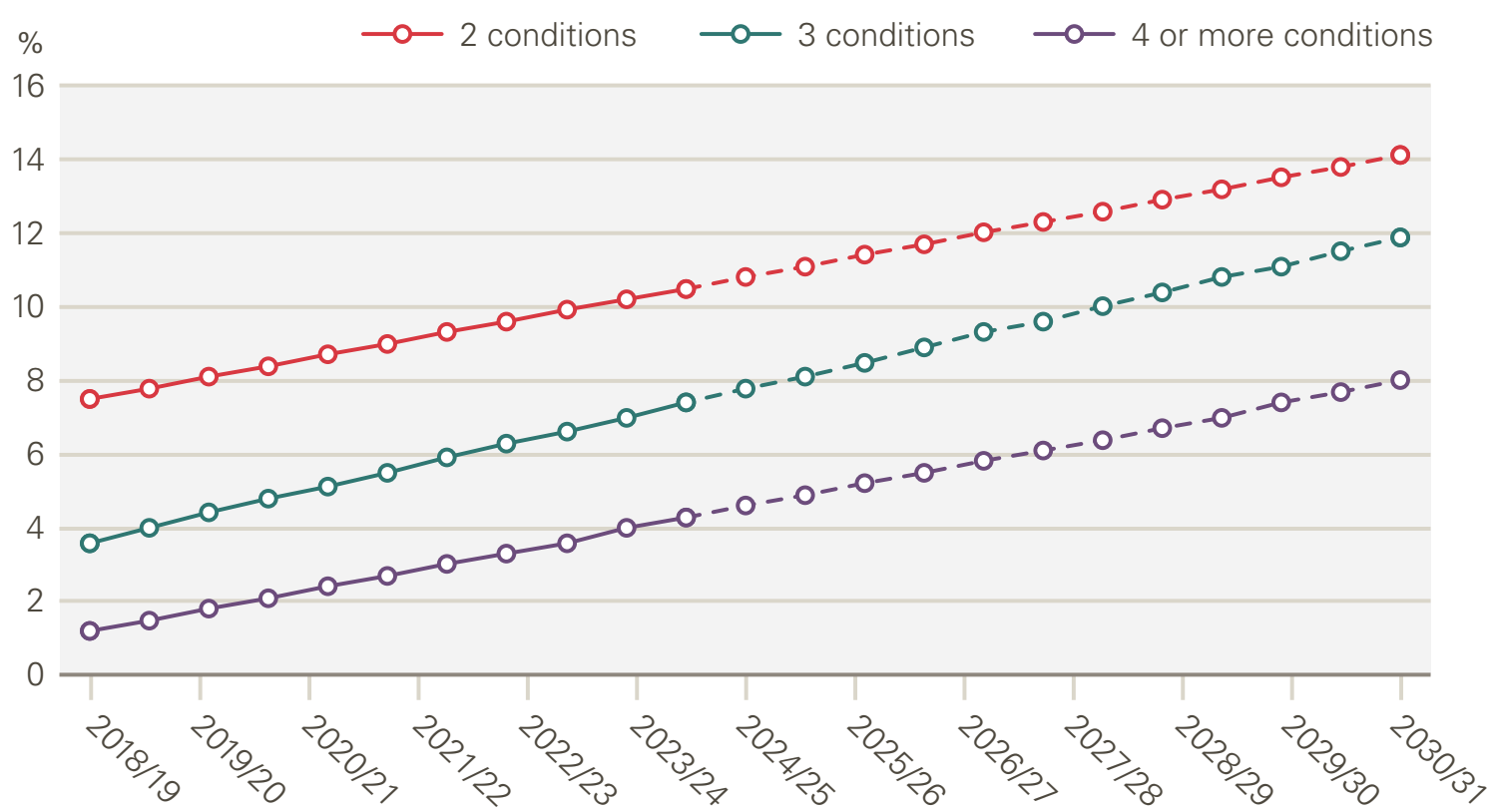

Source: REAL Centre analysis of HES.

For primary and community care, the past increasing trend in primary care use from $2000 / 01$ to $2018 / 19$ is projected to continue through to $2030 / 31$ for people aged 50 and older (see Appendix B, Figure B3 and Table B4).

\section{Social care demand factors}

The projected demand for adult social care is based on modelling by CPEC and a full set of assumptions can be found in CPEC's modelling report. ${ }^{25}$ This is based on ONS 2018-based principal population projections, expected changes in marital status and living arrangements. The rates of homeownership, educational level, and the proportion of recipients of privately funded care for older people are projected using the CARESIM model. ${ }^{37}$

Age-gender specific prevalence rates of disability are assumed to remain constant at levels reported in the Health Survey for England (2011-2017), except for younger adults (18 to 30 years old) whose disability prevalence grows in line with projections from the literature. ${ }^{38}$

\subsubsection{Activity projections}

In order to meet the underlying pressures projected, based on 2018/19 patterns of care and the rising demand-side pressures already outlined, health and social care activity would need to rise. The extent of this increase varies by service: from $2.6 \%$ annual growth for non-elective care to a $0.3 \%$ decline in maternity services (as measured by births). 
Figure 18: Activity projections by service area

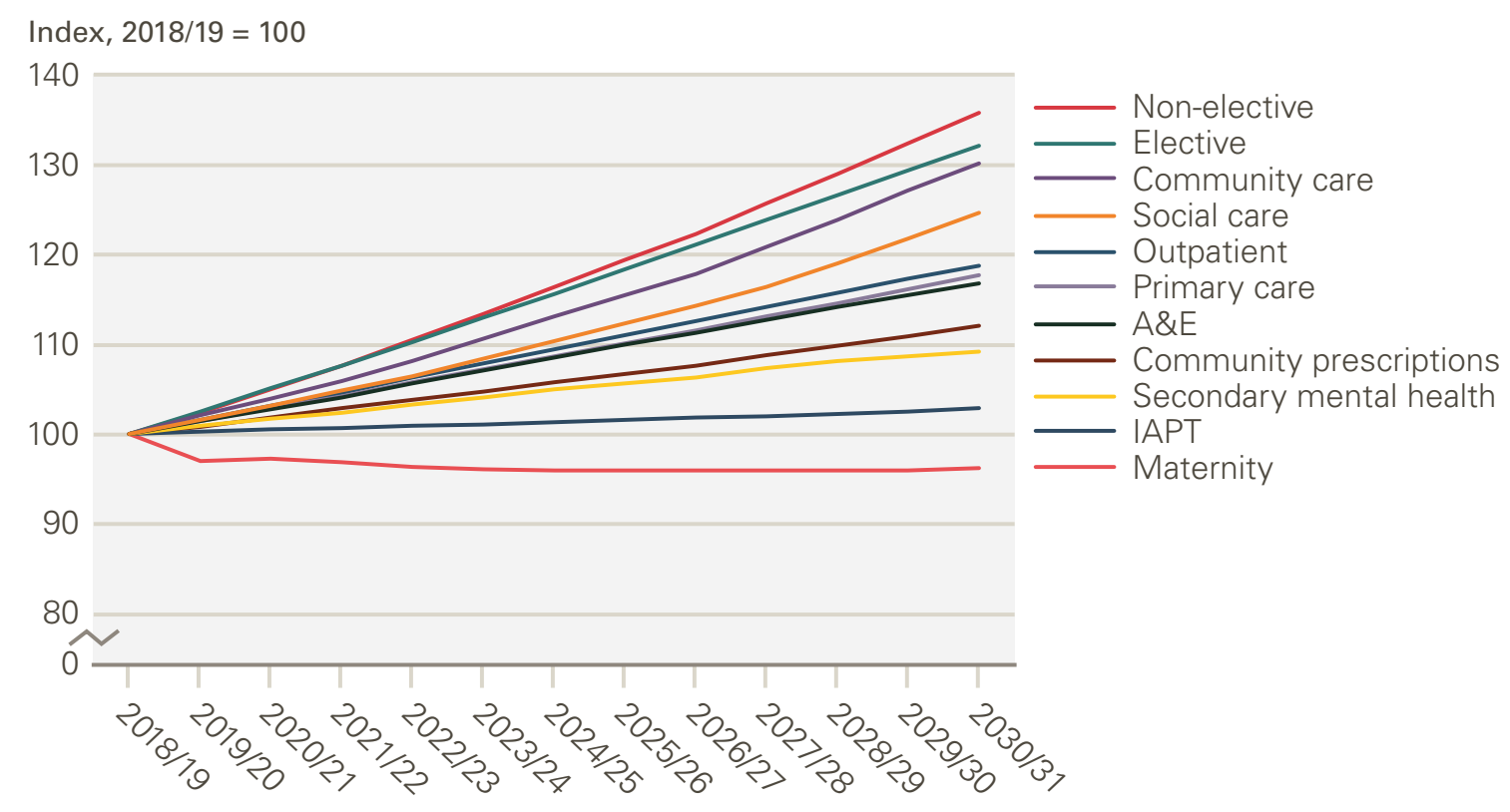

Source: REAL Centre calculations.

Projecting activity increases is determined in part by how rapidly activity rates increase with age (except for maternity activity, which changes in line with the birth rate). Another important factor is the extent to which morbidity contributes to rising demand. This means our projections show the most rapid growth in non-elective $(2.6 \%)$ and elective $(2.3 \%)$ care, as use of these services grows most rapidly with age and morbidity.

Increases in activity for community care $(2.2 \%)$, primary care $(1.4 \%)$ and other mental health services $(0.7 \%)$ do not include long term plan commitments to improve access. This means our projections of activity for these areas are slight underestimates (see Additional funding pressures). However, we do account for the long term plan commitments to improve access in our additional funding pressures. This means our overall projected funding estimates in chapter 5 include commitments in the long term plan.

It is important to note that these projections are not a statement of what should happen, either to improve patient care or make best use of resources. They are an estimate of what could happen if current patterns of service use are combined with projected changes of the drivers of service use (eg age and morbidity). The growth rates shown in Figure 18 are presented in Table 6 and compared to historical averages for each service area. This shows that our projections are broadly in line with trends over the past decade. Notable exceptions include Improving Access to PsychologicalTherapies (IAPT), a recently introduced service which has seen rapid increases in uptake. Another is outpatient activity, which has grown markedly in recent years, reflecting a policy push to expand elective care. 
Table 6: Activity projections by service area, projected vs. historical average

\begin{tabular}{llll}
\hline Area & $\begin{array}{l}\text { Actual historical } \\
(\mathbf{2 0 0 9 / 1 0 - 2 0 1 8 / 1 9 )}\end{array}$ & $\begin{array}{l}\text { Projected growth } \\
(\mathbf{2 0 1 8 / 1 9 - 2 0 3 0 / 3 1 )}\end{array}$ & $\begin{array}{l}\text { Difference (percentage } \\
\text { points) }\end{array}$ \\
\hline Outpatient & $4.1 \%$ & $1.4 \%$ & -2.6 \\
\hline A\&E & $1.6 \%$ & $1.0 \%$ & -0.6 \\
\hline Non-elective & $1.8 \%$ & $2.6 \%$ & 0.7 \\
\hline Elective & $2.4 \%$ & $2.3 \%$ & -0.1 \\
\hline Maternity (births) & $-0.4 \%$ & $-0.3 \%$ & 0.1 \\
\hline Primary care & $0.9 \%$ & $1.4 \%$ & 0.5 \\
\hline Community prescribing & $2.3 \%$ & $1.3 \%$ & -1.0 \\
\hline IAPT* & $16.6 \%$ & $0.2 \%$ & -16.4 \\
\hline Other mental health** & $0.8 \%$ & $0.7 \%$ & -0.1 \\
\hline Community care & $-0.9 \%$ & $2.2 \%$ & 3.1 \\
\hline Social care*** & $-0.6 \%$ & $1.9 \%$ & 2.4 \\
\hline *2012/13-2018/19; * 2011/12-2018/19; **2015/16-2018/19 & \\
\hline
\end{tabular}

Source: REAL Centre calculations. The difference may not exactly match due to rounding of numbers.

\subsubsection{Supply factors}

We combine these activity projections with the following assumptions about supply factors to produce an initial set of funding projections, based on underlying funding pressures.

\section{Pay}

Our projections include pay falling by $1.4 \%$ in real terms from $2018 / 19$ to $2020 / 21$, in line with actual NHS pay growth figures. ${ }^{*}$ Pay is then projected to grow by $1.3 \%$ in real terms every year, in line with the OBR's long-term forecast for all-economy earnings. Pay pressures apply to the proportion of unit costs made up by wages in each service, around $64 \%$ for acute care and $73 \%$ for non-acute care. ${ }^{+39}$ The nonlabour component of unit costs remains flat in real terms, except for drug costs for acute care, which are modelled separately.

\footnotetext{
* The GDP deflator follows an expected pattern in 2019/20 and 2020/21 due to the pandemic, which affects real-terms figures.

$\dagger \quad$ This is based on the PSSRU unit costs reported for GP practice nurses and GPs (primary care), scientific and professional staff and nurses (bands 5 to 9) (community care), and hospital-based mental health nurses and behavioural activation delivered by non-specialists for depression treatment (mental health). The proportion of labour-related costs is very similar across areas of non-acute care (ranging from $72 \%$ to $74 \%$ ). For simplicity we therefore use the average across primary, community and mental health care (at $73 \%)$ for non-acute care.
} 


\section{Drug costs}

The cost of technology, driven by high-priced new treatments, primarily falls on the acute sector where more complex and specialist care is provided. Drug unit costs in the community sector remain constant in real terms, but hospital drug unit costs grow annually by $5.9 \%$ in real terms, corresponding to the historical cost growth in recent years.

\section{Inflation}

Economy-wide inflation averages $2.1 \%$ through to $2030 / 31$ based on the OBR longterm GDP deflator forecasts ${ }^{*}, 40$ (see Figure B4 in Appendix B).

\section{Productivity}

IPC measures, the partial suspension of services and higher rates of staff absence due to the COVID-19 pandemic are likely to have reduced service productivity. Our projections therefore include zero productivity growth in 2020/21 and 2021/22 due to these constraints. From $2022 / 23$ onwards, productivity grows by $0.8 \%$ every year, ${ }^{41}$ in line with the ONS long-term average non-quality adjusted productivity growth rate for public service health care in England (1998-2018). ${ }^{\dagger}$

\section{Social care supply factors}

In the social care projections from CPEC, unit costs rise in real terms based on the $\mathrm{OBR}^{42}{ }^{42}$ forecast for inflation and all-economy productivity. Unit costs include an uplift between 2018 and 2024 to reflect announced rises in the national living wage, while non-labour and non-capital costs remain constant in real terms.

\subsubsection{Funding projections given underlying funding pressures}

Figure 19 and Table 7 present our funding projections by service area, given the underlying funding pressures we have described.

\footnotetext{
* Health-specific measures of inflation are not available consistently throughout our period. The Health Service Cost Index was discontinued in 2017 and replaced by a set of deflators. To have consistency over the projection period, the OBR GDP deflator is used.

$\dagger \quad$ Note that the pandemic might have resulted in productivity gains for the future via changes in the way of delivering care.
} 
Figure 19: Funding projections by service area

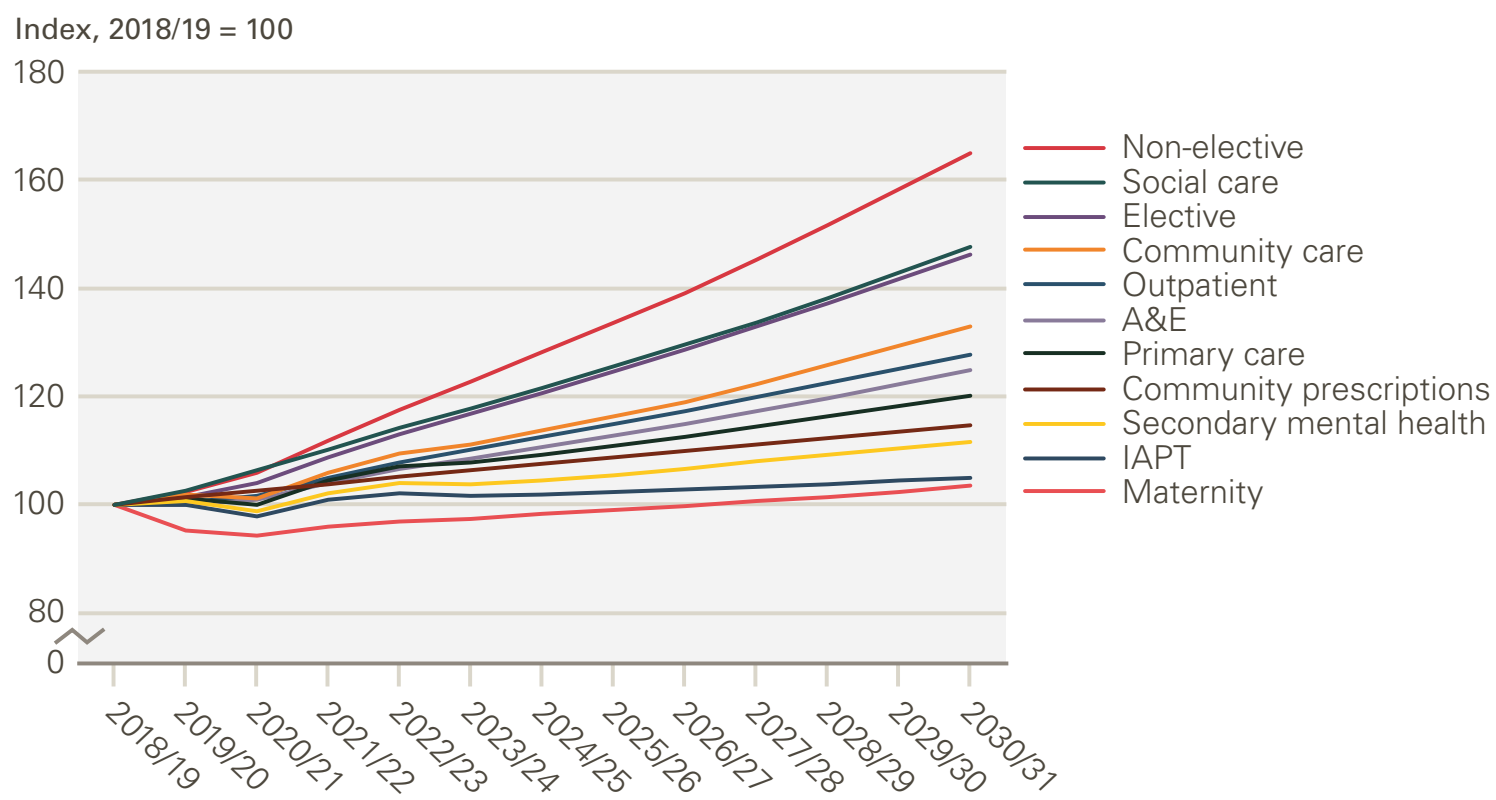

Source: REAL Centre calculations.

Table 7: Average annual funding growth $2018 / 19-2030 / 31$ by service area

\begin{tabular}{ll}
\hline Service area & $\begin{array}{l}\text { Average funding growth } \\
\mathbf{2 0 1 8 / 1 9 - 2 0 3 0 / 3 1}\end{array}$ \\
\hline Outpatient & $2.1 \%$ \\
\hline A\&E & $1.9 \%$ \\
\hline Non-elective & $4.3 \%$ \\
\hline Elective & $3.2 \%$ \\
\hline Maternity & $0.3 \%$ \\
\hline Community care & $2.4 \%$ \\
\hline Primary care & $1.5 \%$ \\
\hline IAPT & $0.4 \%$ \\
\hline Other mental health & $0.9 \%$ \\
\hline Community prescriptions & $1.1 \%$ \\
\hline Social care & $3.3 \%$ \\
\hline
\end{tabular}

Source: REAL Centre calculations.

Once again there is considerable variation by service. Funding growth varies from $4.3 \%$ for non-elective care to just $0.3 \%$ for maternity. The pattern of funding needs broadly mirrors that of activity growth, but the extent of the increase is further affected by the distribution of costs. For instance, while a GP consultation has a similar cost regardless of the patient's age or morbidity, treatment for those with more severe conditions in hospital rises significantly. Box 2 shows that the main driver of costs in acute care is increased morbidity. 
Again, these are projections and are not a statement of what should happen, either to improve patient care or make best use of resources. They are an estimate of what could happen if current patterns of service use are combined with projected changes of the drivers of service use and costs (eg age, morbidity and medicines prices).

\section{Box 2: Drivers of acute care funding}

Acute spend in our central assumptions regarding pay and productivity increases from f45bn to $f 65$ bn between $2018 / 19$ and $2030 / 31$. Funding growth is attributable to changes in three factors: population change, morbidity and input prices. Figure 20 shows the contribution of each of these factors in acute care between 2018/19 and 2030/31. Morbidity is the single biggest driver, accounting for $53 \%$ of funding pressures, followed by population $(27 \%)$ and input prices $(20 \%)$.

\section{Figure 20: Waterfall - contribution of key drivers to 2030/31 acute funding}

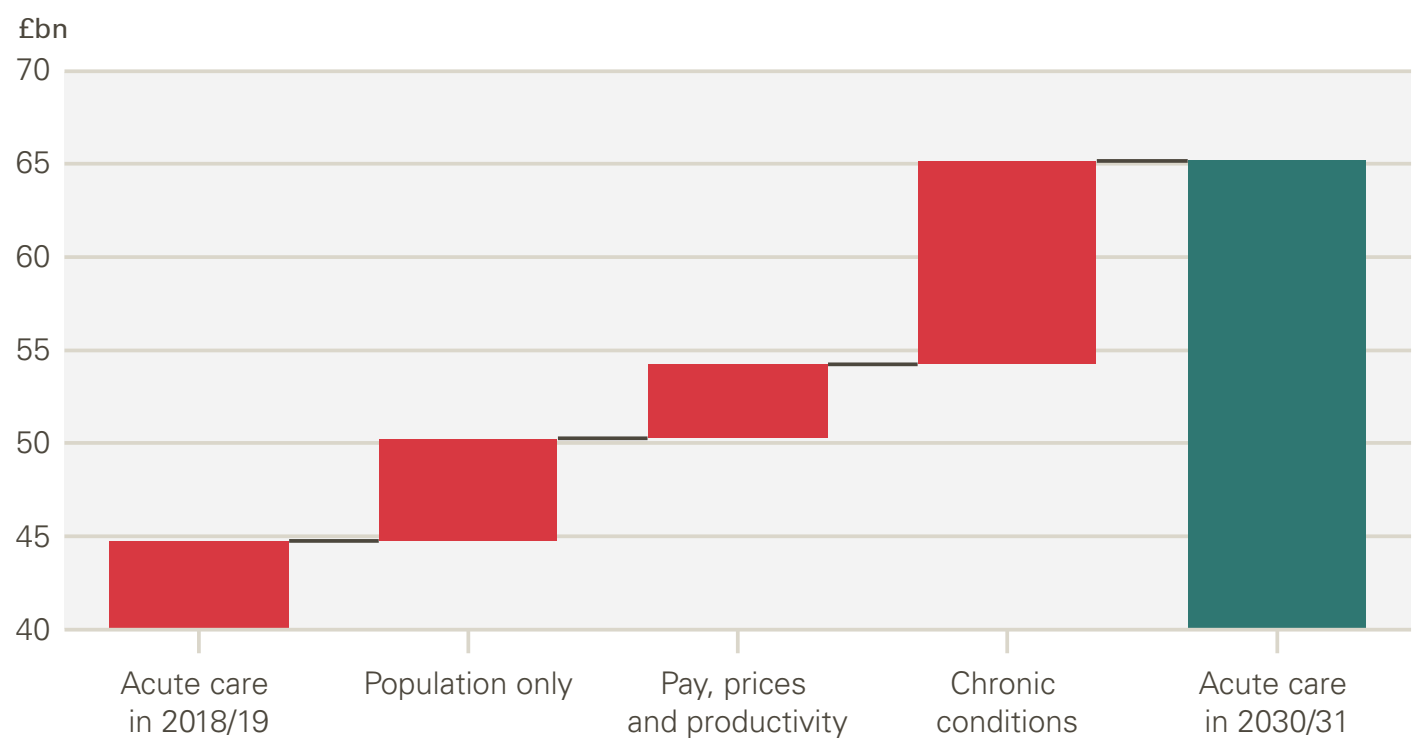

Source: REAL Centre calculations. 


\subsection{Additional funding pressures and policy choices}

Over and above the underlying funding pressures described in the previous section, we examine the impact of a number of additional funding pressures, summarised in Table 8. Before combining assumptions around these funding pressures in the following chapter, we examine each in turn.

\section{Table 8: Summary of additional funding pressures}

\begin{tabular}{ll}
\hline COVID-19* & Costs of ongoing COVID-19 measures \\
& $\begin{array}{l}\text { Vaccination programme } \\
\text { Additional mental health demand }\end{array}$ \\
\hline Policy choices & $\begin{array}{l}\text { Pay policy } \\
\text { Long term plan funding commitments (primary, community and mental health care) }\end{array}$ \\
\cline { 2 - 2 } & $\begin{array}{l}\text { Constitutional standards: } \\
\text { Referral to Treatment (RTT) waiting time target } \\
\text { Bed occupancy and performance against the A\&E 4-hour wait target }\end{array}$ \\
\hline Social care & Improving pay and offering additional social care packages \\
\hline
\end{tabular}

*We do not explicitly model the impact of long COVID or future acute care needs under potential repeated COVID-19 waves, nor do we model the costs of NHS Test and Trace or PPE.

\subsubsection{COVID-19}

\section{Ongoing COVID-19 costs}

During the COVID-19 pandemic, the need for IPC measures alongside higher than usual rates of staff absence meant more inputs (eg staff) were needed to deliver the same or less output (eg admissions). In Figure 21, we compare 2020/21 with 2019/20 and show that during the pandemic there was less activity, but fewer of the usual stock of general and acute beds available, higher staff absences and significantly more funding needed (NHSE RDEL was around $£ 11$ bn higher in real terms in 2020/21). Taken together, this can be considered a productivity shock. ${ }^{*}, 43$ 
Figure 21: NHS productivity shock: \% change in selected inputs and outputs in $2020 / 21$ vs $2019 / 20$

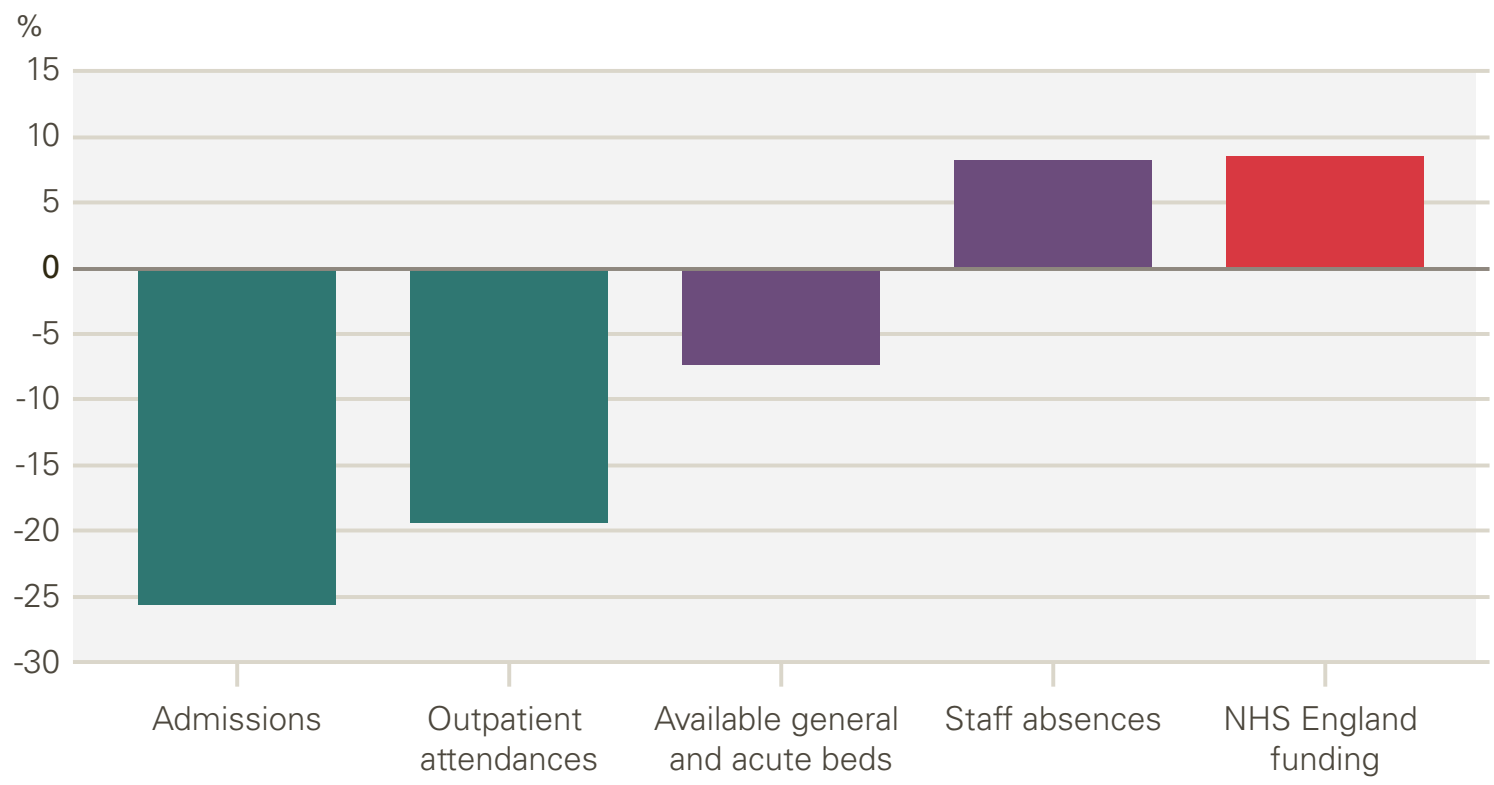

Source: REAL Centre calculations from NHS Digital, Provisional Monthly Hospital Episode Statistics and NHS Sickness Absence Rates, NHS England, Bed Availability and Occupancy, HM Treasury, PESA.

A crucial factor in dictating future funding needs is how enduring these impacts will be. Additional funding has already been committed for 2021/22, but in the future this is highly uncertain and depends at least in part on the path of COVID-19. In Figure 22, we show illustrative examples of different possible paths for productivity. For instance, productivity may return to its pre-pandemic path, with changes instated during the pandemic meaning the level of productivity would be higher post-pandemic than before ('no lost productivity'). Alternatively, COVID-19 may result in lost productivity gains during the pandemic but from 2022/23 prepandemic growth rates in productivity could return with no ongoing cost ('lost productivity gains; return to level'). More pessimistically, beyond the short-term shock, the level of productivity may remain lower than pre-pandemic, consistent for example with retaining some IPC measures ('ongoing COVID-19 impact'). 
Figure 22: Illustration of the potential impacts of COVID-19 on productivity

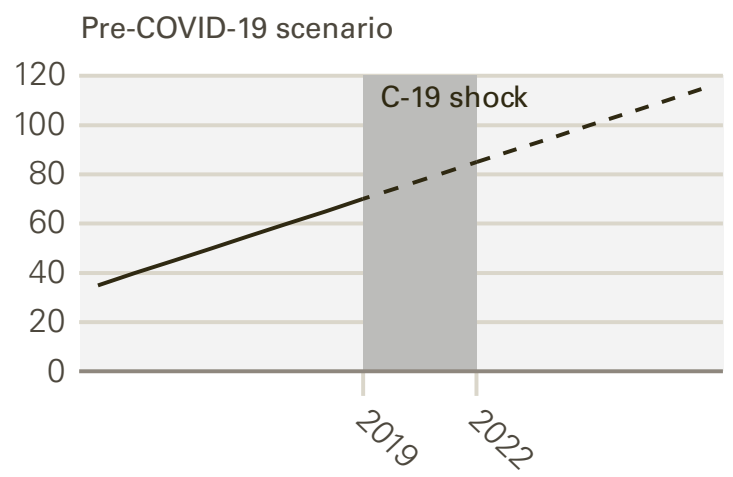

No lost productivity

Lost productivity gains; return to level

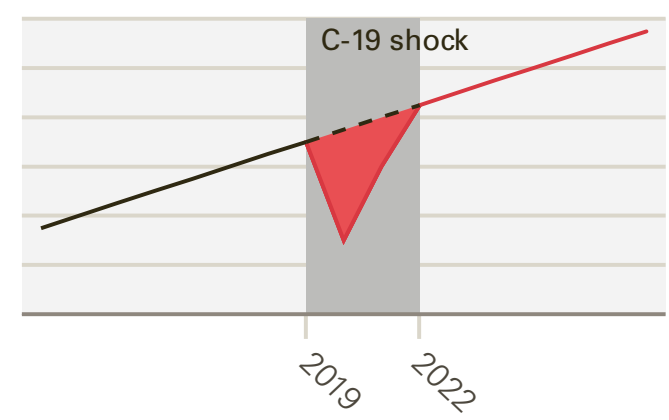

Ongoing COVID-19 impact
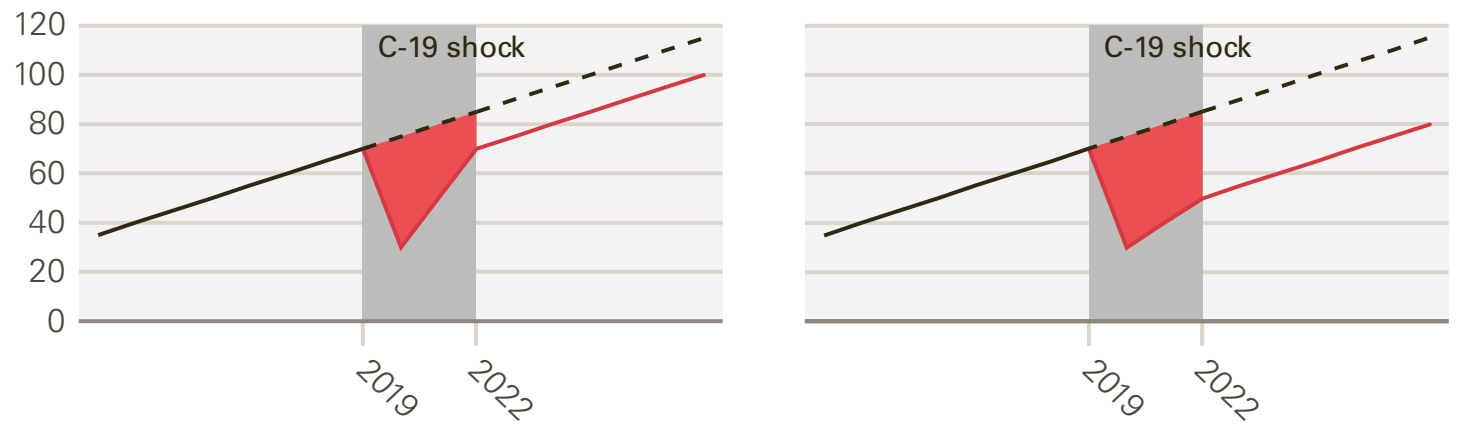

Source: REAL Centre.

In the boxes that follow, we illustrate the direct costs of treating hospitalised COVID-19 patients and patients suffering from long COVID. We do not add these estimates to our projections because: the costs may not be additional - a COVID-19 patient might otherwise have received a different treatment in the same year; the costings are highly uncertain due to data limitations; some of the costs are captured by our assumptions on post-pandemic productivity, and adding both would therefore represent double-counting.

\section{Box 3: Direct acute care costs from endemic COVID-19}

We estimate the demand on acute care from endemic COVID-19 using the COVID simulation model from Imperial (Covidsim). Covidsim projects hospital and critical care demand for the UK (we apportion to England based on population). We assume 100\% vaccine availability, a rapid rollout (1.7 million vaccines per week), high uptake ( $80 \%)$ and an underlying rate of infection (R) of 2.4 .

On this basis, we estimate the demand for acute care needed for waves of COVID-19 in $2021 / 22$ based on the following assumptions about vaccine effectiveness and uptake: 1 ) $90 \%$ efficacy against infection; 2) 70\% efficacy against infection; 3) 50\% efficacy against infection; and 4), $30 \%$ efficacy against infection and vaccine availability going from $100 \%$ to $60 \%$ - reflecting the possible impact of a new variant resistant to vaccines. 


\section{Figure 23: Possible future COVID-19 hospitalisations under different assumptions}

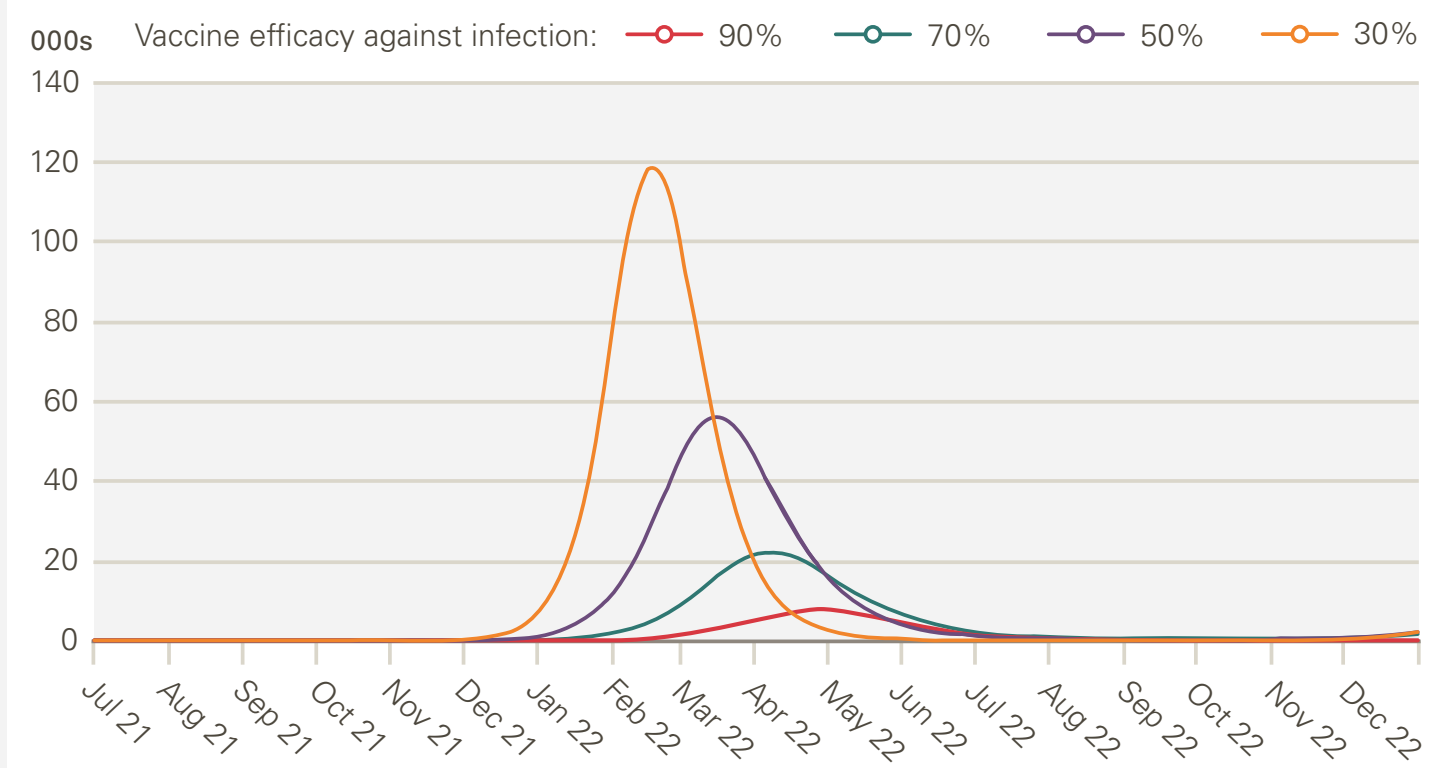

Source: Outputs from Imperial's Covidsim model (Version 4).

Using the average length of stay for non-elective and critical care, and the associated costs, we estimate the costs of direct care for those with COVID-19 under these assumptions. The cost in $2021 / 22$ ranges from less than $£ 72 m$ through to nearly $£ 2 b n$ depending on vaccine efficacy. While inexact - the estimates here are indicative only - these numbers suggest the direct cost of treating COVID-19 patients represents only a fraction of the wider cost to the health system arising from IPC measures and staff absences (as outlined).

\section{Figure 24: Estimated direct cost of treating COVID-19 patients in 2021/22}

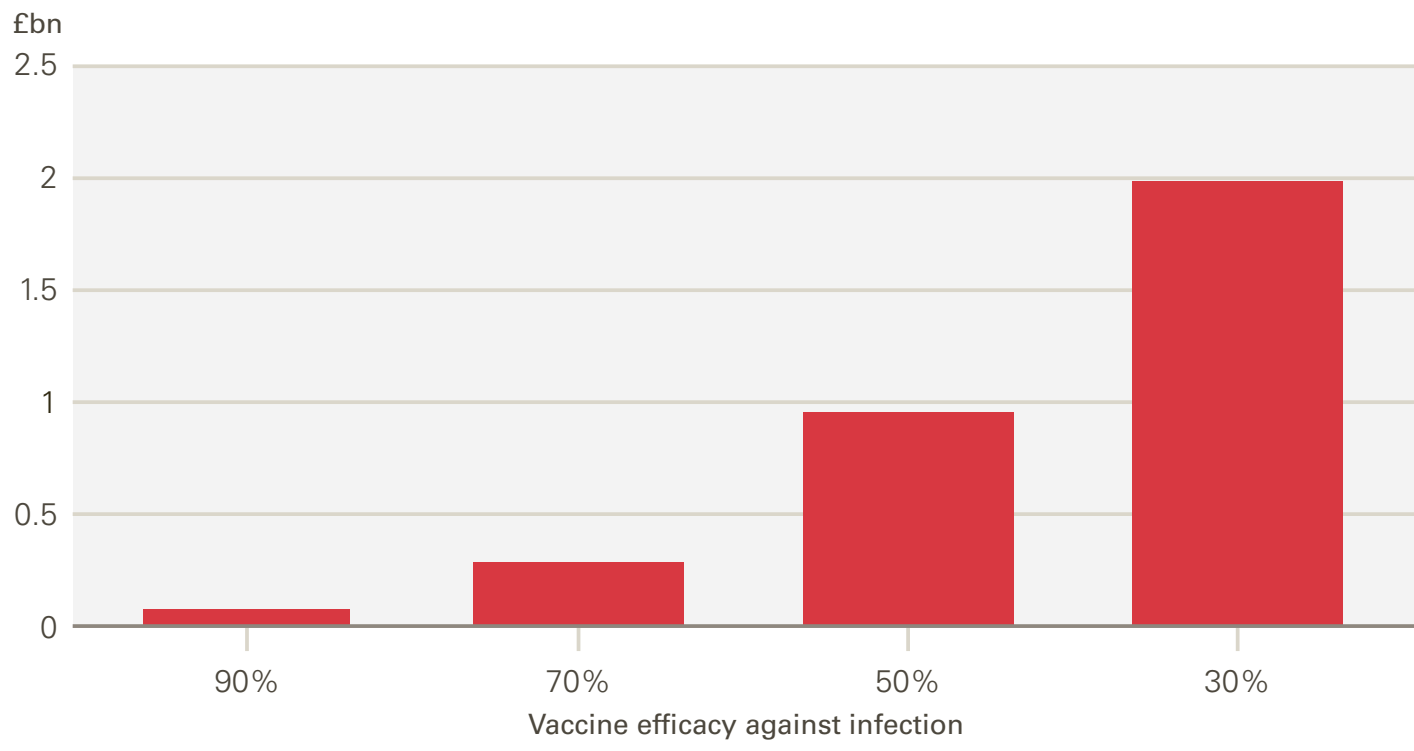

Source: REAL Centre analysis based on NHS Digital data and COVIDsim output. 


\section{Box 4: Costs of long COVID}

Long COVID refers to patients whose symptoms persist for at least several weeks after infection. The evidence on the condition is evolving rapidly. The ONS estimated that around 932,000 people had had long COVID in England by 1 April 2021, and that one in five people with COVID-19 are affected by long COVID. Recent figures from the ZOE COVID study suggest that there are 500 new cases of long COVID every day among unvaccinated people in the UK. The latest REACT study found that over 2 million people had long COVID in England (symptoms persisting beyond 12 weeks).

As long COVID is an emerging condition, little is known about the most appropriate treatment. Existing NICE guidance focuses on assessment and, where appropriate, treatment from community, rehabilitation and multidisciplinary teams. Assuming all of those with symptoms receive an assessment, and those with symptoms after 12 weeks require ongoing care (1 multidisciplinary assessment; 1 in 5 see a physio; 1 in 10 receive rehabilitation), we estimate a cost per case of long COVID of around $£ 180$.

For the estimated 2.5 million with persisting symptoms, based on prevalence from the REACT study, this would imply a total cost of $£ 396 \mathrm{~m}$ so far. These estimates are uncertain but indicate a higher funding pressure than funding announced to date with, costs falling mainly on primary and community care.

Source: ONS, Prevalence of ongoing symptoms following coronavirus (COVID-19) infection in the UK; ZOE COVID Study; NICE COVID-19 rapid guideline. Estimated prevalence from the REACT study.

\section{Vaccination programme}

It is likely that an ongoing programme of COVID-19 vaccination will be required. ${ }^{44}$ There are already plans for administering a third dose (booster) in winter for certain groups. ${ }^{45}$ The estimated annual costs of an ongoing vaccination programme are based on the whole population receiving one vaccine dose per year for the next 5 years (up until 2025/26), then only a population 'at-risk' receiving one dose per year for the following 5 years. The at-risk population used is all those aged 50 and older, and $5 \%$ of the population aged $0-49 .{ }^{46}$ We project future years using the ONS population projections. These are simplifying assumptions given high uncertainty regarding population immunity and the effectiveness of the vaccines in the future in case of new variants.

We calculate the costs of both procurement and delivery, but only the delivery cost is met by DHSC and therefore included in our funding estimates in chapter $5 .{ }^{47}$ The unit costs of vaccines are modelled to be $£ 11$ per dose for purchasing and $£ 12.58$ for GP per vaccination. * Unit costs for the vaccination delivery grow in line with assumptions on pay growth and productivity changes, while the costs of vaccine procurement are assumed constant in real terms. Based on these assumptions we estimate an average of $£ 1.4 \mathrm{bn}$ ( $£ 750 \mathrm{~m}$ for delivery) a year to $2025 / 26$, falling to $£ 640 \mathrm{~m}$ (£340m for delivery) thereafter (Figure 25).

* These are likely to underestimate the actual costs if the costs of vaccination increase, given the low prices charged by AstraZeneca. 


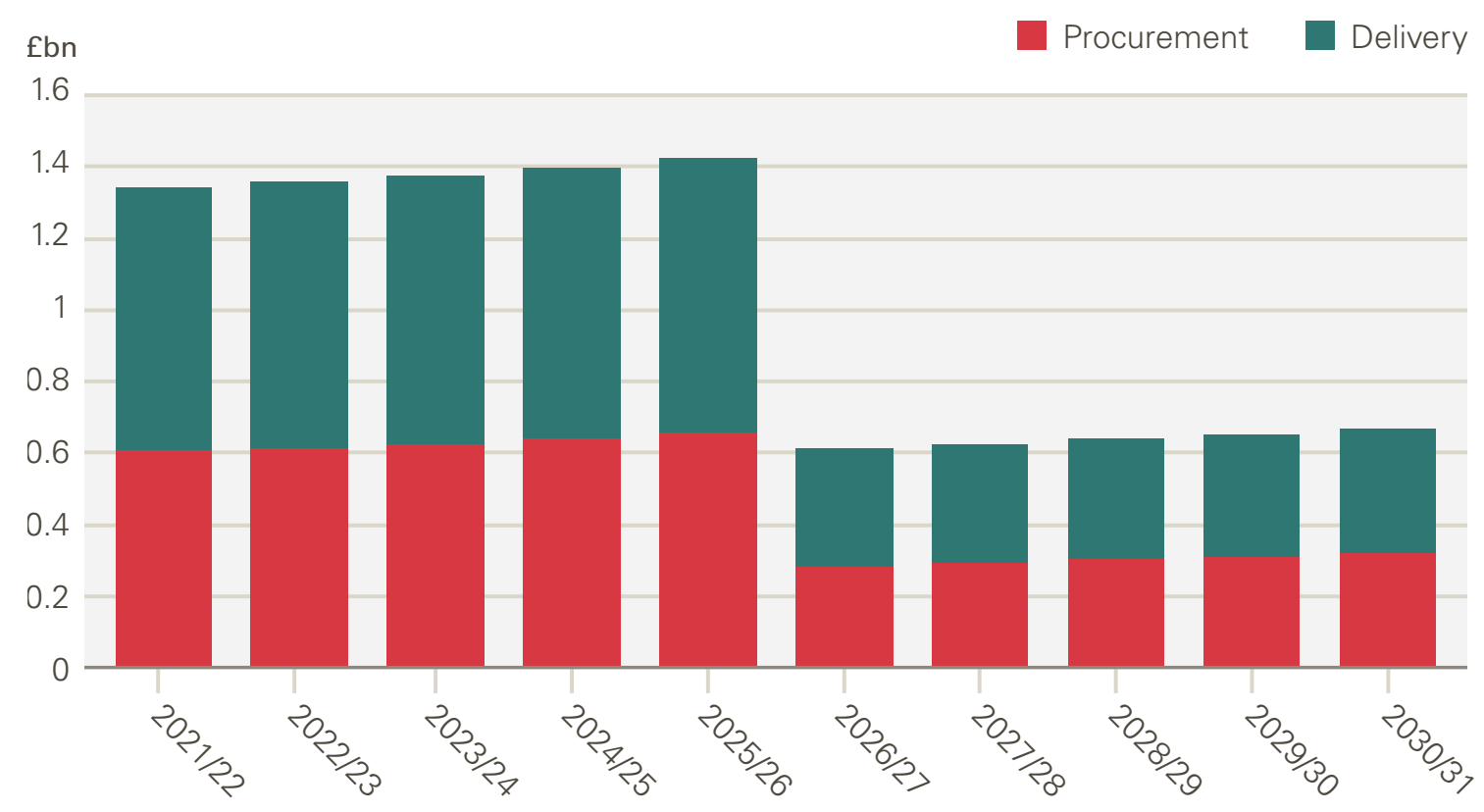

Source: REAL Centre calculations.

\section{NHS Test and Trace, and PPE}

The budget for the test and trace programme was $£ 22$ bn in $2020 / 21$. We do not model the potential future costs of running a test and trace programme as these are highly uncertain.

Procurement of PPE is reflected in the total NHS budget and accounted for $£ 15 \mathrm{bn}$ in 2020/21, while the NAO reports that trusts spent only f0.2bn on PPE in 2019.48 Our modelling assumes spending returns to pre-pandemic levels on PPE and that any additional costs, resulting from future impacts of COVID-19, are captured in our assumptions regarding the post-pandemic level of productivity.

\section{Additional mental health demand}

The COVID-19 pandemic has had a significant impact on the mental health of the population, through reduced social interaction, health impacts, income loss, bereavement and economic uncertainty. ${ }^{49}$ This can be observed in levels of wellbeing across society, with the ONS finding lower levels of happiness overall. ${ }^{50}$ We use modelling from the Strategy Unit (see the detailed model online ${ }^{51}$ ) to estimate the impact of the pandemic on certain at risk groups.

We estimate there could be an additional 300,000-730,000 referrals for mental health services between $2020 / 21$ and $2023 / 24$. Some of this impact may already have been felt in mental health services, although subsequent waves of COVID-19 may have delayed presentation. The peak of activity is expected in $2021 / 22$, but this may depend on the trajectory of COVID-19. 
Table 9: Additional mental health referrals arising from the COVID-19 pandemic

\begin{tabular}{llllll}
\hline Referrals & $\mathbf{2 0 2 0 / 2 1}$ & $\mathbf{2 0 2 1 / 2 2}$ & $\mathbf{2 0 2 2 / 2 3}$ & $\mathbf{2 0 2 3 / 2 4}$ & Annual average \\
\hline Low & 240,000 & 690,000 & 220,000 & 40,000 & 300,000 \\
\hline Point & 370,000 & $1,080,000$ & 370,000 & 60,000 & 470,000 \\
\hline High & 550,000 & $1,590,000$ & 640,000 & 130,000 & 730,000 \\
\hline
\end{tabular}

Source: Strategy Unit analysis.

However, not everyone referred will enter treatment. We therefore estimate that of the potential 300,000-730,000 average annual referrals (Table 9), an average of $210,000-520,000$ people will enter treatment each year (the range is that given by our low and high estimates). Almost $40 \%$ of this would be for IAPT or other primary care mental health services. A small proportion (less than 1\%) would require expensive inpatient care. The rest would require support from a range of mental health teams (see Appendix $\mathrm{C}$ for full breakdown).

Costing mental health treatment is complicated owing to the variety of services, with different unit costs and time spent in treatment. To account for this variation we use cluster costs per day (from NHS reference costs), and the average number of days spent in service by team. On this basis, we estimate the additional cost of the COVID-19 pandemic for mental health services could range from $£ 1.6 \mathrm{bn}$ to $£ 3.6 \mathrm{bn}$ over the next 4 years, an annual average of $£ 400 \mathrm{~m}-£ 900 \mathrm{~m}$. ${ }^{*}$ Most mental health referrals come through primary care, which implies a significant additional pressure on general practice.

\subsubsection{Pay policy and the Baumol effect}

As highlighted previously, a key determinant of funding pressure is the Baumol effect: the combined impact of pay (which generally increases cost pressure) and productivity (which generally reduces it).

Pay increases may depart from our medium projection, which is based on OBR projections. A high vacancy rate and public pressure after the pandemic may mean a higher pay settlement is needed for health care than the $1.6 \%$ real pay increase projected by the OBR (2021/22-2030/31). As a proxy, we use $2.6 \%$ annual real-terms growth, corresponding to the growth in nurse pay in 2000-2010. Alternatively, policy choices may limit pay rises. For this, we use a real-terms decrease of $0.4 \%$,

\footnotetext{
* Using a previous costing approach, which applied an average unit cost regardless of time in service, we estimate a cost which is nearly twice as high: $f 780 \mathrm{~m}-\mathrm{f} 1.7 \mathrm{bn}$ per year. We consider the existing approach to better reflect the variation in care but would reiterate that costing at this level is complicated based on existing data.

† 2000-2010 is an appropriate proxy for high growth as this decade saw high investment in the workforce. We use nurse pay because earnings for all NHS staff were only reported from 2010 onwards; the ONS reports long-term statistics on pay but only for specific staff groups, ie nurses or health professionals (comprising doctors, psychologists, pharmacists or dentists but not nurses). Nurses accounted for about $30 \%$ of all NHS staff and $50 \%$ of all professionally qualified clinical staff in 2018/19.
} 
in line with the rate observed in the NHS between 2010 and 2020 (see Figure B5 in Appendix B). These are average rates over time - settlements in any given year may vary considerably.

Productivity might also deviate from the 20 -year long-term average of $0.8 \%$. The minimum 10 -year average in that period was $0.4 \%$ growth and the maximum $1.2 \%$ (see Figure B6 in Appendix B). In Figure 26, we present possible paths for acute funding based on this range of pay and productivity assumptions.

Figure 26: Range of possible acute care funding needs (underlying pressures only)

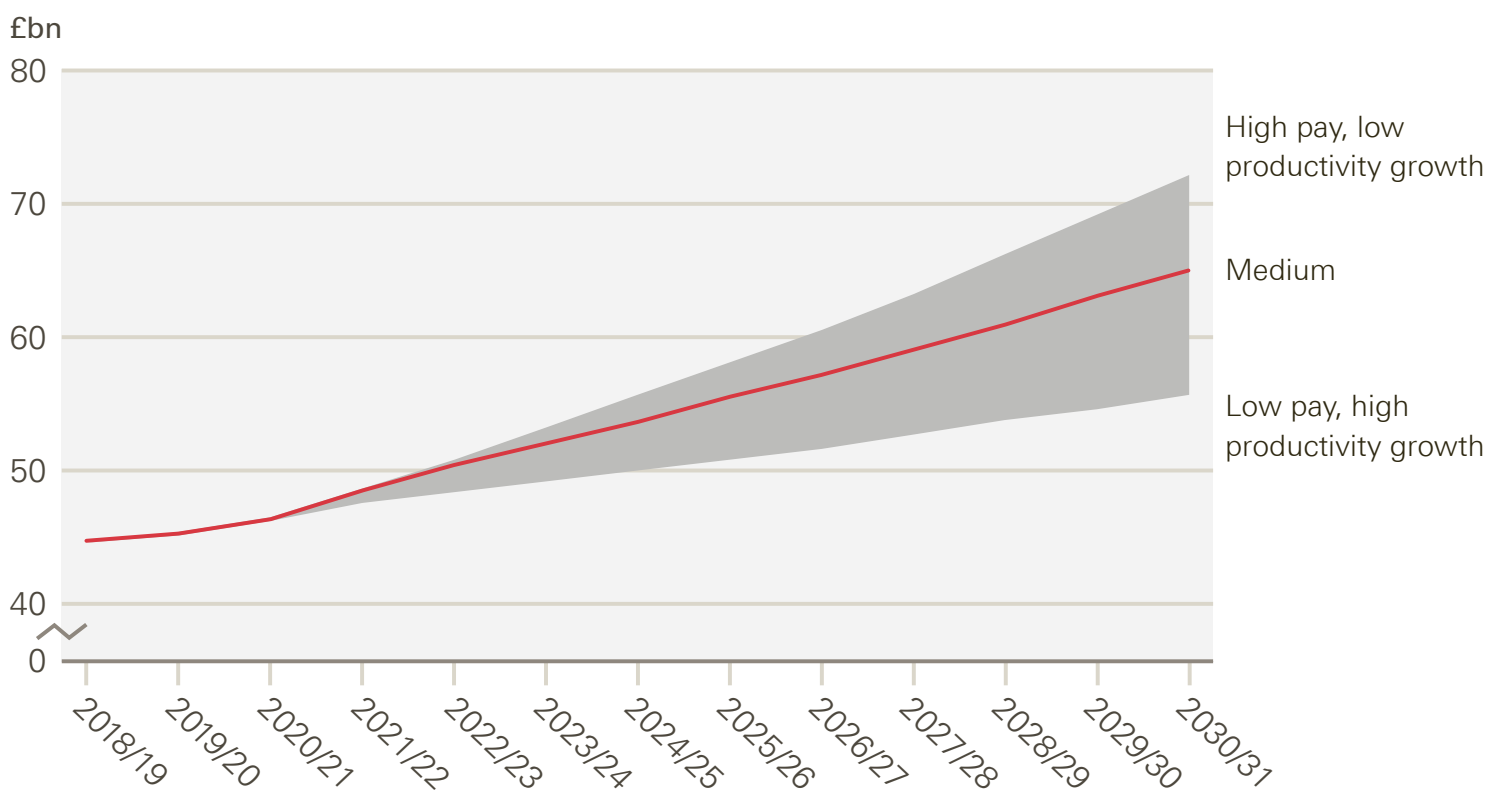

Source: REAL Centre calculations.

Table 10: Range of projected acute care costs, average annual growth rate (2018/19-2030/31)

\begin{tabular}{ll}
\hline Scenario & Annual growth (\%) \\
\hline Low (low pay/high productivity) & $1.8 \%$ \\
\hline Medium (medium pay/medium productivity) & $3.2 \%$ \\
\hline High (high pay/low productivity) & $4.1 \%$ \\
\hline
\end{tabular}

Source: REAL Centre calculations. 


\subsubsection{NHS Long Term Plan}

The long term plan committed an increase of $£ 4.5 \mathrm{bn}$ in real terms by $2023 / 24$ over and above spending in 2018/19 for primary care and community health services. ${ }^{52}$ This is apportioned between both sectors proportionately to the size of their budgets in 2018/19. ${ }^{53, *}$ After $2023 / 24$, funding is projected to grow in line with demographic changes and modelled input cost pressures. ${ }^{\dagger}$

The NHS Mental Health Implementation Plan committed $£ 2.3 \mathrm{bn}$ in real terms by 2023/24. ${ }^{54}$ The mental health investment standard means funding should grow at least as fast as the total health budget. Our funding projections correspond to the annual funding growth rate needed to meet this extra budget by $2023 / 24$, after which funding grows at a rate based on our projections of underlying funding pressures (based on demographic and input cost growth).

Figure 27 shows the $f 6.8 \mathrm{bn}$ in funding represented by these long term plan commitments (£4.5bn for primary and community care and £2.3bn for mental health). Although some of this funding would have been needed in 2023/24 to meet underlying funding pressures, we estimate that the majority ( $f 4.7 \mathrm{bn}, 68 \%$ ) is additional.

Figure 27: Additional funding pressures over $2018 / 19$ budget by $2023 / 24$ (end of the long term plan)

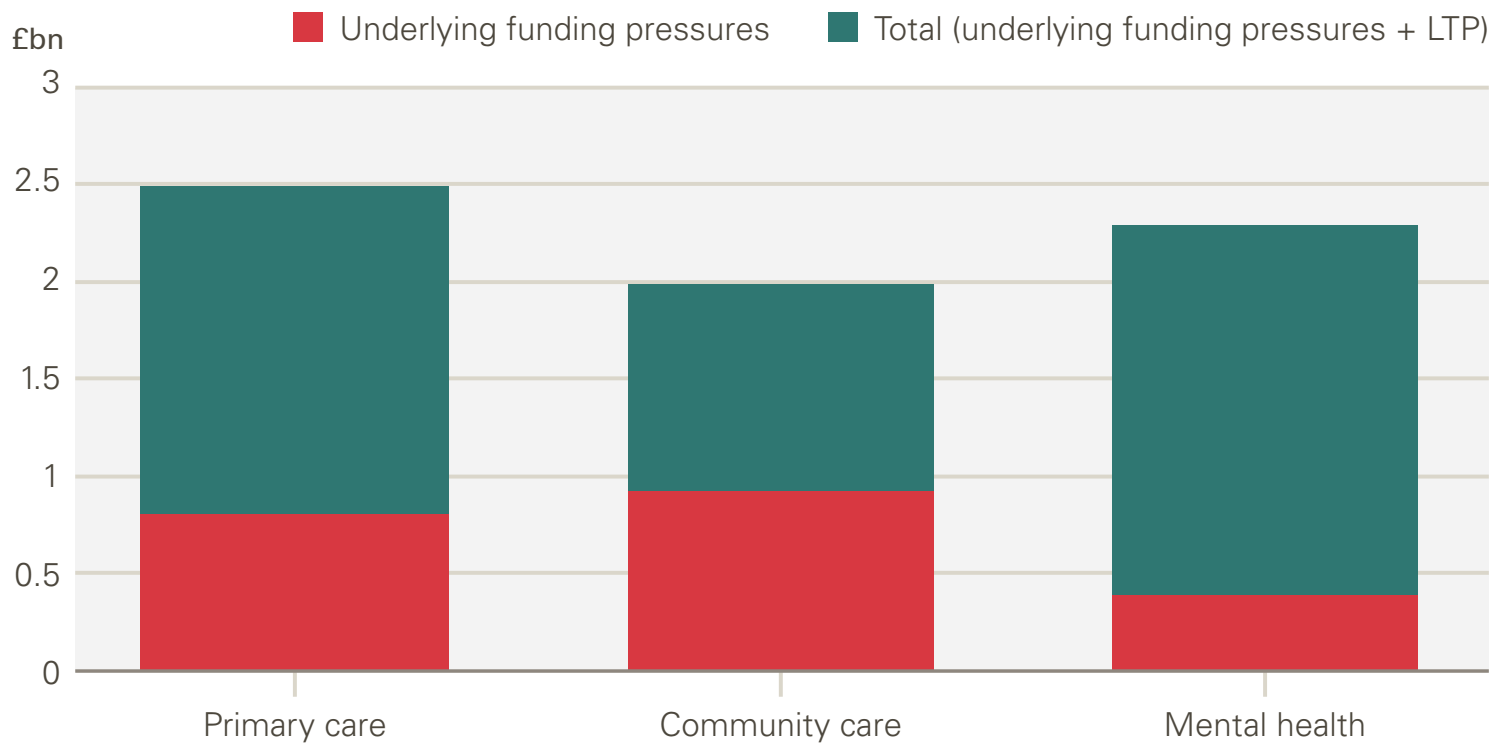

Source: REAL Centre calculations

The budget for primary care in $2018 / 19$ was $f 10.5 b n$ in $2018 / 19$ prices, representing $56 \%$ of the primary and community care budget combined.

$\dagger \quad$ We do not explicitly model changes in utilisation patterns (eg higher rate of consultations), which may be possible through the extra budget. 


\subsubsection{Meeting constitutional standards}

\section{Referral to treatment (RTT) waiting time target and the elective backlog}

The RTT target is one of the most prominent measures of health system performance in England. The NHS constitution states that $92 \%$ of patients should be seen within 18 weeks of a referral. ${ }^{9}$ Even prior to the pandemic, waiting lists were growing: indeed, the target was last met in $2016 .{ }^{55}$ It has grown since then, with the waiting list in May 2021 at a record 5.3 million patients. ${ }^{56}$

Moreover, during the COVID-19 pandemic, much of the care the NHS would usually deliver was reduced or brought to a halt. As a result, millions of patients who would have been expected to be referred for treatment were not. We estimate the number of so-called 'missing patients' is now approaching 8 million. ${ }^{57}$ As services resume some of these patients would be expected to return, but there is significant uncertainty over what proportion. We estimate the waiting list could grow to $10-13$ million if the majority (50-90\%) do return and activity continues as usual (Figure 28).

Figure 28: Actual and projected elective waiting list size

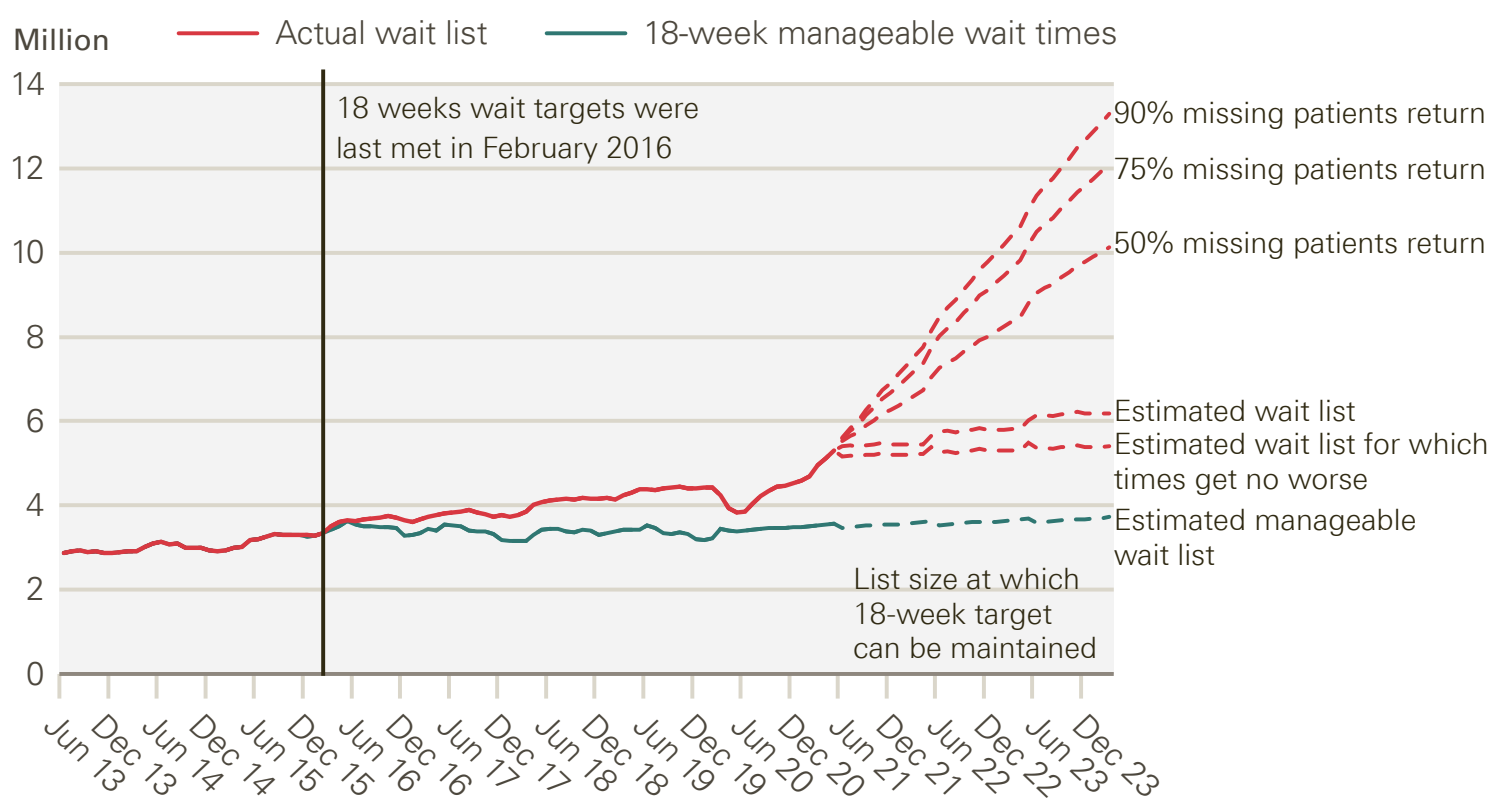

Source: REAL Centre calculations, based on the Findlay model.

To meet constitutional waiting times standards, the waiting list would need to be brought back to a manageable 18-week level. To achieve this, the NHS would therefore need to do two things: first, undertake more activity on an ongoing basis to stop the waiting lists from growing; and second, clear the elective care backlog. ${ }^{58}$ The first corresponds to a recurrent or ongoing cost, while clearing the backlog is modelled as a one-off or non-recurrent cost to treat both those already waiting and returning 'missing patients'. ${ }^{59}$ 
Costs are based on a weighted average of outpatient and inpatient costs of admission. Only some patients will require a hospital admission. In 2018/19, 22\% of all completed pathways were admitted. Looking only at those pathways completed over 18 weeks, a higher proportion of patients were admitted (39\%). We assume $39 \%$ of those in the backlog are admitted, including missing patients. ${ }^{*}$ Furthermore, the non-recurrent costs of clearing the backlog are uprated to account for the price premium associated with using more bank and agency staff or capacity in the private sector. The extra costs associated with hiring more temporary staff are likely to be substantial. While bank and agency staff account for around $8 \%$ of the NHS workforce on average, ${ }^{\dagger} \mathrm{REAL}$ Centre analysis indicates that they cost on average $90 \%$ more than establishment staff per full time equivalent. ${ }^{60} \mathrm{We}$ account for the expected higher costs by assuming a $50 \%$ and $25 \%$ cost premium, respectively, associated with clearing the backlog over a 4 or 8 -year horizon.

In Figure 29 we show two charts:

\section{Option A}

- This is the cost of meeting the RTT target ( $92 \%$ within 18 weeks) by $2024 / 25$.

- $\quad$ Average annual cost over 10 years ranges from $£ 2.1 \mathrm{bn}(90 \%$ return of missing patients) to $£ 1.5 \mathrm{bn}(50 \%)$.

- $\quad$ But this is not spread evenly: costs fall almost entirely in the next 4 years (from an average of $£ 4.8 \mathrm{bn}$ to $£ 3.2 \mathrm{bn}$ ).

- $\quad$ The cumulative cost of clearing the backlog (non-recurrent) would be f15.7bn ( $75 \%$ of patients returning) over 4 years.

- $\quad$ There is also some recurring cost each year to stop waiting lists growing again ( $£ 300 \mathrm{~m})$, giving a total cost to clear the backlog and return to the 18-weeks waiting time standard by $2024 / 25$ of $£ 16.8 b n$.

\section{Option B}

- $\quad$ This is the cost of returning to $2018 / 19$ levels of performance ( $87 \%$ within 18 weeks) by $2028 / 29$.

- The annual cost over 10 years is lower ( $f 1.7 \mathrm{bn}-\mathrm{f} 1.2 \mathrm{bn})$ and more evenly spread across time.

- $\quad$ The average cost over the next 4 years would be $£ 1.3 \mathrm{bn}-£ 2.0 \mathrm{bn}$.

\footnotetext{
* There are several reasons for extending this assumption to returning missing patients. For one, admitted patient care fell more significantly than non-admitted patient care during the pandemic. Another is that returning patients are likely to have higher needs, both because GPs are more likely to refer those in greatest need and because 'missing' patients, by definition, are being referred later than usual.

$\dagger \quad$ This is an estimate based on the fact that vacancy rates for total NHS workforce have averaged $8 \%$ since $2018 / 19$ and that most vacancies are filled by bank and agency staff according to latest data from NHS England.
} 
- $\quad$ The cumulative cost of clearing the backlog (non-recurrent) would be $£ 12.3 \mathrm{bn}$ (75\% of patients returning).

- As above, there is also some recurring cost each year to stop waiting lists growing ( £300m).

Figure 29: Costs of treating the elective care backlog (2021/22-2030/31)

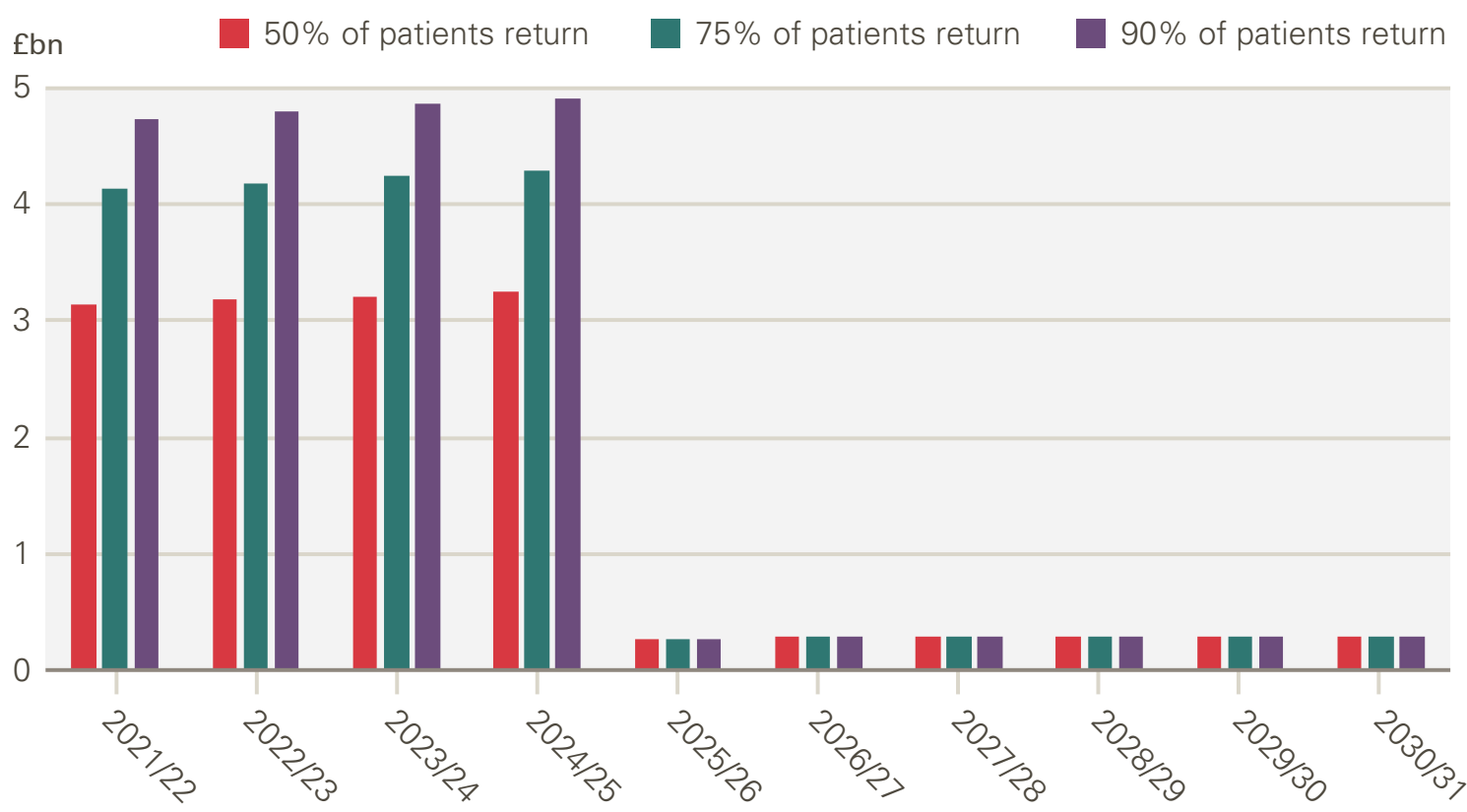

fbn $\square 50 \%$ of patients return $\square 75 \%$ of patients return $\square 90 \%$ of patients return 5

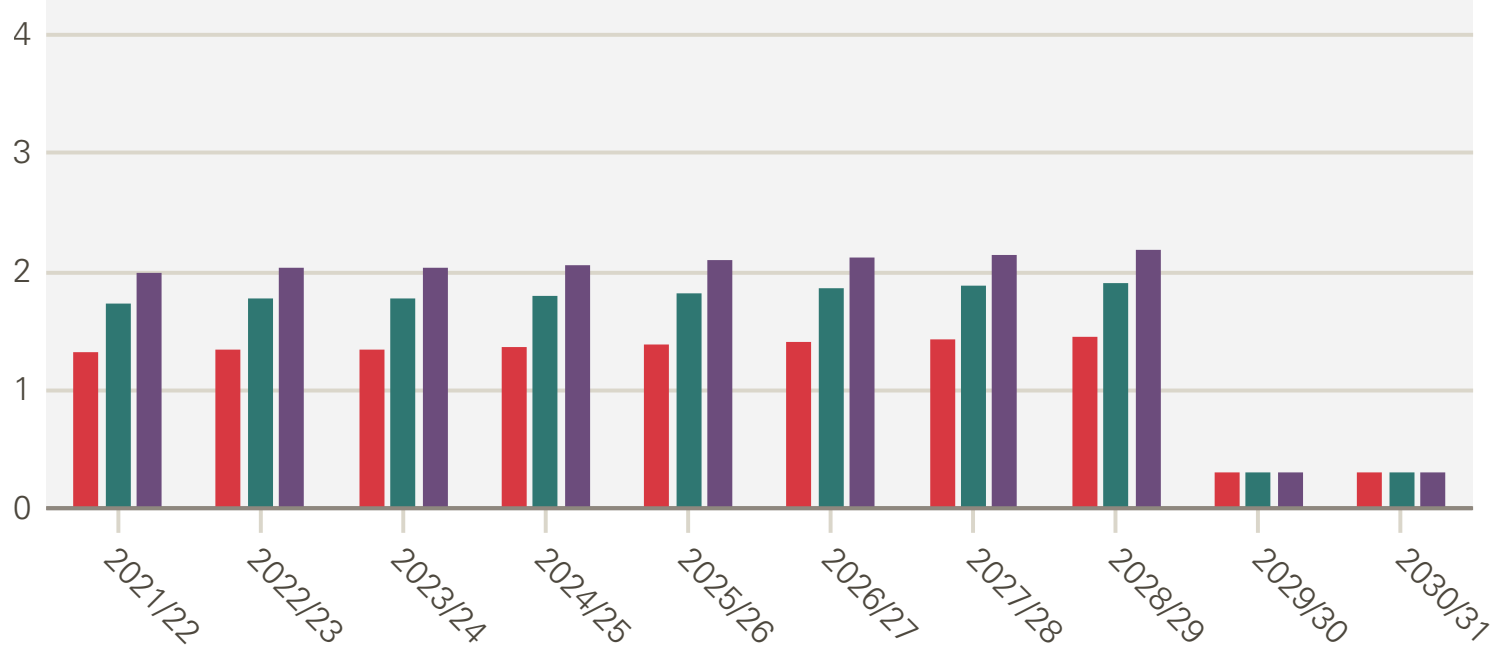

Source: REAL Centre calculations, based on the Findlay model.

The costs of meeting the backlog also need to be weighed against the health impacts of delayed care, including potentially greater severity and $\operatorname{cost}^{61}$ and any wider losses to the whole economy from higher sickness rates. 


\section{Bed occupancy and A\&E waiting times}

The number of available general and acute beds has been in decline in England, resulting in rising bed occupancy rates (Figure 30 ). This has been associated with, and is one factor in explaining, a deteriorating performance against the 4-hour A\&E waiting times target prior to the pandemic. ${ }^{22,63}$ Bed occupancy in 2018/19 averaged $90 \%$ (89.6\%), while in 2011/12, the last time the 4-hour waiting time target was met throughout the year, occupancy averaged $87 \%$.

\section{Figure 30: Occupancy rates, A\&E 4-hour target and performance}

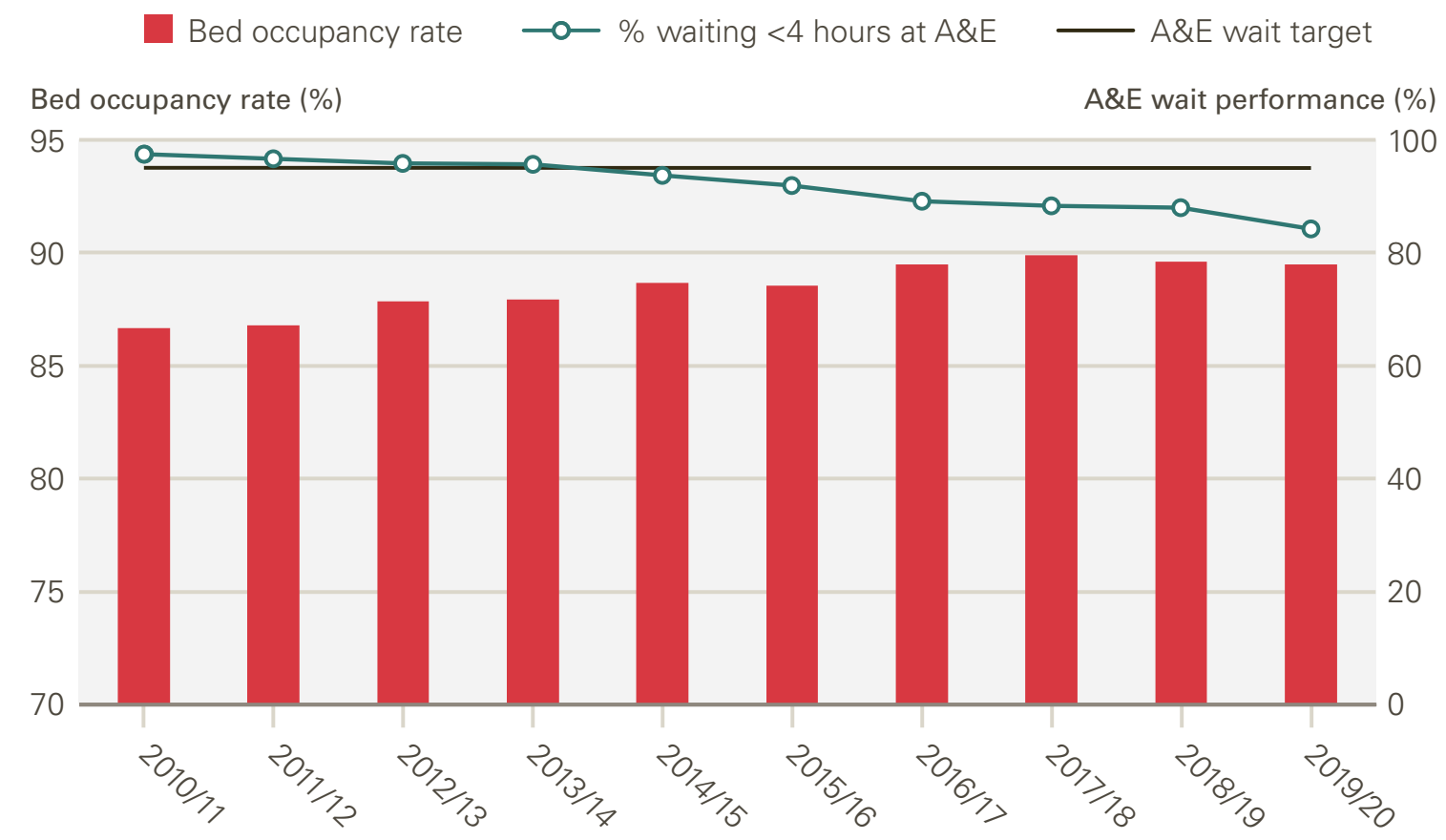

Source: REAL Centre analysis from NHS Digital.

Guidance from the NAO suggests a maximum occupancy level of $85 \% .{ }^{64}$ NICE guidelines recommend planning capacity to minimise the risk of occupancy levels exceeding $90 \% .{ }^{65}$ Either of these levels would mean running at a much lower average occupancy across the year. Doing so would enable better performance against the 4-hour A\&E target and improve the resilience of the system to regular fluctuations, including winter pressures and wider shocks, such as COVID-19. ${ }^{43}$

We model the expected revenue cost associated with increased inpatient bed capacity. We use our projections of future demand for inpatient care and model the extra staffing needed to: 1) maintain the 2018/19 (pre-pandemic) bed occupancy rate $(89.6 \%)$; or 2 ) return to $85 \%$ bed occupancy rate by $2024 / 25$ in line with NAO guidance. ${ }^{\dagger, 66}$ Using NHS reference costs, ${ }^{64}$ we project future bed day costs by

\footnotetext{
* The 4-hour A\&E target may be replaced by a set of access standards (average waiting time in A\&E, time to initial clinical assessment and time to emergency treatment for critically ill and injured patients). In the absence of new published standards, we keep to the existing standards. For more on proposed changes, see NHS England's consultation response Clinically led review of urgent and emergency care standards.

$\dagger \quad$ The return to $85 \%$ bed occupancy rate is phased in, such that the bed occupancy rate goes gradually from pre-pandemic level (89.6\%) in 2020/21 to reach $85 \%$ in $2024 / 25$.
} 
assuming a continuation of the previous trend in growth. Taken together, this gives us our projections of the funding needed, which we estimate to be $f 820 \mathrm{~m}$ in $2030 / 31$ to maintain $89.6 \%$ occupancy and $£ 2.4 b n$ in $2030 / 31$ to reduce it to $85 \%$.

\section{Figure 31: Estimated revenue cost of additional beds over time}

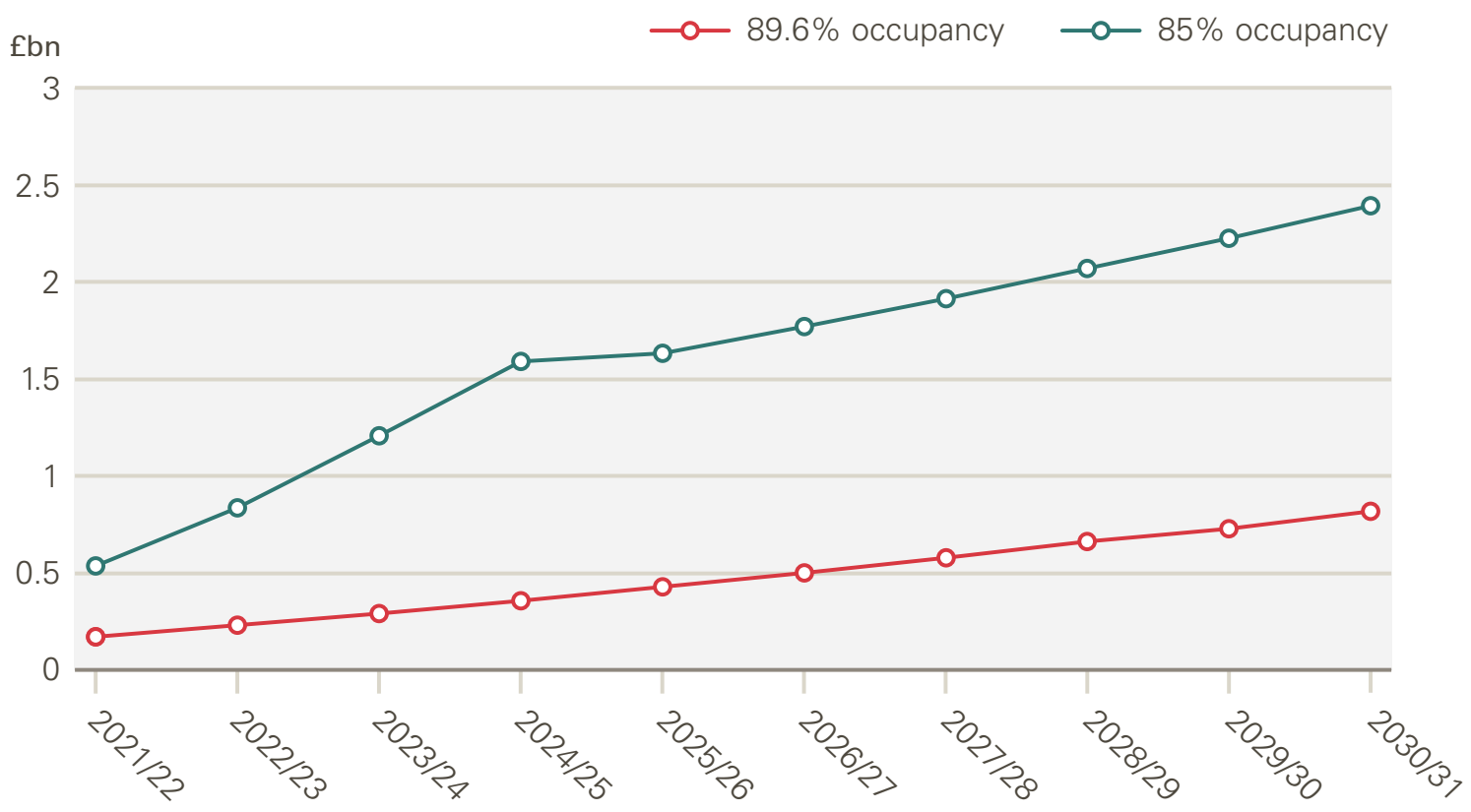

Source: REAL Centre calculations.

\subsubsection{Social care policy}

In addition to estimating how much more funding will be required to keep up with underlying demand for social care, we model the impact of expanding access to care by offering additional social care packages and/or paying more for care to allow for wages of care workers to rise.

As set out in the REAL Centre's Social care funding gap analysis, we model an increase in local authority budgets ${ }^{33}$ (the full modelling approach and rationale for the assumptions are detailed in the Technical Annex of the funding gap analysis). ${ }^{67}$ Additional funding is needed in order for adult social care to keep pace with demand. This funding could be used to stabilise the social care market, increase pay and improve access to care.

Among the possible policy options, we model the costs needed to:

- 'Meet future demand and improve access to care': increasing local authority budgets by $10 \%$ to increase the amount of care people already receive or to expand care to more people, or both. This is illustrative as the level of unmet need in social care is not known. 
- 'Meet future demand and pay more for care (leading to higher staff pay)': providing local authorities with additional funding to pay higher costs for adult social care packages, relying on adult social care providers to pay higher wages to staff.

- $\quad$ 'Meet future demand, improve access to care and pay more for care (leading to higher staff pay)': a combination of the previous two policies (increasing the amount of care by $10 \%$ and paying more for care).

In 2030/31, enacting these policy options would cost $£ 8.9 \mathrm{bn}, £ 11.1 \mathrm{bn}$ and $£ 14.4 \mathrm{bn}$, respectively, above our projections of current spending plans on adult social care by local authorities.

\subsection{Other budgets - capital, public health, HEE and specialised services}

Specialised services support people with a range of rare and complex conditions. They often involve treatments provided to patients with rare cancers, genetic disorders or complex medical or surgical conditions. ${ }^{68}$ Funding for specialised services is driven at least in part by the availability of new health care technologies. This is more unpredictable than other areas of funding. Therefore, we adopt a simpler approach and project costs based on trend growth over the period 2014/15-2019/20 (this results in 4.6\% annual growth in real terms over the period 2018/19-2030/31).

We assume capital spending (DHSC CDEL) grows in line with plans through to 2021/22. Otherwise, all other funding including other NHS England funding, DHSC CDEL after 2021/22, the public health grant and Health Education England grow in line with the projected growth in existing categories (see the scenarios in chapter 5). 


\section{5. \\ Funding projections and scenarios}

In this chapter we combine assumptions about the underlying and additional funding pressures into overall funding projections required under different scenarios. Through these scenarios we explore the impact of different policy choices on the funding needed over the next decade. Given the extraordinary circumstances of the pandemic, we also present analysis of the potential additional funding needed for different impacts from COVID-19 on the level of productivity. After presenting our projections, we look at the implications for the health and social care workforce. All funding figures are presented in real terms in 2021/22 prices unless otherwise stated.

\subsection{Scenarios: 'stabilisation' and 'recovery'}

Table 11 summarises the assumptions across all scenarios. A number of assumptions, eg for demographic trends, morbidity, drug costs, capital and specialised services, are the same for both scenarios. Other assumptions, eg the speed at which the elective backlog is tackled, vary in order to reflect the impact of different policy choices. The assumptions we vary are those more amenable to policy changes including pay, productivity and policy ambitions.

\section{Stabilisation}

In the stabilisation scenario, the health and social care system is projected to return to pre-pandemic levels of service after the COVID-19 shock. We assume pay grows in line with the OBR forecast for all-economy earnings (average 1.3\% annual real-terms growth rate) for health care. For social care, unit costs rise from 2018/19 to $2024 / 25$ to reflect increases in the national living wage. ${ }^{69}$ Productivity growth is flat during the COVID-19 pandemic but returns to its long-term average growth rate of $0.8 \%$ for health care from $2022 / 23$ onwards.

In this scenario, we also assume:

- Inpatient bed capacity is increased to reach $89.6 \%$ of bed occupancy rate from 2021/22, to improve system resilience and allow a return to the 4-hour A\&E waiting time target. 
- $\quad$ Elective waiting times are back to their 2018/19 levels by $2028 / 29$, but not to the constitutional standard of 18 weeks.

- $\quad$ Future demand for social care is met and access to care is improved increasing local authority budgets by $10 \%$ to increase the amount of care people already receive or to expand care for more people (or both). This is illustrative as the level of unmet need in social care is not known.

- Additional mental health demand resulting from the COVID-19 pandemic is met.

- $\quad$ The public health budget grows in line with NHS RDEL at 3.1\%.

- $\quad$ Funding for mental health (not related to the specific effects associated with COVID-19) rises in line with the NHS Mental Health Implementation Plan commitments to 2022/23 and then in line with demographic and input cost growth.

\section{Recovery}

In the recovery scenario, we assume that the effects of COVID-19 beyond the pandemic are limited and that more ambitious policy choices are made to fund recovery. Pay is modelled to grow at $2.6 \%$ in real terms, corresponding to the pay growth rate for nurses during 2000-2010. From 2022/23, we assume higher productivity gains at $1.2 \%$ annually, equivalent to the maximum 10 -year average of public health care productivity since 1998 . Higher productivity growth could result from better staff recruitment and morale, reflecting higher pay assumptions, and/or through factors such as a better uptake of technologies or digital infrastructure.

In this scenario, we assume a number of policy choices:

- $\quad$ To improve system resilience and facilitate a return to the 4-hour A\&E wait time target, inpatient bed capacity is increased to reach the $85 \%$ bed occupancy rate recommended by the NAO by $2024 / 25$.

- The constitutional standard for elective care of 18 weeks from referral to treatment is met by $2024 / 25$.

- $\quad$ Future demand for social care is met and access to care is improved (as per the stabilisation scenario). Funding is made available for local authorities to pay higher costs for care and care providers use this to pay staff higher wages.

- $\quad$ Additional mental health demand resulting from the COVID-19 pandemic is met.

- $\quad$ The public health budget grows in line with NHS RDEL (3.5\% per year).

- $\quad$ Funding for mental health (not related to the specific effects associated with COVID-19) rises in line with the NHS Mental Health Implementation Plan commitments to $2022 / 23$ and continues to grow as quickly as the rest of the NHS budget. 
These policy choices mean additional funding pressures. However, better pay, to the extent that it improves working conditions, staff hiring, retention and morale, can fuel higher productivity gains, which can offset some cost pressures. The recovery scenario is not therefore intended as the maximum possible funding requirement over this period, but a different policy trajectory.

Table 11: Summary of our assumptions across scenarios

\begin{tabular}{|c|c|c|c|c|}
\hline & & & Stabilisation & Recovery \\
\hline \multicolumn{3}{|c|}{ Scenario summary } & $\begin{array}{l}\text { The system is stabilised after } \\
\text { the COVID-19 shock }\end{array}$ & $\begin{array}{l}\text { The ongoing effects of } \\
\text { COVID-19 are limited, and } \\
\text { more ambitious policy } \\
\text { choices are made to fund } \\
\text { recovery }\end{array}$ \\
\hline \multirow{11}{*}{$\begin{array}{l}\text { Assumptions } \\
\text { consistent } \\
\text { across all } \\
\text { scenarios }\end{array}$} & \multirow{2}{*}{\multicolumn{2}{|c|}{ Demand factors }} & \multirow{2}{*}{\multicolumn{2}{|c|}{$\begin{array}{l}\text { Size and age structure of the population } \\
\text { Mortality and birth rates }\end{array}$}} \\
\hline & & & & \\
\hline & \multirow{6}{*}{\multicolumn{2}{|c|}{ Supply factors }} & \multicolumn{2}{|c|}{$\begin{array}{l}\text { Hospital drug price growth ( } 5.9 \% \text { in real terms) and community } \\
\text { drug price growth (flat in real terms) }\end{array}$} \\
\hline & & & \multicolumn{2}{|c|}{ Actual NHS pay growth $(2018 / 19$ to $2020 / 21)$} \\
\hline & & & \multicolumn{2}{|c|}{$\begin{array}{l}\text { Flat productivity during COVID-19 pandemic (2020/21 to } \\
2021 / 22)\end{array}$} \\
\hline & & & \multicolumn{2}{|c|}{ Capital funding grows with plans and with NHS RDEL } \\
\hline & & & \multicolumn{2}{|c|}{$\begin{array}{l}\text { Public health grant and Health Education England funding } \\
\text { grows in line with NHS RDEL }\end{array}$} \\
\hline & & & \multicolumn{2}{|c|}{ Specialised services grow in line with trend ( $4.6 \%$ in real terms) } \\
\hline & \multirow{3}{*}{\multicolumn{2}{|c|}{$\begin{array}{l}\text { Additional funding } \\
\text { pressures and policy } \\
\text { choices }\end{array}$}} & \multirow{3}{*}{\multicolumn{2}{|c|}{$\begin{array}{l}\text { Long term plan commitments for primary care, community } \\
\text { care and mental health } \\
\text { Ongoing vaccination programme linked to COVID-19 } \\
\text { Addressing the additional COVID-19-related mental health } \\
\text { demand }\end{array}$}} \\
\hline & & & & \\
\hline & & & & \\
\hline \multirow{6}{*}{$\begin{array}{l}\text { Assumptions } \\
\text { varied across } \\
\text { scenarios }\end{array}$} & $\begin{array}{l}\text { Supply } \\
\text { factors }\end{array}$ & Pay & $\begin{array}{l}\text { Medium: } 1.3 \% \text { real-terms } \\
\text { annual increase from } 2021 / 22\end{array}$ & $\begin{array}{l}\text { High: } 2.6 \% \text { real-terms annual } \\
\text { increase from } 2021 / 22\end{array}$ \\
\hline & \multirow{5}{*}{$\begin{array}{l}\text { Additional } \\
\text { funding } \\
\text { pressures } \\
\text { and policy } \\
\text { choices }\end{array}$} & $\begin{array}{l}\text { Post- } \\
\text { pandemic } \\
\text { productivity }\end{array}$ & $\begin{array}{l}\text { Medium: } 0.8 \% \text { annual growth } \\
\text { from } 2022 / 23\end{array}$ & $\begin{array}{l}\text { High: } 1.2 \% \text { annual growth } \\
\text { from } 2022 / 23\end{array}$ \\
\hline & & \multirow[t]{3}{*}{$\begin{array}{l}\text { Policy } \\
\text { choices and } \\
\text { constitutional } \\
\text { standards }\end{array}$} & $\begin{array}{l}\text { Increase in bed capacity to } \\
\text { return to } 2018 / 19 \text { occupancy } \\
\text { rates }(89.6 \%) \text { from } 2021 / 22\end{array}$ & $\begin{array}{l}\text { Increase in bed capacity to } \\
\text { reach } 85 \% \text { occupancy rate } \\
\text { by } 2024 / 25\end{array}$ \\
\hline & & & $\begin{array}{l}\text { RTT waiting time back to } \\
2018 / 19 \text { levels (but not } 18 \text { - } \\
\text { week target) by } 2028 / 29\end{array}$ & $\begin{array}{l}\text { RTT waiting time back to } \\
18 \text {-week target by } 2024 / 25\end{array}$ \\
\hline & & & $\begin{array}{l}\text { Mental health growing with } \\
\text { underlying funding pressures }\end{array}$ & $\begin{array}{l}\text { Mental health growing in line } \\
\text { with rest of budget }\end{array}$ \\
\hline & & Social care & $\begin{array}{l}\text { Meet future demand and } \\
\text { improve access to care }\end{array}$ & $\begin{array}{l}\text { Meet future demand, improve } \\
\text { access to care and pay more } \\
\text { for care (leading to higher } \\
\text { staff pay) }\end{array}$ \\
\hline
\end{tabular}




\subsection{Funding projections}

Under the stabilisation scenario, total health care funding (DHSCTDEL) would need to grow by an average rate of $3.3 \%$ a year from 2018/19 to 2030/31, with higher growth in capital (5.3\% growth in DHSC CDEL) than in day-to-day spend $(3.2 \%$ growth in DHSC RDEL). NHS RDEL would grow by $3.1 \%$ a year; social care funding at $4.3 \%$ a year.

Under the recovery scenario, total health care funding (DHSCTDEL) would need to grow by an average rate of 3.6\% a year during 2018/19-2030/31, DHSC CDEL by $5.5 \%$ a year and DHSC RDEL by $3.5 \%$. NHS RDEL would grow by $3.5 \%$ a year; social care funding would grow at $5.8 \%$ a year.

In both scenarios growth in the period 2018/19-2024/25 is greater than in 2024/252030/31. For instance, in stabilisation, NHS RDEL grows by $3.6 \%$ a year during 2018/19-2024/25, dropping to $2.7 \%$ thereafter. In part this reflects the higher baseline in 2024/25 owing to non-recurrent funding on progress against waiting times, but also other increases in funding such as fulfilling long term plan commitments.

Table 12: Real-terms funding growth by scenario

\begin{tabular}{|c|c|c|c|}
\hline & 2018/19-2030/31 & $2018 / 19-2024 / 25$ & $2024 / 25-2030 / 31$ \\
\hline \multicolumn{4}{|l|}{ Stabilisation } \\
\hline Acute spend & $3.3 \%$ & $3.7 \%$ & $2.9 \%$ \\
\hline Specialised commissioning & $4.6 \%$ & $4.8 \%$ & $4.4 \%$ \\
\hline NHS RDEL & $3.1 \%$ & $3.6 \%$ & $2.7 \%$ \\
\hline DHSC RDEL & $3.2 \%$ & $3.7 \%$ & $2.6 \%$ \\
\hline DHSC CDEL & $5.3 \%$ & $8.0 \%$ & $2.7 \%$ \\
\hline DHSCTDEL & $3.3 \%$ & $3.9 \%$ & $2.6 \%$ \\
\hline Social care & $4.3 \%$ & $5.5 \%$ & $3.3 \%$ \\
\hline \multicolumn{4}{|l|}{ Recovery } \\
\hline Acute spend & $3.7 \%$ & $4.8 \%$ & $2.6 \%$ \\
\hline Specialised commissioning & $4.6 \%$ & $4.8 \%$ & $4.4 \%$ \\
\hline NHS RDEL & $3.5 \%$ & $4.2 \%$ & $2.9 \%$ \\
\hline DHSC RDEL & $3.5 \%$ & $4.3 \%$ & $2.8 \%$ \\
\hline DHSC CDEL & $5.5 \%$ & $8.2 \%$ & $2.9 \%$ \\
\hline DHSCTDEL & $3.6 \%$ & $4.5 \%$ & $2.8 \%$ \\
\hline Social care* & $5.8 \%$ & $9.0 \%$ & $3.3 \%$ \\
\hline
\end{tabular}

Source: REAL Centre calculations.

Notes: the growth rates cited above exclude any pensions adjustments. ${ }^{*}$ For social care modelling, the baseline year is $2019 / 20$. 
The pressures identified in this report all imply significant increases in health and social care funding. As Table 13 shows, by 2024/25 the NHS RDEL budget will have to be $f 29 \mathrm{bn}$ (stabilisation) to $£ 34 \mathrm{bn}$ (recovery) higher than in 2018/19 (we provide a more detailed breakdown of NHS funding in C2 and C3 of Appendix C). The additional $£ 5 \mathrm{bn}$ for recovery reflects faster progress against the elective backlog. An additional f10bn will be needed to attend to the elective care backlog over the next 5 years alongside other policy goals, such as meeting long term plan commitments.

In terms of other budgets, by 2030/31:

- $\quad$ DHSC RDEL would be around $£ 200 b n$

- $\quad$ the public health grant would rise to at least $£ 5 b n$

- $\quad$ funding for Health Education England would be at least $£ 6.4 \mathrm{bn}$

- $\quad$ capital funding, DHSC CDEL, would be around f12bn, and

- $\quad$ social care would account for $£ 31 b n-f 37 b n$. 
Table 13: Funding by budget

\begin{tabular}{|c|c|c|c|}
\hline fbn (2021/22 prices) & 2018/19 & $2024 / 25$ & $2030 / 31$ \\
\hline \multicolumn{4}{|l|}{ Stabilisation } \\
\hline DHSC RDEL* & 134.2 & 169.5 & 197.1 \\
\hline \multicolumn{4}{|l|}{ Of which: } \\
\hline NHS RDEL* & 123.3 & 155.3 & 181.0 \\
\hline Public health grant & 3.5 & 4.3 & 5.0 \\
\hline Health Education England & 4.4 & 5.5 & 6.4 \\
\hline DHSC CDEL & 6.4 & 10.2 & 11.9 \\
\hline DHSCTDEL* & 140.6 & 179.6 & 209.0 \\
\hline Social care ${ }^{* *}$ & 19.5 & 25.5 & 30.9 \\
\hline \multicolumn{4}{|l|}{ Recovery } \\
\hline DHSC RDEL* & 134.2 & 175.0 & 206.0 \\
\hline \multicolumn{4}{|l|}{ Of which: } \\
\hline NHS RDEL* & 123.3 & 160.4 & 189.2 \\
\hline Public health grant & 3.5 & 4.4 & 5.2 \\
\hline Health Education England & 4.4 & 5.7 & 6.7 \\
\hline DHSC CDEL & 6.4 & 10.3 & 12.2 \\
\hline DHSCTDEL* & 140.6 & 185.3 & 218.2 \\
\hline Social care ${ }^{* *}$ & 19.5 & 30.0 & 36.5 \\
\hline
\end{tabular}

Source: REAL Centre calculations.

*Notes: NHS RDEL, DHSC RDEL and DHSC TDEL include $£ 2.85 \mathrm{bn}$ for pensions adjustments, which is not reflected in the growth rates in Table 12

** For social care modelling, the baseline year is 2019/20.

\subsubsection{Comparison with the long term plan}

In the short term, to 2024/25, either scenario would require more funding than committed under the NHS funding settlement. For NHS day-to-day spending (NHS RDEL), our projections imply the following above the long term plan (excluding pensions adjustment):

- Under stabilisation: an additional $£ 4.7 \mathrm{bn}$ in $2021 / 22$, £4.0bn in $2022 / 23$ and £2.9bn in 2023/24.

- Under recovery: an additional $£ 7.7 b n$ in $2021 / 22$, $£ 7.1$ bn in $2022 / 23$ and $£ 6.4 b n$ in $2023 / 24$.

- In 2024/25, NHS RDEL would need to be $f 153 b n$ under stabilisation and £158bn under recovery. 
Figure 32: NHS RDEL funding: long term plan scenarios

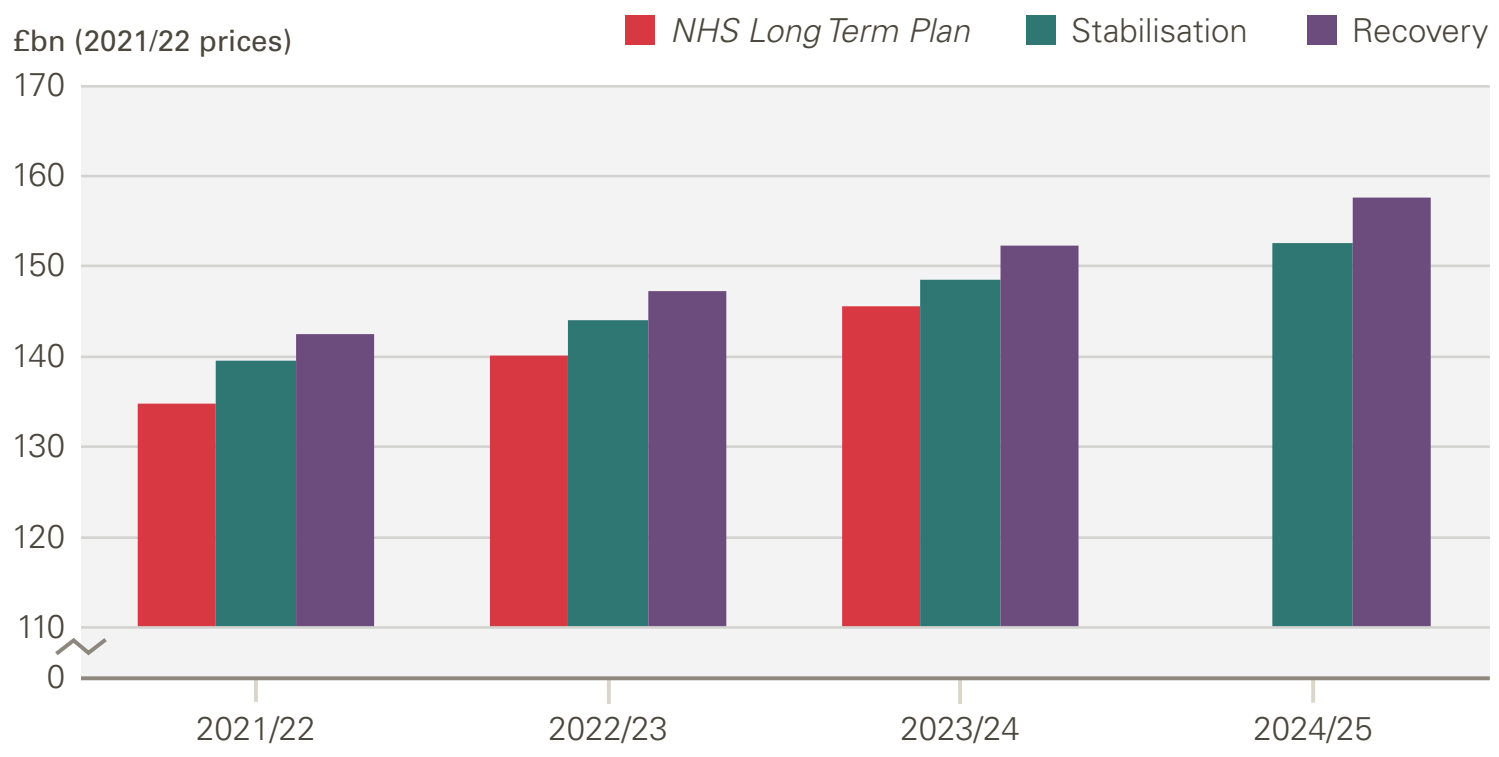

Source: REAL Centre calculations.

Notes: NHS RDEL excludes $£ 2.85$ bn for pensions; NHS Long Term Plan in 2021/22 funding includes an additional $£ 1$ bn for elective backlog and $f 500 \mathrm{~m}$ for mental health as part of the COVID-19 response.

Table 14: Potential additional funding needed for NHS England (fbn, 2021/22 prices)

\begin{tabular}{llllll}
\hline & & $\mathbf{2 0 2 1 / 2 2}$ & $\mathbf{2 0 2 2 / 2 3}$ & $\mathbf{2 0 2 3 / 2 4}$ & $\mathbf{2 0 2 4 / 2 5}$ \\
\hline \multirow{2}{*}{ NHS Long Term Plan } & NHS RDEL (Nominal) & 134.8 & 140.0 & 148.5 & n/a \\
\cline { 2 - 6 } & NHS RDEL (Real terms) & 134.8 & 140.1 & 145.6 & n/a \\
\cline { 2 - 6 } & Annual real-terms growth & $6.7 \%$ & $5.1 \%$ & $3.9 \%$ & n/a \\
\hline \multirow{2}{*}{ Stabilisation } & NHS RDEL (Nominal) & 139.5 & 143.9 & 151.4 & 158.7 \\
\cline { 2 - 6 } & NHS RDEL (Real terms) & 139.5 & 144.1 & 148.6 & 152.5 \\
\cline { 2 - 6 } & Annual real-terms growth & $7.0 \%$ & $3.3 \%$ & $3.1 \%$ & $2.7 \%$ \\
\cline { 2 - 6 } & Difference (fbn) & 4.7 & 4.0 & 2.9 & $\mathrm{n} / \mathrm{a}$ \\
\hline \multirow{2}{*}{ Recovery } & NHS RDEL (Nominal) & 142.5 & 147.0 & 155.2 & 164.0 \\
\cline { 2 - 6 } & NHS RDEL (Real terms) & 142.5 & 147.2 & 152.4 & 157.6 \\
\hline & Annual real-terms growth & $9.5 \%$ & $3.3 \%$ & $3.5 \%$ & $3.5 \%$ \\
\hline & Difference (fbn) & 7.7 & 7.1 & 6.7 & n/a \\
\hline
\end{tabular}

Source: REAL Centre calculations.

Notes: Real-terms growth rate are relative to the previous year. NHS RDEL presented here excludes $£ 2.85 \mathrm{bn}$ for pensions, and thus differ slightly from figures in Table 13; NHS Long Term Plan funding in 2021/22 includes an additional f1bn for elective backlog and $f 500 \mathrm{~m}$ for mental health as part of the COVID-19 response. 


\subsubsection{Ongoing COVID-19 costs}

These funding figures assume that the level of productivity after the pandemic can return to normal. However, there is a risk that COVID-19 continues to impose significant additional costs in the future. In Figure 33 and Table 15, we set out the additional funding associated with a $1 \%, 3 \%, 5 \%$ and $10 \%$ hit to productivity between 2021/22 and 2024/25. Every percentage point reduction in productivity results in additional cost of around $£ 1.5 \mathrm{bn}$. A $5 \%$ hit to productivity would mean an annual cost of more than $f 7 \mathrm{bn}$.

Figure 33: NHS RDEL with additional COVID-19 funding (fbn, 2021/22 prices)

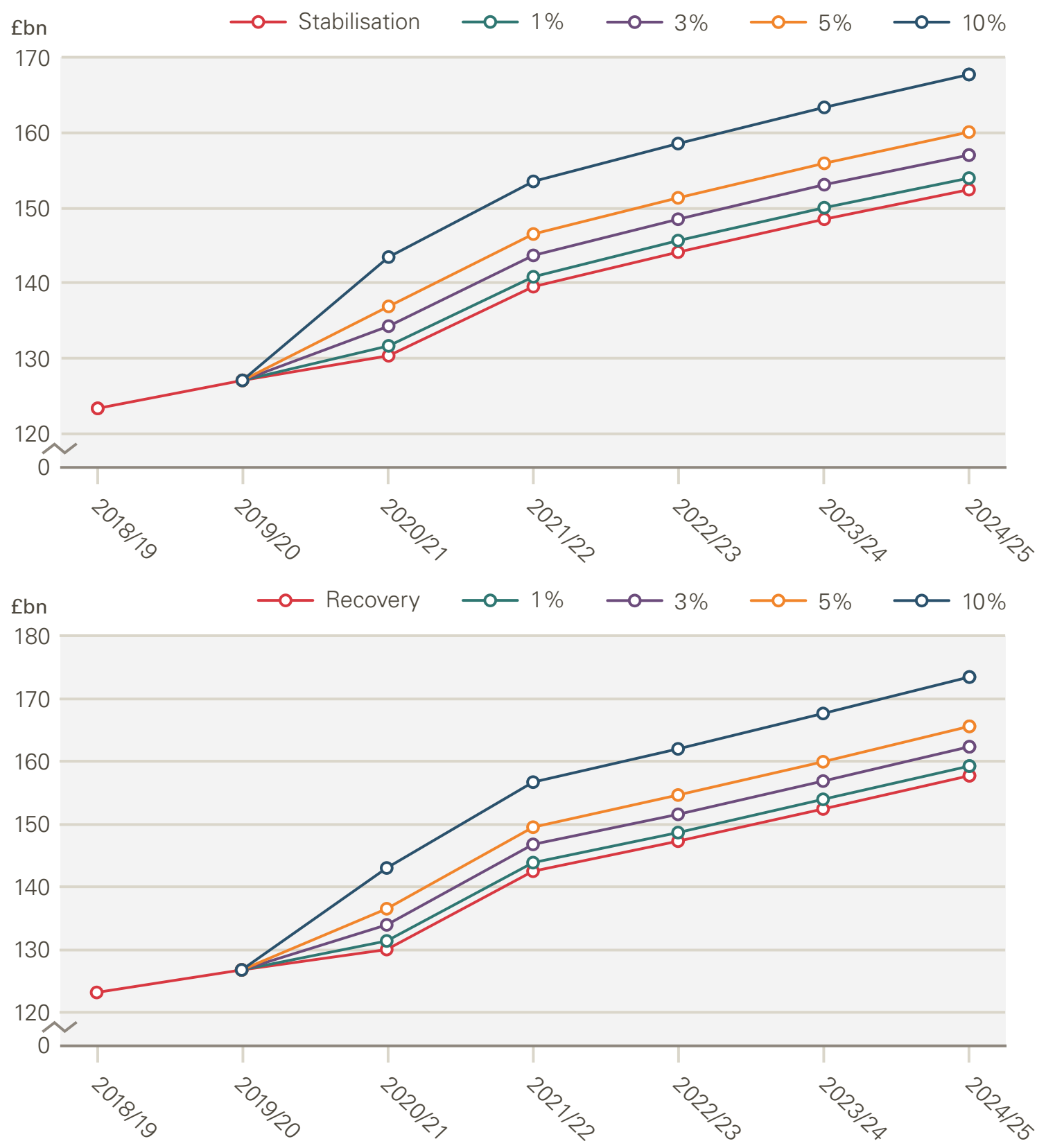

Source: REAL Centre calculations. 
Table 15: Additional COVID-19 funding needed for NHS England (fbn, 2021/22 prices)

\begin{tabular}{|c|c|c|c|c|c|}
\hline & & $2021 / 22$ & $2022 / 23$ & $2023 / 24$ & $2024 / 25$ \\
\hline \multirow[t]{6}{*}{ Stabilisation } & NHS RDEL (Real terms) & 139.5 & 144.1 & 148.6 & 152.5 \\
\hline & \multicolumn{5}{|l|}{ Additional cost of a COVID-19 hit to productivity } \\
\hline & $1 \%$ & 1.4 & 1.4 & 1.5 & 1.5 \\
\hline & $3 \%$ & 4.2 & 4.3 & 4.5 & 4.6 \\
\hline & $5 \%$ & 7.0 & 7.2 & 7.4 & 7.6 \\
\hline & $10 \%$ & 14.0 & 14.4 & 14.9 & 15.3 \\
\hline \multirow[t]{6}{*}{ Recovery } & NHS RDEL (Real terms) & 142.5 & 147.2 & 152.4 & 157.6 \\
\hline & \multicolumn{5}{|l|}{ Additional cost of a COVID-19 hit to productivity } \\
\hline & $1 \%$ & 1.4 & 1.5 & 1.5 & 1.6 \\
\hline & $3 \%$ & 4.3 & 4.4 & 4.6 & 4.7 \\
\hline & $5 \%$ & 7.1 & 7.4 & 7.6 & 7.9 \\
\hline & $10 \%$ & 14.2 & 14.7 & 15.2 & 15.8 \\
\hline
\end{tabular}

Source: REAL Centre calculations.

\subsubsection{Social care funding}

Both scenarios also imply a significant increase in social care funding over the short term. Our projections imply the following above projected increases in spending power:

- Under stabilisation: an additional f3.0bn in 2021/22, £3.7bn in 2022/23, f4.2bn in 2023/24 and f4.8bn in 2024/25.

- Under recovery: an additional $£ 7.1$ bn in $2021 / 22, £ 7.9 b n$ in $2022 / 23$, f8.6bn in 2023/24 and $£ 9.3$ bn in 2024/25. 
Table 16: Projected funding for social care

\begin{tabular}{llllll}
\hline & & $\mathbf{2 0 2 1 / 2 2}$ & $\mathbf{2 0 2 2 / 2 3}$ & $\mathbf{2 0 2 3 / 2 4}$ & $\mathbf{2 0 2 4 / 2 5}$ \\
\hline $\begin{array}{l}\text { Current spending power } \\
\text { (excluding one-off } \\
\text { COVID-19 funding) }\end{array}$ & fbn & 20.1 & 20.3 & 20.5 & 20.7 \\
\cline { 2 - 6 } & Annual real-terms growth rate & $0.6 \%$ & $0.9 \%$ & $1.1 \%$ & $1.0 \%$ \\
\hline Stabilisation & fbn & 23.1 & 24.0 & 24.7 & 25.5 \\
\cline { 2 - 6 } & $\begin{array}{l}\text { Additional funding (compared with } \\
\text { current spending power, fbn) }\end{array}$ & 3.0 & 3.7 & 4.2 & 4.8 \\
\cline { 2 - 6 } & $\begin{array}{l}\text { Annual real-terms growth rate } \\
\text { Recovery }\end{array}$ & $8.6 \%$ & $3.6 \%$ & $3.2 \%$ & $3.2 \%$ \\
\hline & fbn & 27.2 & 28.2 & 29.1 & 30.0 \\
\hline & $\begin{array}{l}\text { Additional funding (compared with } \\
\text { current spending power, fbn) }\end{array}$ & 7.1 & 7.9 & 8.6 & 9.3 \\
\cline { 2 - 6 } & Annual real-terms growth rate & $17.4 \% *$ & $3.6 \%$ & $3.2 \%$ & $3.2 \%$ \\
\hline
\end{tabular}

Source: REAL Centre calculations.

Notes: Figures are for England. Annual real-terms growth rates are relative to the previous year.

* Fast increase is driven by the projected increase in social care package and staff pay.

\subsection{Workforce}

Under either scenario, the combined effect of population growth, ageing and an increased burden of chronic disease results in hospital activity growing substantially by $2030 / 31$. Our model projects that emergency admissions would increase by more than a third by this point, with major implications for the capacity needed in the health service. The activity required to meet additional pressures, particularly for elective care, creates further short to medium-term demand.

These activity projections take no account of potential productivity gains, some of which may be labour saving. Nor do they allow for significant changes in demand - for instance, through better disease prevention and health promotion action and/ or radically different models of care. However, while it may be possible to 'bend' the demand curve, our projections show that changes would need to be very substantial to reduce acute activity.

To meet this demand, the health and social care workforce would need to expand significantly (Table 17). By $2024 / 25$, an additional 275,000 health care staff could be needed, including an additional 69,000 hospital nurses and health visitors. By 2030/31, an extra 488,000 health care staff could be needed, corresponding to a growth of $2.8 \%$ per year. The number of social care staff employed by local authorities would need to increase by 51,000 , corresponding to a growth of $3.7 \%$ per year (with much larger increases across the total social care workforce). 
Table 17: Workforce projections

\begin{tabular}{|c|c|c|c|c|c|c|c|c|}
\hline Area & 2018/19 & $2024 / 25$ & $\begin{array}{l}\text { Extra } \\
\text { FTE }\end{array}$ & $\%$ change & $2030 / 31$ & $\begin{array}{l}\text { Extra } \\
\text { FTE }\end{array}$ & $\%$ change & $\begin{array}{l}\text { CAGR } \\
(2018 / 19- \\
2030 / 31)\end{array}$ \\
\hline Health care & $1,225,000$ & $1,500,000$ & 275,000 & $22 \%$ & $1,713,000$ & 488,000 & $40 \%$ & $2.8 \%$ \\
\hline \multicolumn{9}{|l|}{ Of which: } \\
\hline Doctors & 147,000 & 180,000 & 34,000 & $23 \%$ & 205,000 & 59,000 & $40 \%$ & $2.8 \%$ \\
\hline Nurses & 306,000 & 375,000 & 69,000 & $22 \%$ & 429,000 & 122,000 & $40 \%$ & $2.8 \%$ \\
\hline Social care & $1,130,000$ & $1,447,000$ & 317,000 & $28 \%$ & $1,757,000$ & 627,000 & $55 \%$ & $3.7 \%$ \\
\hline \multicolumn{9}{|l|}{ Of which: } \\
\hline $\begin{array}{l}\text { Local } \\
\text { authority }\end{array}$ & 92,000 & 117,000 & 26,000 & $28 \%$ & 143,000 & 51,000 & $55 \%$ & $3.7 \%$ \\
\hline
\end{tabular}

Source: REAL Centre calculations.

Note: doctors and nurses include both acute staff and those in primary care; nurses include health visitors.

These projected increases come on top of existing workforce shortages. In 2018/19, there were 1.19 million funded posts in hospital and community care, with a vacancy rate of $8.9 \%$. At current rates of training, we estimate there could be a shortfall of 360,000 staff by $2030 / 31$. It is possible that more activity could be delivered by the independent sector, especially in the intervening years to tackle the backlog of elective care, but this could only account for a small amount of the additional activity required.

Figure 34: Comparison of health care workforce projections with trend growth in posts

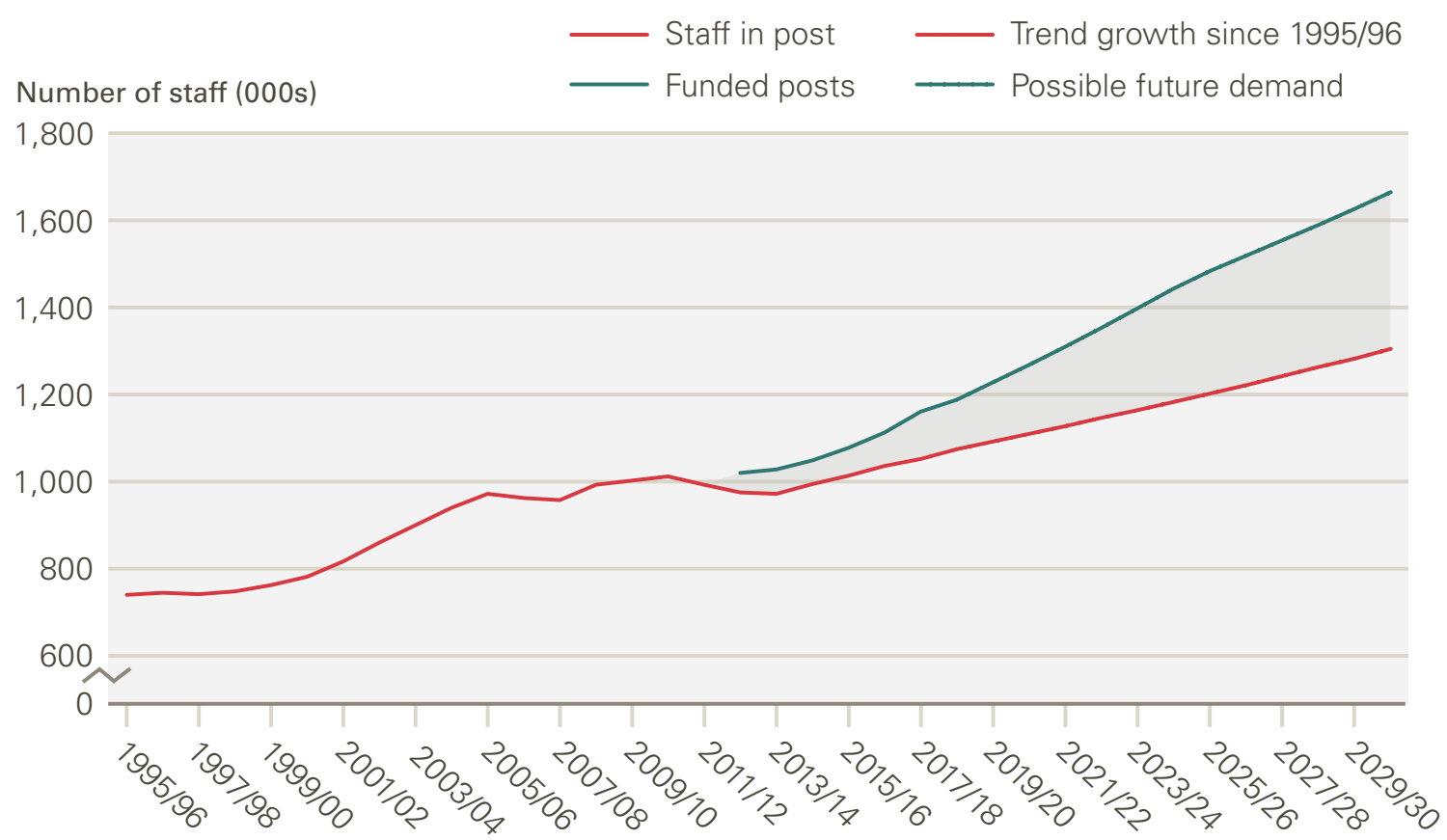

Source: NHS Digital; REAL Centre calculations.

Note: projections for hospital and community health services workforce. 


\subsection{UK funding and comparisons with international projections}

Using our projections, we estimate what this would mean for UK funding over this period (see section 2.1 for different definitions of health spending and section 3.5 for our approach to UK funding projections). Under our estimates, health funding would grow faster than GDP. We project that health funding could rise close to or above $10 \%$ of GDP by $2030 / 31$ from just $7.8 \%$ in $2018 / 19$. Our estimates of funding required in 2030/31 are higher than those from the OECD's macro model.

Table 18: Public spending on health, comparison with OECD projections

\begin{tabular}{llll}
\hline fbn (2018/19 prices) & $\begin{array}{l}\text { Functional spending on } \\
\text { health (UK) }\end{array}$ & $\begin{array}{l}\text { System of health } \\
\text { accounts (UK) }\end{array}$ & \% of GDP \\
\hline $\mathbf{2 0 1 8 / 1 9}$ & 149 & 169 & $7.8 \%$ \\
\hline $\mathbf{2 0 3 0 / 3 1}$ projections & & & \\
\hline Stabilisation & 218 & 260 & $9.8 \%$ \\
\hline Recovery & 228 & 270 & $10.2 \%$ \\
\hline OECD projection for UK & & & $8.8 \%$ \\
\hline
\end{tabular}

Source: REAL Centre calculations; OECD Health Spending Projections to 2040 (unpublished). 


\section{6.}

\section{Implications}

In this final chapter we draw out the implications of our analysis. First, we consider how funding will need to grow to meet underlying pressures. Then we consider implications for health and social care after the pandemic, and the elective care backlog and hospital capacity in particular. We provide a comparison of our projections with corresponding historical and international figures, before concluding with reflections on what the projections mean for the workforce and for the balance of spend between different parts of the health and care system.

\subsection{Underlying funding pressures}

In 2018 the government announced a 5-year funding settlement for NHS England covering the period $2018 / 19$ to $2023 / 24 .^{70}$ The additional funding amounted to an annual average increase of $3.4 \%$ a year, meaning NHS England's budget would be $£ 20.5$ bn higher in $2023 / 24$ than in $2018 / 19$. This level of increase was below the historical average for the NHS (between 1948 and 2019, NHS funding grew up an average of $3.7 \%$ a year), but double the rate of growth since $2010(1.7 \%)$.

Although the 2018 settlement represented a significant increase in NHS funding, the attached terms meant it was always going to be challenging to implement. The settlement was accompanied by the long term plan that set ambitious goals to:

- $\quad$ invest in mental health, community, and primary care services

- $\quad$ reduce waiting times across a range of services

- $\quad$ return providers to financial balance

- deliver a higher rate of annual productivity growth.

For the NHS to deliver these long term plan goals, and stay within budget, growth in hospital activity would need to slow. Indeed, growth in hospital activity would need to be lower than the historical average and lower than the rate of growth implied by the growing and ageing population.

The funding settlement covered the spending controlled by NHS England and represents the majority (88\%) of the budget for health. However, it excluded capital investment, public health, and workforce training and development - all vital if the health system is to deliver the ambitions in the plan. This analysis confirms that delivering the plan's ambitious goals within the government funding settlement would have been incredibly challenging even before COVID-19 - especially without the investment in physical infrastructure, workforce and public health, all of which were excluded. 
The settlement also excluded social care, which has had no multi-year funding since 2015 and even that only survived for 2 years. The underlying pressures for the sector were already much greater than the resources being made available; local government funding has been reduced since 2010 and there have been limited settlements for adult social care in recent years. COVID-19 has since placed huge additional demands on the system, further exacerbating existing pressures. As this analysis shows, the amount of care provided within the publicly funded social care system has fallen by an average of $0.6 \%$ a year over the past decade. Over the coming decade, our analysis shows that demand for care could increase by $1.9 \%$ a year.

\subsection{Health and care after the pandemic}

The pandemic has had a profound impact on health and care funding, the nature of the pressures on the system and the organisation of care. It has slowed progress made towards the vision for health care set out in the NHS Long Term Plan. ${ }^{71}$ Recently, the NHS has been subject to a temporary funding regime. Health received f63bn in 2020/21 and a further $£ 29 \mathrm{bn}$ in $2021 / 22$ to meet the health-related direct costs of the pandemic, $23 \%$ of this funding going to NHS England. In addition, $£ 2 b n$ was provided to meet pandemic costs in adult social care. As the OBR notes, the UK spent $16.2 \%$ of GDP over 2020/21 and 2021/22 on the COVID-19 rescue package: the third largest among 35 advanced economies after the United States and New Zealand. COVID-19 spending has also been more heavily skewed toward spending on health care (as opposed to social care). A third of total pandemic-related spending in the UK was on health care, more than double the average across the advanced economies. ${ }^{1}$

Some of these costs will be one-offs, but as the health and social care system recover from the pandemic and establish the new normal, much has changed in the demand for care, the way care is provided and the associated costs.

There is an enormous amount of uncertainty about how COVID-19 will evolve and the policy response that may subsequently be needed. The projections analysis in this report point to four critical factors that will shape health and care funding pressures:

1. The scale of the backlog of care in the NHS and the policy ambitions set by government to reduce the waiting times and waiting lists that have grown during the pandemic.

2. The ongoing prevalence of COVID-19 and the impact on staffing, direct care for COVID-19 patients and the IPC measures needed. 
3. The amount of ongoing additional capacity needed to provide a more resilient health service.

4. The sustainability and potential to improve access to the adult social care system.

\subsubsection{Backlog of elective care}

Our analysis suggests that delivering the constitutional standard of $92 \%$ of patients being treated within 18 weeks by the end of $2024 / 25$ would require $£ 4.2 \mathrm{bn}$ a year in additional funding between $2021 / 22$ and $2024 / 25$ ( $f 16.8 b n$ in total). This assumes that $75 \%$ of patients not referred for treatment during the pandemic return to seek treatment. The one-off (non-recurrent) cost of clearing the backlog corresponds to around $£ 3.9$ bn a year ( $£ 15.7 b n$ in total by $2024 / 25$ ) and there is an additional $£ 280$ $300 \mathrm{~m}$ a year (recurrent) to keep waiting lists at this level. There is a real question mark over the ability of the health service to treat sufficient patients over the next 4 years to meet this standard, even if funding were forthcoming. It would mean nearly 800,000 extra elective admissions a year on top of the $2.3 \%$ growth needed to keep pace with underlying demand.

Even if some of that capacity could be secured from the independent sector, it would require staff, beds and diagnostic capacity. Some of that capacity may also be needed for emergency care if there are significant ongoing outbreaks of COVID-19. If the backlog is cleared over a longer period and the policy goal is not to return to the constitutional standard - but rather to return to the waiting times in 2018/19 (87\% within 18 weeks) - then the additional funding for the remainder of this parliament would be around $£ 1$.8bn a year between 2021/22 and 2024/25 ( $€ 7.1 \mathrm{bn}$ in total over 4 years). This, however, would likely mean the waiting list remains high in 2024/25.

\subsubsection{Ongoing prevalence of COVID-19}

Experts anticipate that COVID-19 will move from a pandemic to an endemic disease, with epidemic wavelets diminishing over time. ${ }^{72}$ Our analysis assumes that there will be ongoing costs from the vaccine programme. We have also looked at some of the direct costs of treating COVID-19 and long COVID patients. However, the biggest impact of the pandemic on the NHS comes from the way care is delivered and organised.

During the pandemic, IPC measures and higher rates of staff absence meant more beds and staff (inputs) were needed to deliver the same or less activity (output). This can be thought of as a productivity shock. A crucial question facing the NHS is for how long and to what extent this will continue. We have examined a significant ongoing impact, equivalent to a $5 \%$ hit on NHS productivity. If COVID-19 has a continuing impact on this scale the additional cost would be $f 7-8 \mathrm{bn}$ a year between $2022 / 23$ and 2024/25. 
Table 19: Additional COVID-19 funding needed for NHS England (fbn, 2021/22 prices)

\begin{tabular}{|c|c|c|c|c|c|}
\hline & & $2021 / 22$ & $2022 / 23$ & $2023 / 24$ & $2024 / 25$ \\
\hline \multirow[t]{6}{*}{ Stabilisation } & NHS RDEL (Real terms) & 139.5 & 144.1 & 148.6 & 152.5 \\
\hline & \multicolumn{5}{|l|}{ Additional cost of a COVID-19 hit to productivity } \\
\hline & $1 \%$ & 1.4 & 1.4 & 1.5 & 1.5 \\
\hline & $3 \%$ & 4.2 & 4.3 & 4.5 & 4.6 \\
\hline & $5 \%$ & 7.0 & 7.2 & 7.4 & 7.6 \\
\hline & $10 \%$ & 14.0 & 14.4 & 14.9 & 15.3 \\
\hline \multirow[t]{6}{*}{ Recovery } & NHS RDEL (Real terms) & 142.5 & 147.2 & 152.4 & 157.6 \\
\hline & \multicolumn{5}{|l|}{ Additional cost of a COVID-19 hit to productivity } \\
\hline & $1 \%$ & 1.4 & 1.5 & 1.5 & 1.6 \\
\hline & $3 \%$ & 4.3 & 4.4 & 4.6 & 4.7 \\
\hline & $5 \%$ & 7.1 & 7.4 & 7.6 & 7.9 \\
\hline & $10 \%$ & 14.2 & 14.7 & 15.2 & 15.8 \\
\hline
\end{tabular}

Source: REAL Centre calculations.

\subsubsection{Hospital capacity}

We showed in chapter 2 how the NHS has fewer beds and staff per head of population than most other comparable countries across the EU and OECD. Before the pandemic, hospital bed occupancy rates were running at almost $90 \%$, with the NHS struggling to meet both the waiting times target for planned care and the 4-hour A\&E target. With so little capacity in the system, spikes in demand placed huge pressures on staff during 'normal' winter pressures, with consequences for access to care and quality. We do not yet know how the system will respond to the ongoing pressures of COVID-19.

As the NHS emerges from the pandemic, government faces key decisions about how close to capacity the NHS should run. In this analysis we look at the funding implications of different capacity assumptions; maintaining pre-pandemic occupancy rates, and operating at $85 \%$ bed occupancy as recommended in NICE guidance ${ }^{66}$ Reducing occupancy to $85 \%$ would add f1.6bn to the cost of delivering care in $2024 / 25$, rising to $f 2.4$ bn by $2030 / 31$.

\subsubsection{Social care}

Our scenarios suggest that this decade will see significant pressures (1.9\% a year) from demographic trends, notably an ageing population. The government faces decisions over the amount of funding it is prepared to commit to expand access to 
social care, support provider stability and reform the staffing model for both care homes and home care. Alongside this the number of people in receipt of publicly funded adult social care has been falling. This raises significant concerns about unmet need.

\subsubsection{Other budgets}

Our scenarios also see significant changes in other budgets. By 2030/31, DHSC CDEL will be about $£ 5.5 b n$ higher than in 2018/19 in the stabilisation scenario and £5.8bn higher under recovery. However, this near doubling of the capital budget may not be sufficient to achieve all the changes in capacity required under our scenarios. The public health grant would grow by $3.1 \%$ or $3.4 \%$ for stabilisation or recovery respectively, rising to more than $£ 5 b n$ in either scenario. This would allow for greater investment in preventative services and early intervention. In both scenarios, the budget for specialised services grows at $4.6 \%$ a year in real terms over 2018/19-2030/31, rising to more than $£ 29 \mathrm{bn}$.

\subsection{Comparison of scenarios}

Table 20 summarises our funding projections for NHS RDEL and social care in $2024 / 25$ and $2030 / 31$ and the associated average annual growth rates compared to $2018 / 19$ under both scenarios. In both our recovery and stabilisation scenarios, funding for health and social care will need to increase at a higher rate over the first half of the decade (to 2024/25) compared with the second half. Short to medium-term growth rates include the additional policy pressures, while longer term growth rates (up to 2030/31) reflect underlying pressures. 
Table 20: Funding projections for health and social care to $2030 / 31$

\begin{tabular}{|c|c|c|c|c|c|c|c|}
\hline & & $\begin{array}{l}\text { 2018/19 } \\
\text { (fbn) }\end{array}$ & $\begin{array}{l}2024 / 25 \\
\text { (fbn) }\end{array}$ & $\begin{array}{l}2030 / 31 \\
\text { (fbn) }\end{array}$ & $\begin{array}{l}(2018 / 19- \\
2024 / 25)\end{array}$ & $\begin{array}{l}(2024 / 25- \\
2030 / 31)\end{array}$ & $\begin{array}{l}(2018 / 19- \\
2030 / 31)\end{array}$ \\
\hline \multirow[t]{4}{*}{ Stabilisation } & $\begin{array}{l}\text { NHS RDEL } \\
\text { (Nominal) }\end{array}$ & 114.3 & 158.7 & 212.6 & & & \\
\hline & $\begin{array}{l}\text { NHS RDEL } \\
\text { (Real terms) }\end{array}$ & 123.3 & 152.5 & 178.6 & $3.6 \%$ & $2.7 \%$ & $3.1 \%$ \\
\hline & $\begin{array}{l}\text { Social care } \\
\text { (Nominal) }\end{array}$ & $\mathrm{n} / \mathrm{a}$ & 26.5 & 36.8 & & & \\
\hline & $\begin{array}{l}\text { Social care } \\
\text { (Real terms) }\end{array}$ & $\mathrm{n} / \mathrm{a}$ & 25.5 & 30.9 & $5.5 \%$ & $3.3 \%$ & $4.3 \%$ \\
\hline \multirow[t]{4}{*}{ Recovery } & $\begin{array}{l}\text { NHS RDEL } \\
\text { (Nominal) }\end{array}$ & 114.3 & 164.0 & 222.3 & & & \\
\hline & $\begin{array}{l}\text { NHS RDEL } \\
\text { (Real terms) }\end{array}$ & 123.3 & 157.6 & 186.8 & $4.2 \%$ & $2.9 \%$ & $3.5 \%$ \\
\hline & $\begin{array}{l}\text { Social care } \\
\text { (Nominal) }\end{array}$ & $\mathrm{n} / \mathrm{a}$ & 29.4 & 40.8 & & & \\
\hline & $\begin{array}{l}\text { Social care } \\
\text { (Real terms) }\end{array}$ & $\mathrm{n} / \mathrm{a}$ & 30.0 & 36.5 & $9.0 \%$ & $3.3 \%$ & $5.8 \%$ \\
\hline \multicolumn{5}{|c|}{ Long-term historical growth rate for health (1949/50-2019/20) } & $3.70 \%$ & & \\
\hline
\end{tabular}

Source: REAL Centre calculations.

Notes: NHS RDEL presented here excludes $£ 2.85 \mathrm{bn}$ for pensions. For social care modelling, the baseline year is 2019/20.

Table 20 shows the medium-term funding that would be required for core NHS England activity compared with spending plans from before the pandemic for $2021 / 22,2022 / 23,2023 / 24$ and 2024/25. Our analysis shows that the NHS will not be able to deliver the ambitions in the long term plan alongside making even modest inroads into the elective backlog within the current funding settlement, and would need a significant further increase in the last year of current parliament (2024/25).

For day-to-day NHS spending (NHS RDEL) our projections imply the following above the long term plan (2021/22 prices) (Table 21):

- Under stabilisation: an additional $£ 4.7 \mathrm{bn}$ in $2021 / 22, £ 4.0 \mathrm{bn}$ in $2022 / 23$ and £2.9bn in $2023 / 24$.

- Under recovery: an additional f7.7bn in $2021 / 22$, $f 7.1 \mathrm{bn}$ in $2022 / 23$ and $\mathrm{f} 6.7 \mathrm{bn}$ in $2023 / 24$.

- In $2024 / 25$, NHS RDEL would need to be $£ 153 b n$ in stabilisation and $£ 158 b n$ in recovery.

And this is without accounting for any additional impacts from COVID-19 on productivity; every $1 \%$ impact on productivity from COVID-19 would require around f1.5bn in additional funding (a $5 \%$ impact requires $f 7-8 \mathrm{bn}$ ). The potential level 
of additional funding required therefore depends on both the speed at which the government seeks to reduce the elective care backlog and the ongoing impact of COVID-19 on the delivery of care.

In $2024 / 25$, funding needs to grow at $2.7 \%$ under stabilisation and $3.5 \%$ in recovery. However, this is contingent on progress against the backlog starting in 2021/22. Any delay would mean the additional funding needed in subsequent years is higher.

Table 21: Funding projections for health care (fbn)

\begin{tabular}{llllll}
\hline & & $\mathbf{2 0 2 1 / 2 2}$ & $\mathbf{2 0 2 2 / 2 3}$ & $\mathbf{2 0 2 3 / 2 4}$ & $\mathbf{2 0 2 4 / 2 5}$ \\
\hline \multirow{2}{*}{ NHS Long Term Plan } & NHS RDEL (Nominal) & 134.8 & 140.0 & 148.5 & n/a \\
\cline { 2 - 6 } & NHS RDEL (Real terms) & 134.8 & 140.1 & 145.6 & n/a \\
\cline { 2 - 6 } & Annual real-terms growth & $6.7 \%$ & $5.1 \%$ & $3.9 \%$ & n/a \\
\hline \multirow{2}{*}{ Stabilisation } & NHS RDEL (Nominal) & 139.5 & 143.9 & 151.4 & 158.7 \\
\cline { 2 - 6 } & NHS RDEL (Real terms) & 139.5 & 144.1 & 148.6 & 152.5 \\
\cline { 2 - 6 } & Annual real-terms growth & $7.0 \%$ & $3.3 \%$ & $3.1 \%$ & $2.7 \%$ \\
\cline { 2 - 6 } Recovery & Difference (fbn) & 4.7 & 4.0 & 2.9 & $\mathrm{n} / \mathrm{a}$ \\
\hline & NHS RDEL (Nominal) & 142.5 & 147.0 & 155.2 & 164.0 \\
\cline { 2 - 6 } & NHS RDEL (Real terms) & 142.5 & 147.2 & 152.4 & 157.6 \\
\cline { 2 - 6 } & Annual real-terms growth & $9.5 \%$ & $3.3 \%$ & $3.5 \%$ & $3.5 \%$ \\
\cline { 2 - 6 } & Difference (fbn) & 7.7 & 7.1 & 6.7 & $\mathrm{n} / \mathrm{a}$ \\
\hline
\end{tabular}

Source: REAL Centre calculations.

Notes: Annual real-term growth rates are relative to the previous year. NHS RDEL excludes $£ 2.85 \mathrm{bn}$ for pensions; NHS Long Term Plan funding includes an additional $£ 1$ bn for elective backlog and $£ 500 \mathrm{~m}$ for mental health as part of the COVID-19 response.

A substantial increase in adult social care funding is required to expand access to care, pay enough for care to sustain the provider sector and pay higher wages. These increases are comparable to, or exceed, the funding needs of the NHS - and to some extent reflect a decade of underfunding compared with the NHS.

The level of funding needed is sensitive to how quickly access can be expanded under the stabilisation and recovery scenarios. Table 22 shows this happening in $2021 / 22$, but in practice this objective would likely be smoothed over a few years. Funding would need to be approximately $25 \%$ ( $£ 4.8 \mathrm{bn}$ ) to $50 \%$ ( $£ 9.9 \mathrm{bn}$ ) higher in real terms by $2024 / 45$ under the stabilisation and recovery scenarios respectively. In addition, this analysis assumes no productivity improvements in the sector, nor any additional costs associated with COVID-19 (eg PPE). 
Table 22: Funding projections for social care (fbn)

\begin{tabular}{llllll}
\hline & & $\mathbf{2 0 2 1 / 2 2}$ & $\mathbf{2 0 2 2 / 2 3}$ & $\mathbf{2 0 2 3 / 2 4}$ & $\mathbf{2 0 2 4 / 2 5}$ \\
\hline $\begin{array}{l}\text { Current spending } \\
\text { power (excluding one- } \\
\text { off COVID-19 funding) }\end{array}$ & fbn & 20.1 & 20.3 & 20.5 & 20.7 \\
\cline { 2 - 6 } & Annual real-terms growth rate & $0.6 \%$ & $0.9 \%$ & $1.1 \%$ & $1.0 \%$ \\
\hline Stabilisation & fbn & 23.1 & 24.0 & 24.7 & 25.5 \\
\cline { 2 - 6 } & $\begin{array}{l}\text { Additional funding (compared to } \\
\text { current spending power, fbn) }\end{array}$ & 3.0 & 3.7 & 4.2 & 4.8 \\
\cline { 2 - 6 } & Annual real-terms growth rate & $8.6 \%$ & $3.6 \%$ & $3.2 \%$ & $3.2 \%$ \\
\hline \multirow{2}{*}{ Recovery } & fbn & 27.2 & 28.2 & 29.1 & 30.0 \\
\cline { 2 - 6 } & $\begin{array}{l}\text { Additional funding (compared with } \\
\text { current spending power, fbn) }\end{array}$ & 7.1 & 7.9 & 8.6 & 9.3 \\
\cline { 2 - 6 } & $\begin{array}{l}\text { Annual real-terms growth rate } \\
\text { Ann }\end{array}$ & $17.4 \% *$ & $3.6 \%$ & $3.2 \%$ & $3.2 \%$ \\
\hline
\end{tabular}

Source: REAL Centre calculations.

Notes: Annual real term growth rates are relative to the previous year. Figures are for England. ${ }^{*}$ Fast increase in 2021/22 is driven by the projected increase in social care package and staff pay.

The level of NHS funding growth in the second half of this decade remains below the historical average rate of spending growth under both the stabilisation and recovery scenarios. This may appear surprising given the short-term funding demands from COVID-19 and the legacy of backlogs and underlying activity pressures. The reasons for this are threefold:

The impact of the pandemic on the wider economy means that the OBR now expects earnings across the economy as a whole to grow at a slower rate than it forecast before the pandemic. The forecast for whole economy earnings growth over this decade is now an average increase of $1.3 \%$ a year above the GDP deflator measure of inflation. In 2018 the OBR forecast real earnings growth of $1.7 \%$ a year. This feeds through into the projected spending pressures, as we assume that over the decade health service earnings growth will be influenced by earnings across the economy. In our recovery scenario we explore the impact of higher earnings growth in part to attract and retain more of the staff needed to expand capacity, but we match this with higher productivity. All of this is highly uncertain. If the economy rebounds strongly and there is strong earnings growth, the funding pressures facing the NHS and care system will be much higher.

Many of the costs associated with the legacy of COVID-19 are borne early in this decade, and so the level of spending to 2025 would be higher than previously planned. After 2025 our modelling assumes most of those costs (eg from reduced bed occupancy rates) have been incurred.

The projections modelled explore the funding implications of meeting the underlying demand pressures, the existing commitments in the long term plan and the legacy of COVID-19. They do not consider further policy ambitions to improve or modernise the NHS. It is very unlikely that in $2030 / 31$ the ambitions for quality and access to care will be the same as in $2018 / 19$. One obvious example is in relation 
to mental health. Even after the improvements set out in the long term plan, many people will not have timely access to mental health services. If government wants to go beyond the commitments of the long term plan and make further improvements to the service, more funding will be needed.

COVID-19's economic legacy has an impact on the share of national wealth that would be spend on health and social care in response to rising funding pressures. Funding for the NHS and social care system over the next decade would grow faster than the OBR's forecast for economic growth. Table 23 shows that funding increases in line with these scenarios would see health and social care spending as a share of GDP increase.

Table 23: Health and social care spending as a share of GDP - 2018/19 and projected

\begin{tabular}{llll}
\hline fbn (2018/19 prices) & $\begin{array}{l}\text { Functional spending on } \\
\text { health (UK) }\end{array}$ & $\begin{array}{l}\text { System of Health } \\
\text { Accounts (UK) }\end{array}$ & \% of GDP \\
\hline $\mathbf{2 0 1 8 / 1 9}$ & 149 & 169 & $7.8 \%$ \\
\hline $\mathbf{2 0 3 0 / 3 1}$ projections & & & \\
\hline Stabilisation & 218 & 260 & $9.8 \%$ \\
\hline Recovery & 228 & 270 & $10.2 \%$ \\
\hline OECD projection for UK & & & $8.8 \%$ \\
\hline
\end{tabular}

Source: REAL Centre calculations; OECD, Health Spending Projections to 2040 (unpublished).

Under both scenarios, the share of national income required to meet the funding needs for the UK would be in the range of $10 \%$ by $2030 / 31$. This is an increase of more than 2 percentage points against the 2018/19 baseline. This is similar to the levels projected by the OECD for France, Germany, Sweden and Norway, and above the projection for the UK (8.8\%). 


\subsection{Workforce}

The implied increase in the workforce for both the NHS and social care is shown in Table 24. By $2030 / 31$, an estimated 488,000 full-time equivalent NHS staff would be needed and 627,000 adult social care staff, totalling 1,115,000 additional full-time equivalent staff across health and social care.

Table 24: Increase in the NHS and social care workforces

\begin{tabular}{|c|c|c|c|c|c|c|c|c|}
\hline Area & 2018/19 & $2024 / 25$ & $\begin{array}{l}\text { Extra } \\
\text { FTE }\end{array}$ & $\%$ change & $2030 / 31$ & $\begin{array}{l}\text { Extra } \\
\text { FTE }\end{array}$ & $\%$ change & $\begin{array}{l}\text { CAGR } \\
(2018 / 19- \\
2030 / 31)\end{array}$ \\
\hline Health care & $1,225,000$ & $1,500,000$ & 275,000 & $22 \%$ & $1,713,000$ & 488,000 & $40 \%$ & $2.8 \%$ \\
\hline \multicolumn{9}{|l|}{ Of which: } \\
\hline Doctors & 147,000 & 180,000 & 34,000 & $23 \%$ & 205,000 & 59,000 & $40 \%$ & $2.8 \%$ \\
\hline Nurses & 306,000 & 375,000 & 69,000 & $22 \%$ & 429,000 & 122,000 & $40 \%$ & $2.8 \%$ \\
\hline Social care & $1,130,000$ & $1,447,000$ & 317,000 & $28 \%$ & $1,757,000$ & 627,000 & $55 \%$ & $3.7 \%$ \\
\hline \multicolumn{9}{|l|}{ Of which: } \\
\hline $\begin{array}{l}\text { Local } \\
\text { authority }\end{array}$ & 92,000 & 117,000 & 26,000 & $28 \%$ & 143,000 & 51,000 & $55 \%$ & $3.7 \%$ \\
\hline
\end{tabular}

Source: REAL Centre calculations.

* Note: doctors and nurses include both acute staff and those in primary care. Numbers may not sum up due to rounding.

Staffing shortages will be a constraint in both the NHS and social care if COVID-19 remains a significant and enduring pressure. If services cannot recruit sufficient staff to meet these activity pressures, the access to care will bear the brunt of the impact and waiting lists and times would continue to grow. There is also an obvious risk of further negative feedback loops that impact on capacity, ie the impact on staff if COVID-19 remains such an enduring significant pressure would be considerable. There is a real risk that staff may leave, reducing retention rates and adding to vacancies.

\subsection{Implications for the balance of spend}

Our projections for health and social care imply some continuation of previous trends but also some important changes. Over many years NHS funding has grown at a faster rate than social care funding. This analysis suggests that given the pressures on social care to address unmet need and substantial staffing challenges, social care funding will need to outpace health service funding. These estimates do not include the cost of policy changes to the balance of funding between individuals and the state, such as imposing a cap on catastrophic care costs as 
recommended by the Dilnot Commission. The cost of introducing a Dilnot-style cap - with lifetime costs capped at $£ 46,000$ before the state pays - would be around £3.1bn a year by $2023 / 24 .{ }^{73}$

Our projection of underlying activity growth is higher than in the past decade $1.7 \%$ compared with $1.4 \%$ a year), but the pattern of growth between the two decades is very similar. The past decade saw inpatient activity increase at a faster rate than primary care while community services activity fell. The main exception to this pattern is for IAPT services, which grew by $16.6 \%$ a year.

All of our projections imply that hospitals' share of total health care spending will increase over the decade. In part, this reflects the funding required to meet the waiting lists backlog, currently at a record high, and the need for a more resilient service with lower bed occupancy. However, this is not the whole story as underlying demand and cost pressures, combined with the current model of care, would also result in higher growth in the acute sector. The projections do not suggest this is the optimal model of care but rather highlight how, under the existing model of care, demand pressures could manifest. The higher growth is driven by the ageing population, rising number of deaths (as the numbers of older people increase with the baby boomer population 'bulge') and the increasing number of people with multiple long-term conditions.

It has long been a policy ambition to rebalance care towards primary and community services, with funding ringfenced in the long term plan. Our modelling suggests that the underlying pressures on acute services remain as strong as ever. The experience of the past decade also indicates it is very challenging to fundamentally shift the balance of care away from acute hospitals and towards provision in the community and primary care.

\subsection{Conclusion}

Our analysis suggests that the underlying demand and cost pressures facing the NHS will rise at a fast rate than the economy over the coming decade. While ageing plays a part in driving funding needs, it is clear that the pattern of chronic disease and the NHS response to it is an even bigger factor.

To an extent, these underlying pressures were anticipated in the NHS Long Term Plan. COVID-19, however, was not. We find the legacy of the pandemic will add significantly to funding pressures over the rest of this parliament. Meeting these pressures would mean the government increasing the NHS England budget by at least $£ 3$ bn a year over and above planned funding growth from the long term plan. It would also mean a further significant increase in 2024/25.

The funding pressures for health care for the second half of this decade are much more uncertain. They depend critically on pay, productivity and policy ambitions for improvements to the range and quality of care the NHS can provide. 
Finally, COVID-19-related pressures are not the only area in which our projections suggest the next few years need to be different: the pressures currently facing social care are even greater than those facing the NHS. Our analysis would suggest that to meet these pressures, social care funding needs to increase over the next decade at a higher rate than NHS funding. If this were to happen it would mark a major break with the past. 


\section{Glossary}

Additional funding pressures: these are pressures arising from policy choices, which may respond to population expectations around provision and the quality of health care. These could encompass funding commitments, such as those implied by the long term plan or those devoted to address the direct impact from COVID-19.

Barnett formula: a mechanism used by theTreasury to calculate changes in the annual budgets of the devolved administrations - the 'block grants' - based on changes in spending on public services in England. The formula is mainly used at spending reviews, where the Treasury set the departments' budgets. The outcome from the calculation is often known as the 'Barnett consequential'. The Treasury calculate the Barnett consequentials for each department, and these are then summed to come up with changes in the block grants.

Capital spending: money spent on investment, that is formation and acquisition of capital contributing to productivity.

CDEL: Capital DEL is part of the total DEL spent on new investment and financial transactions. It includes items such as spending on new assets, capital grants to the private sector, net policy lending to the private sector or R\&D spending. This aggregate also includes capital grants to local authorities.

Current or resource spending: spending on items that are consumed in the process of providing public services or, in other words, recurring spending. This includes, for example, wages and salaries, benefits, and purchasing goods and services.

Depreciation: includes impairments and the release of donated assets and government grant reserves.

Functional spending: spending allocated to a particular socioeconomic function, according to the Classification of the Functions of Government (COFOG).

Health spending according to System of Health Accounts (SHA)/OECD: the headline aggregate is current health spending, which refers to final consumption or demand for health care goods and services by households, government and nonprofit institutions.

Health-related long term care: this is part of long term care spending and is included within the measure total current health care expenditure recognised by the SHA. It relates to medical or nursing care (eg wound dressing, administering medication, health counselling, palliative care, and medical diagnosis with relation to a LTC condition), and personal care services that provide help with activities of daily living, such as support with food intake, bathing, washing, dressing. 
Identifiable spending: spending that can be identified as benefitting individuals, enterprises, or communities within specific regions. Examples include health, education and social protection. Examples of non-identifiable spending are defence, overseas representation, tax collection and debt interest.

Long term care according to SHA: this accounts for services aimed at managing chronic health conditions related to long-term care dependency (including old-age and disability-related conditions) and reducing suffering where an improvement in health is not expected. The OECD split total long term care expenditure into health-related long term care (which is included within the measure total current health care expenditure recognised by the SHA) and social long term care (which sits outside the definition of current health care spending used in the SHA or by the OECD).

RDEL: resource DEL is part of the total DEL that is spent on day-to-day resources and administration costs. It captures current expenditure (including depreciation, which is the current cost associated with fixed assets). This aggregate also includes current grants to local authorities.

Social long term care: this is part of long term care spending that sits outside the definition of current health care spending used in the SHA or by the OECD. It consists of assistance services that enable a person to live independently, such as shopping, cooking and managing finances.

TDEL:Total Departmental Expenditure Limit represents the amount each department has been allocated to spend. This spending is subject to limits, set in the Spending Review, and departments may not exceed these. TDEL is split into RDEL excluding depreciation and CDEL budgets. These also include the Arm's Length Bodies (ALB) resource consumption and capital expenditure, in the same way as the department's own expenditure. Grants made available by each department to ALB are outside their budget.

- $\quad$ CDEL makes up around $6 \%$ of the total. CDEL spending reached $f 7 \mathrm{bn}$ in $2019 / 20,64 \%$ of which was spent by NHS providers. $36 \%$ of CDEL was spent on land and buildings.

- $\quad$ RDEL makes up around 94\% of the total and this share has remained unchanged since the financial crisis. As of 2019/20, the biggest item of RDEL spending* $^{*}$ is NHS provider staff costs ( $42 \%$ of the total, or $£ 61 \mathrm{bn}$ ), followed by procurement ( $17 \%$ of the total, or $£ 24 \mathrm{bn}) .^{74}$

Underlying funding pressures: demand and supply factors that drive health and social care expenditure. These include the size and age structure of the population, changes in ill health or morbidity, but also pay, the cost of technologies and productivity.

The DHSC group, including NHS England and other bodies, received around $f 11 \mathrm{bn}$ of RDEL income in 2019/20 from varying sources. This was mainly received by NHS providers and included prescribing and dental charges, trading with local authorities and income from treating private patients. RDEL figures exclude depreciation. These percentage figures are gross of income received by the NHS. 


\section{References}

1. OBR. Fiscal risks report - July 2021. OBR; 2021 (https://obr.uk/docs/dlm_uploads/Fiscal_risks_report_ July_2021.pdf).

2. The King's Fund. Activity in the NHS [webpage]. The King's Fund; 2020 (https://www.kingsfund.org.uk/ projects/nhs-in-a-nutshell/NHS-activity\#: :text=In\%20total\%20there\%20were\%20an,interactions $\% 20$ with\%20patients\%20every\%20day).

3. Curtice J, Hudson N and Montagu I (eds.). British Social Attitudes: The 37th Report. The National Centre for Social Research; 2020 (https://bsa.natcen.ac.uk/media/39399/bsa37_key-time-series.pdf).

4. NHS Digital. Adult Social Care Finance Return 2019-20. ASCFR and SALT reference tables (table 40) (https://digital.nhs.uk/data-and-information/publications/statistical/adult-social-care-activity-and-financereport/2019-20).

5. Department for Work and Pensions. Family Resources Survey: financial year 2019 to 2020 (section 6). Department for Work and Pensions; 2021 (https://www.gov.uk/government/statistics/family-resourcessurvey-financial-year-2019-to-2020/family-resources-survey-financial-year-2019-to-2020\#care-1).

6. Cameron G, Dixon J and Alderwick H. How can policymakers plan better for the long term? The Health Foundation; 2021 (https://www.health.org.uk/publications/long-reads/how-can-policymakers-plan-betterfor-the-long-term). NHS. NHS Long Term Plan. NHS; 2019 (https://www.longtermplan.nhs.uk/publication/nhs-long-term-plan/).

8. Charlesworth A, Johnson P, Firth Z, Gershlick B, WattT, Kelly E, Roberts A, Lee T, Stoye G, Zarenko B. Securing the future: funding health and social care to the 2030s. The Health Foundation; 2018 (https://www. health.org.uk/publications/reports/securing-the-future-funding-health-and-social-care-to-the-2030s).

9. Department of Health. NHS Constitution for England. Department of Health; March 2012, updated October 2015 (https://www.gov.uk/government/publications/the-nhs-constitution-for-england).

10. Ministry of Housing, Communities and Local Government. Local authority revenue expenditure and financing England: 2021 to 2022 budget. Ministry of Housing, Communities and Local Government; 2021 (https://www.gov.uk/government/statistics/local-authority-revenue-expenditure-and-financing-england2021-to-2022-budget).

11. Department of Health and Social Care. $f 7$ billion for NHS and social care for COVID-19 response and recovery [webpage]. Department of Health and Social Care; 2021 (https://www.gov.uk/government/ news/7billion-for-nhs-and-social-care-for-covid-19-response-and-recovery).

12. National Audit Office. COVID-19 cost tracker [webpage]. National Audit Office; 2021 (https://www.nao.org uk/covid-19/cost-tracker/).

13. HMTreasury. Public Expenditure Statistical Analyses 2021. HMTreasury; 2021 (https://www.gov.uk/ government/statistics/public-expenditure-statistical-analyses-2021).

14. HMTreasury. Supplementary Estimates 2020-21. HMTreasury; 2021 (https://www.gov.uk/government/ publications/supplementary-estimates-2020-21).

15. IMF Fiscal Affairs Department. Fiscal Monitor Database of Country Fiscal Measures in Response to the COVID-19 Pandemic [webpage]. IMF; 2021 (https://www.imf.org/en/Topics/imf-and-covid19/Fiscal-PoliciesDatabase-in-Response-to-COVID-19).

16. Department of Health and Social Care. The Government's 2021-22 mandate to NHS England and NHS Improvement. Department of Health and Social Care; 2021 (https://assets.publishing.service.gov.uk/ government/uploads/system/uploads/attachment_data/file/972947/The_government_s_2021_to_2022_ mandate_to_NHS_England_and_NHS_Improvement.pdf).

17. NHS Digital. Adult Social Care Activity and Finance Report, England-2019-20. NHS Digital; 2020 (https:// digital.nhs.uk/data-and-information/publications/statistical/adult-social-care-activity-and-financereport/2019-20).

18. Department of Health and Social Care. Adult social care given over $£ 250$ million extra to continue coronavirus (COVID-19) protections [webpage]. Department of Health and Social Care; 2021 (https://www. gov.uk/government/news/adult-social-care-given-over-250-million-extra-to-continue-coronavirus-covid-19protections).

19. OECD. OECD Health Statistics 2021 [webpage]. OECD; 2021 (https://www.oecd.org/els/health-systems/ health-data.htm).

20. OECD. Health at a glance 2019. OECD Indicators. OECD; 2019 (https://www.oecd.org/health/health-systems/ health-at-a-glance-19991312.htm). 
Licchetta M, Stelmach, M. Fiscal sustainability analytical paper: Fiscal sustainability and public spending on health. OBR; 2016 (https://obr.uk/fiscal-sustainability-analytical-paper-published-today/).

OBR. Drivers of rising health spending [webpage]. OBR; 2015 (http://obr.uk/box/drivers-of-rising-healthspending/).

Chapter 1 of OECD, Fiscal Sustainability of Health Systems: Bridging Health and Finance Perspectives. OECD Publishing; 2015.

OECD, European Observatory. United Kingdom: Country Health Profile 2019, State of Health in the EU. OECD Publishing; 2019 (https://ec.europa.eu/health/sites/default/files/state/docs/2019_chp_uk_english.pdf).

23. Greener I. Healthcare funding and its relationship to equity and outcomes: a QCA analysis of Commonwealth Fund and OECD data. Journal of European Social Policy. 2020; 30: 480-494.

24. Idriss O, Tallack C, Shembavnekar N, Carter M. Social care funding gap: Our estimates of what it would cost to stabilise and improve adult social care in England. The Health Foundation; 2021 (https://www. health.org.uk/news-and-comment/charts-and-infographics/REAL-social-care-funding-gap).

25. Hu B, Hancock R, Wittenberg, R. Projections of Adult Social Care Demand and Expenditure 2018 to 2038. CPEC; 2020 (https://www.Ise.ac.uk/cpec/assets/documents/cpec-working-paper-7.pdf).

26. See for instance:

Howdon D, Rice N. Health care expenditures, age, proximity to death and morbidity: Implications for an ageing population. Journal of Health Economics. 2018; 57: 60-74.

De Meijer C, Koopmanschap M, D’UvaTB, Van Doorslaer E. Determinants of long-term care spending: Age, time to death or disability? Journal of Health Economics. 2011; 30: 425-438.

Zweifel P, Felder S, Meiers M. Ageing of population and health care expenditure: a red herring? Health Economics. 1999; 8: 485-496.

27. Jayatunga W, Lewer D, Shand J, Sheringham J, Morris S, George J. Health and social care costs at the end of life: a matched analysis of linked patient records in East London. Age and Ageing. 2020; 49: 82-87.

28. ONS. Health state life expectancies, UK: 2016 to 2018. ONS; 2019 (https://www.ons.gov.uk/ peoplepopulationandcommunity/healthandsocialcare/healthandlifeexpectancies/bulletins/ healthstatelifeexpectanciesuk/2016to2018).

29. Rice N and Aragón MJ. Publicly funded hospital care: expenditure growth and its determinants. CHE Research Paper, no. 177. Centre for Health Economics, University ofYork; 2021 (https://www.york.ac.uk/ media/che/documents/papers/researchpapers/CHERP177_funded_hospital_expenditure_growth.pdf).

30. Baumol W, De Ferranti D, Malach M, Pablos-Méndez A, Tabish H, Wu LG. The Cost Disease: Why computers get cheaper and health care doesn't. Yale University Press; 2012.

31. NHS Digital. Prescribing Costs in Hospitals and the Community. NHS Digital; 2020 (https://digital.nhs.uk/ data-and-information/publications/statistical/prescribing-costs-in-hospitals-and-the-community).

32. Ewbank L, Sullivan K, McKenna H, Omojomolo D. The rising costs of medicines to the NHS: what's the story? The King's Fund; 2018 (https://www.kingsfund.org.uk/publications/rising-cost-medicines-nhs).

33. European Commission. The 2015 Ageing Report: Economic and budgetary projections for the 28 EU member states (2013-2060). European Commission; 2015 (https://ec.europa.eu/economy_finance/ publications/european_economy/2015/pdf/ee3_en.pdf). (See p120.)

34. Mason A, Rodriguez Santana I, Aragón MJ, Rice N, Chalkley M, Wittenberg R, Fernandez JL. Drivers of health care expenditure: final report. CHE Research Paper, no. 169. Centre for Health Economics, University ofYork; 2019.

35. OBR. Drivers of rising health spending [webpage]. OBR; 2015 (http://obr.uk/box/drivers-of-rising-healthspending/).

36. Crofts S. What could the impact of COVID-19 be on UK demography? [webpage]. ONS; 2020 (https://blog ons.gov.uk/2020/12/07/what-could-the-impact-of-covid-19-be-on-uk-demography/).

37. Adams J, Curry C, Espuny-Pujol F, Hancock R, Hu B, King D, Luheshi S, Morciano M, PikeT, Popat S, Witternberg R. State pension and long-term care funding reforms: the costs and distributional effects of alternative uprating policies: technical report. Pension Policy Institute; 2016.

38. Emerson EB, Robertson JM, Coles B, Hatton CR. Estimating the need for social care services for adults with disabilities in England 2012-2030. Centre for Disability Research, Lancaster University; 2012 (https:// eprints.Iancs.ac.uk/id/eprint/129308/1/Emerson_NIHR_SSCR_Final_Report.pdf).

39. Personal Social Services Research Unit. 2019 Unit Costs of Health and Social Care [webpage]. Personal Social Services Research Unit; 2019 (https://www.pssru.ac.uk/project-pages/unit-costs/unit-costs-2019/).

40. OBR. Long-term economic determinants - March 2021 Economic and Fiscal Outlook. OBR; 2021 (https:// obr.uk/efo/economic-and-fiscal-outlook-march-2021/).

41. ONS. Public service productivity estimates: healthcare, England [webpage]. ONS; 2021 (https:// www.ons.gov.uk/economy/economicoutputandproductivity/publicservicesproductivity/datasets/ publicserviceproductivityestimateshealthcareengland).

42. OBR. Economic and Fiscal Outlook-March 2020. OBR; 2020 (https://obr.uk/efo/economic-and-fiscal-outlookmarch-2020/). 
43. Coyle D, Dreesbeimdieck K, Manley A. Productivity in UK healthcare during and after the Covid-19 pandemic. The Productivity Institute; 2021 (https://www.alliancembs.manchester.ac.uk/media/ambs/ content-assets/documents/productivity/health-productivity-diane-coyle.pdf).

44. Department of Health and Social Care. Most vulnerable could be offered booster COVID-19 vaccines from September. Department of Health and Social Care; 2021 (https://www.gov.uk/government/news/ most-vulnerable-could-be-offered-booster-covid-19-vaccines-from-september\#: :text=Millions \%20of\%20 people\%20most\%20vulnerable,Vaccination\%20and\%20Immunisation\%20(\%20JCVI\%20).

45. Roxby P. Covid: NHS plans booster jab for those 50 and over before winter. BBC News; 1 July 2021 (https:// www.bbc.co.uk/news/health-57667987).

46. Walker JL, Grint DJ, Strongman H, Eggo RM, Peppa M, Minassian C, Mansfield KE, Rentsch CT, Douglas IJ, Mathur R, Wong AYS, Quint JK, Andrews N, Lopez Bernal J, Scott JA, Ramsay M, Smeeth L, McDonald HI. UK prevalence of underlying conditions which increase the risk of severe COVID-19 disease: a point prevalence study using electronic health records. BMC Public Health. 2021; 21: 484. (https:// bmcpublichealth.biomedcentral.com/articles/10.1186/s12889-021-10427-2). (See Table 3: Estimated size of the 2019 UK at-risk population according to national guidance.)

47. Institute for Government. Coronavirus vaccine rollout. Institute for Government; 2021 (https://www. instituteforgovernment.org.uk/explainers/coronavirus-vaccine-rollout).

48. National Audit Office. The supply of personal protective equipment (PPE) during the COVID-19 pandemic National Audit Office; 2020 (https://www.nao.org.uk/wp-content/uploads/2020/11/The-supply-of-personalprotective-equipment-PPE-during-the-COVID-19-pandemic.pdf).

49. Suleman M, Sonthalia S, Webb C, Tinson A, Kane M, Bunbury S, Finch D, Bibby J. Unequal pandemic, fairer recovery. The COVID-19 impact inquiry report. The Health Foundation; 2021 (https://doi.org/10.37829/ HF-2021-HL12).

50. ONS. Coronavirus and contributors to subnational well-being [webpage]. ONS; 2021 (https://www.ons.gov.uk/peoplepopulationandcommunity/wellbeing/bulletins/ coronavirusandcontributorstosubnationalwellbeing/januarytomarch2021).

51. The Strategy Unit. Mental Health Surge model [webpage]. The Strategy Unit; 2020 (https://www. strategyunitwm.nhs.uk/mental-health-surge-model).

52. NHS England. NHS Long Term Plan Implementation Framework. NHS England; 2019 (https://www. longtermplan.nhs.uk/implementation-framework/).

See also: NHS England and NHS Improvement. Fair Shares - A guide to NHS allocations for an estimation of the proportion of CCG core services allocation spent on community services. NHS England and NHS Improvement; 2020 (https://allcatsrgrey.org.uk/wp/download/commissioning/nhs-alocations-infographicsfeb-2020.pdf).

53. NHS England. Investment in General Practice, 2015/16 to 2019/20. NHS England; 2021 (https://www. england.nhs.uk/publication/investment-in-general-practice-in-england-2015-16-to-2019-20/). (SeeTable 1.)

54. NHS England. NHS Mental Health Implementation Plan 2019/20-2023/24. NHS England; 2019 (https://www. longtermplan.nhs.uk/publication/nhs-mental-health-implementation-plan-2019-20-2023-24/).

55. Charlesworth A, Watt T, GardnerT. Returning NHS waiting times to 18 weeks for routine treatment. The Health Foundation; 2020 (https://www.health.org.uk/publications/long-reads/returning-nhs-waiting-timesto-18-weeks).

56. NHS England. Consultant-led Referral to Treatment Waiting Times. Data 2021-22. NHS England; 2021 (https://www.england.nhs.uk/statistics/statistical-work-areas/rtt-waiting-times/rtt-data-2021-22/).

57. GardnerT, Fraser C. Longer waits, missing patients and catching up. How is elective care in England coping with the continuing impact of COVID-19? The Health Foundation; 2021 (https://www.health.org.uk/ news-and-comment/charts-and-infographics/how-is-elective-care-coping-with-the-continuing-impact-ofcovid-19).

58. Findlay R. Revealed:The cost of restoring 18-week waits. Health Service Journal; 2017 (https://www.hsj. co.uk/finance-and-efficiency/revealed-the-cost-of-restoring-18-week-waits/7021025.article).

59. NHS England. Consultant-led Referral to Treatment Waiting Times. NHS England; 2021 (https://www. england.nhs.uk/statistics/statistical-work-areas/rtt-waiting-times/).

60. REAL Centre. Nurse supply model. Projecting the future nursing workforce supply in England [webpage]. Health Foundation; 2021 (https://www.health.org.uk/what-we-do/real-centre/nurse-supply-model).

61. Krelle H, Barclay C, Tallack C. Waiting for care: Understanding the pandemic's effects on people's health and quality of life. The Health Foundation; 2021 (https://www.health.org.uk/publications/long-reads/ waiting-for-care).

62. Paling S, Lambert J, Clouting J, González-Esquerré J, Auterson T. Waiting times in emergency departments: exploring the factors associated with longer patient waits for emergency care in England using routinely collected daily data. Emergency Medicine Journal. 2020; 37:781-786.

63. Roberts R. Winter is coming: How much would it cost to keep the pressure down? The Health Foundation; 2017 (https://www.health.org.uk/blogs/winter-is-coming-how-much-would-it-cost-to-keep-the-pressuredown).

64. NuffieldTrust. A\&E waiting times. NuffieldTrust; 2021 (https://www.nuffieldtrust.org.uk/resource/a-ewaiting-times\#background). 
65. NICE. Chapter 39 Bed occupancy. Emergency and acute medical care in over 16s: service delivery and organisation. NICE guideline 94. NICE; 2018 (https://www.nice.org.uk/guidance/ng94/evidence/39.bedoccupancy-pdf-172397464704).

66. National Audit Office. Emergency admissions to hospitals: Managing the demand. National Audit Office; 2013 (https://www.nao.org.uk/wp-content/uploads/2013/10/10288-001-Emergency-admissions.pdf).

67. REAL Centre. Annex: Methodology for calculating adult social care funding gap estimates. The Health Foundation; 2021 (https://www.health.org.uk/sites/default/files/2021-02/20210210_adult_social_care_ funding_gap_technical_annex.pdf).

68. NHS England. Specialised services [webpage] NHS England; no date (https://www.england.nhs.uk/ commissioning/spec-services/).

69. Hu B, Hancock R, Wittenberg, R. Projections of Adult Social Care Demand and Expenditure 2018 to 2038. CPEC; 2020 (https://www.Ise.ac.uk/cpec/assets/documents/cpec-working-paper-7.pdf). (See Box 1: Key assumptions of the base case of the CPEC model.)

70. MayT. PM speech on the NHS: 18 June 2018 [webpage]. UK government, 2018 (https://www.gov.uk/ government/speeches/pm-speech-on-the-nhs-18-june-2018).

71. Thorlby R, GardnerT, Everest G, Allen L, Shembavnekar N, Alderwick H, et al. The NHS Long Term Plan and COVID-19: Assessing progress and the pandemic's impact. The Health Foundation; 2021 (https://doi. org/10.37829/HF-2021-P08).

72. Telenti A, Arvin A, Corey L, et al. After the pandemic: perspectives on the future trajectory of COVID-19. Nature. 596, 495-504; 2021 (https://doi.org/10.1038/s41586-021-03792-w).

73. Charlesworth A, Tallack C, Alderwick H. If not now, when? The long overdue promise of social care reform. The Health Foundation; 2021 (https://health.org.uk/news-and-comment/blogs/if-not-now-when-the-longoverdue-promise-of-social-care-reform).

74. Department of Health and Social Care. DHSC annual report and accounts: 2019 to 2020. Department of Health and Social Care; 2021 (https://www.gov.uk/government/publications/dhsc-annual-report-andaccounts-2019-to-2020). 


\section{About the Health Foundation}

The Health Foundation is an independent charity committed to bringing about better health and health care for people in the UK.

Our aim is a healthier population, supported by high quality health care that can be equitably accessed. We learn what works to make people's lives healthier and improve the health care system. From giving grants to those working at the front line to carrying out research and policy analysis, we shine a light on how to make successful change happen.

We make links between the knowledge we gain from working with those delivering health and health care and our research and analysis. Our aspiration is to create a virtuous circle, using what we know works on the ground to inform effective policymaking and vice versa.

We believe good health and health care are key to a flourishing society. Through sharing what we learn, collaborating with others and building people's skills and knowledge, we aim to make a difference and contribute to a healthier population.

The Health Foundation

8 Salisbury Square, London, EC4Y 8AP

+44 (0)2072578000

e info@ health.org.uk

y @ HealthFdn

www.health.org.uk 